\title{
DISCLAIMER
}

This report was prepared as an account of work sponsored by an agency of the United States Government. Neither the United States Government nor any agency thereof, nor any of their employees, makes any warranty, express or inplied, or assumes any legal liability or responsibility for the accuracy, completeness, or uselulness of any information, apparatus, product, or process disclosed, or represents that its use would not infringe privately owned rights. Reference herein to any specitic commercial product, process, or service by Irade name, trademark, manufacturer, or otherwise does nol necessarily constitute or imply its endorsement, recommendation, or favoring by the United States Government or any agency thereof. The views and opinions of authors expressed herein do not necessarily state or reflect those of the United States Government or any agency thercof.

\section{FORIG: A Computer Code for Calculating Radionuclide Generation and Depletion in Fusion and Fission Reactors User's Manual}

\author{
James A. Blink \\ Manuscript date: March 1985
}

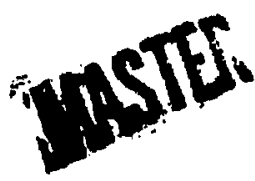

\section{LAWRENCE LIVERMORE NATIONAL LABORATORY University of California - Livermore, California $\cdot 94550$}

Available from: National Technical Information Service - U.S. Deparment of Commerce 5285 Port Royal Road • Springfield, VA 22161 •\$11.50 per copy $\bullet$ (Microfiche $\$ 4.50$ ) 


\section{Preface}

This manual was written for two reasons. First, the manual documents the changes made in the FORIG code since 1982. Second, and most important, the manual provides a stand-alone document that should be easily readable both by new users and by users with previous ORIGEN2 or FORIG experience. At the present time a FORIG user must consult the ORIGEN2 (fission-oriented) manual as well as the previous FORIG manual, which only concerns itself with cifferences between the two codes.

James A. Blink 


\section{FORIG User's Manual}

\section{Contents}

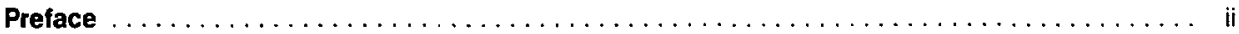

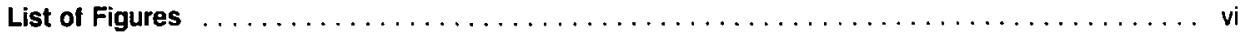

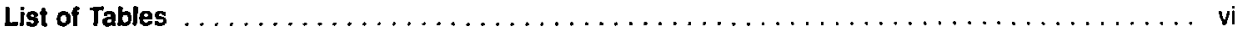

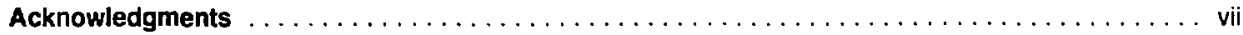

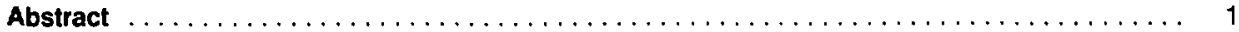

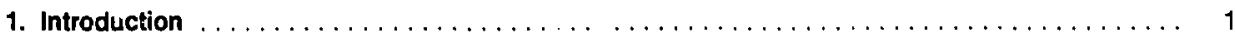

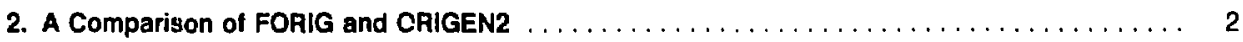

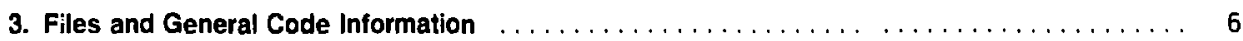

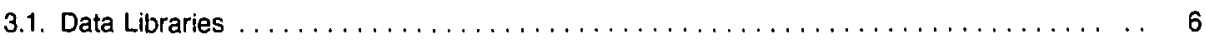

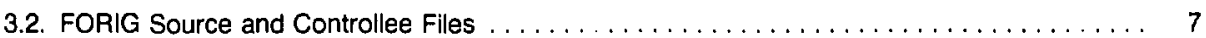

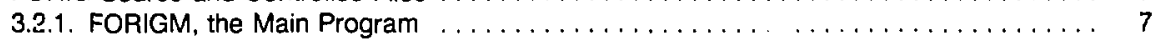

3.2.2. Compiling FORIG Source Files $\ldots \ldots \ldots \ldots \ldots \ldots \ldots \ldots \ldots \ldots \ldots \ldots \ldots \ldots \ldots$

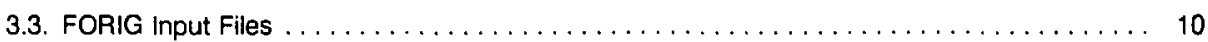

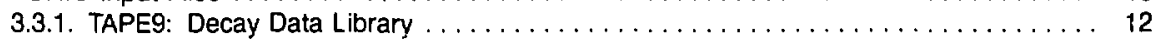

3.3.2. TAPE8: Cross-Section Library $\ldots \ldots \ldots \ldots \ldots \ldots \ldots \ldots \ldots \ldots \ldots \ldots \ldots \ldots \ldots$

3.3.3. TAPE3: Odd-Reaction Cross-Section Library $\ldots \ldots \ldots \ldots \ldots \ldots \ldots \ldots \ldots \ldots, 14$

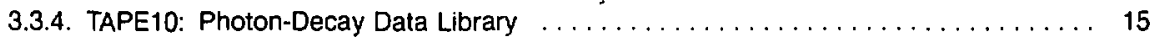

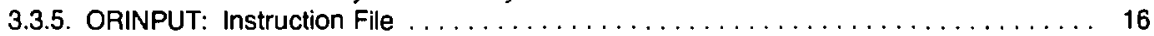

3.3.5.1. Comment and Termination Commands $\ldots \ldots \ldots \ldots \ldots \ldots \ldots \ldots \ldots \ldots, 16$

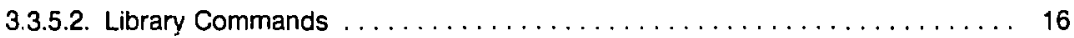

3.3.5.3. Material Input Commands $\ldots \ldots \ldots \ldots \ldots \ldots \ldots \ldots \ldots \ldots \ldots, \ldots \ldots \ldots$

3.3.5.4. Material Manipulation Commands $\ldots \ldots \ldots \ldots \ldots \ldots \ldots \ldots \ldots \ldots, 17$

3.3.5.5. Ccmmands that Take a Time Step $\ldots \ldots \ldots \ldots \ldots \ldots \ldots \ldots \ldots \ldots, 17$

3.3.5 6. Loop Commands ........................................ 17

3.3.5.7. Output Commands $\ldots \ldots \ldots \ldots \ldots \ldots \ldots \ldots \ldots \ldots \ldots \ldots \ldots \ldots$

3.4. FORIG Output Files $\ldots \ldots \ldots \ldots \ldots \ldots \ldots \ldots \ldots \ldots \ldots \ldots \ldots \ldots \ldots, 18$

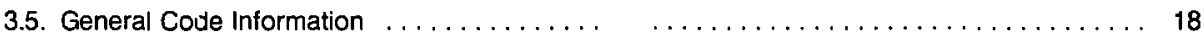

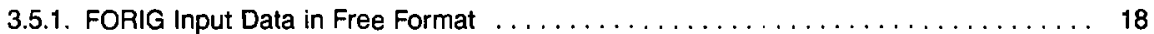

3.5.2. Composition "Vectors" that Store and Output Nuclide Data ............... 18

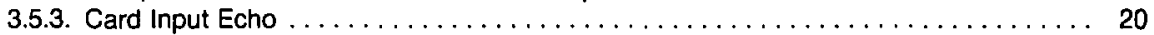

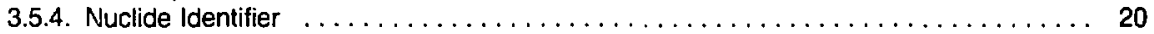

3.5.5. Machine Compatibility Considerations $\ldots \ldots \ldots \ldots \ldots \ldots \ldots \ldots \ldots \ldots \ldots, 21$

4. Instruction File for FORIG Computer Code (ORINPUn) $\ldots \ldots \ldots \ldots \ldots \ldots \ldots \ldots \ldots, 22$

4.1. Miscellaneous Data in the Source Code FORIGS $\ldots \ldots \ldots \ldots \ldots \ldots \ldots \ldots \ldots \ldots, 22$

4.1.1. Suppression of Neutron-Source Printing $\ldots \ldots \ldots \ldots \ldots \ldots \ldots \ldots \ldots \ldots, 22$

4.1.1.1. Fission-Neutron Yield per Neutron-Induced Fission . . . . . . . . . . . , 22

4.1.1.2. $(\alpha, n)$ Neutron Production Rate $\ldots \ldots \ldots \ldots \ldots \ldots \ldots \ldots \ldots \ldots, 22$

4.1.1.3. Fission-Neutron Yield per Spontaneous Fission $\ldots \ldots \ldots \ldots \ldots \ldots \ldots .22$

4.1.2. Miscellaneous Input Data $\ldots \ldots \ldots \ldots \ldots \ldots \ldots \ldots \ldots \ldots \ldots \ldots \ldots \ldots$ ?

4.1.2.1. Fractional-Reprocessing Recoveries for Individual Elements ........... 23

4.1.2.2. Fractional-Reprocessing Recoveries for Element Groups $\ldots \ldots \ldots \ldots \ldots .24$

4.1.2.3. Assignment of Elements to Fractional-Recovery Groups ............ 25

4.1.2.4. Elemental Chemical Toxicities $\ldots \ldots \ldots \ldots \ldots \ldots \ldots \ldots \ldots \ldots \ldots . \ldots \ldots$ 


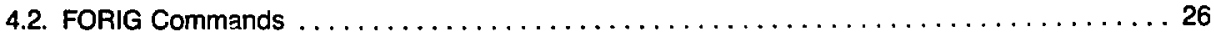

4.2.1. Comment and Termination Commands $\ldots \ldots \ldots \ldots \ldots \ldots \ldots \ldots \ldots \ldots$

RDA - Read Comments Regarding Case Being Input

TIT - Case Title

BAS - Case Basis

HED - Composition Vector Headings

STP - Execute Previous Commands and Branch

SND - Terminate Execution

4.2.2. Library Commands . . . . . . . . . . . . . . . . . . . . . . . . . . . . . 28

LIB - Read Decay and Cross-Section Libraries

LPU - Data Library Replacement Cards

PHo - Read Photon Libraries

I ' - Library Print Control

4.2.3. Material Input Commands . . . . . . . . . . . . . . . . . . . . . . . . 31

INP - Read Input Composition, and Continuous Removal and Feed Rates

HAC - Waste Nuclide Accumulation

PRO - Reprocess Fuel

vol - Material Volume

4.2.4. Material Manipulation Commands

MOV - Move Nuclide Composition from Vector to Vector

ADD - Add Two Composition Vectors

KEQ - Match Infinite Multiplication Factors

FAC - Calculate a Multiplication Factor Based on Total Vector Masses

4.2.5. Commands that Take a Time Step

DEC - Decay

IRF - Flux Irradiation

IRP - Specific Power Irradiation

BUp - Burnup Calculation

4.2.6. Loop Commands

DOL - DO LOOP

CON - Continuation (End of Do Loop)

REC - Loop Counter

4.2.7. Output Commands 40

OUT - Print Calculated Results

OPTL - Specify Activation-Product Output Options

OPTA - Specify Actinide Output Options

OPTF - Specify Fission-Product Output Options

CUT - Cutoff Fractions for Summary Tables

PCH - "Punch" an Output Vector

RADS - Surface Gamma-Dose-Rate Output

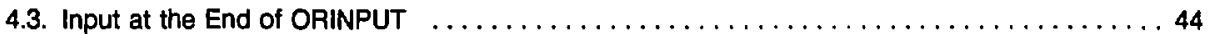

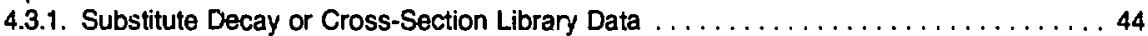

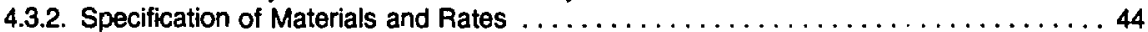

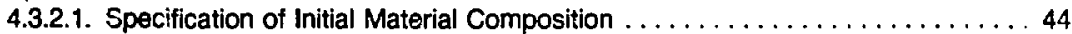

4.3.2.2. Specification of Continuous Nuclide Feed Rates . . . . . . . . . . . 45

4.3.2.3. Specification of Continuous Element-Removal Rates $\ldots \ldots \ldots \ldots \ldots \ldots \ldots 45$ 
5. Organization of FORIG Output Files $\ldots \ldots \ldots \ldots \ldots \ldots \ldots \ldots \ldots \ldots \ldots \ldots \ldots \ldots \ldots$

5.1. Sample Fusion-Froblem Input File (ORINPUT) $\ldots \ldots \ldots \ldots \ldots \ldots \ldots \ldots \ldots \ldots \ldots \ldots$

5.2. TAPE12: The Table of Contents for File OROUT $\ldots \ldots \ldots \ldots \ldots \ldots \ldots \ldots \ldots \ldots \ldots \ldots$

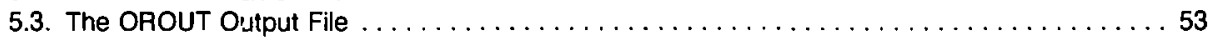

5.4. TAPE13: Table of Contents and TAPE11: Abbreviated Output $\ldots \ldots \ldots \ldots \ldots \ldots \ldots \ldots \ldots 6$

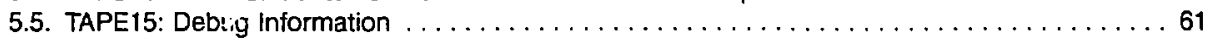

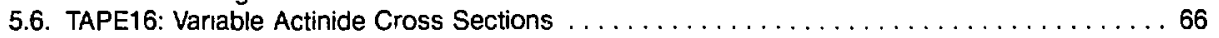

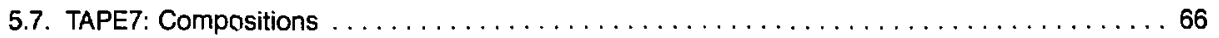

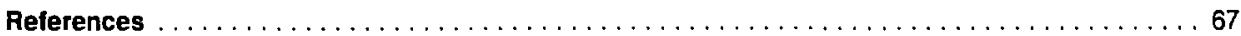




\section{List of Figures}

1. FORIG main source file $($ FORIGM) $\ldots \ldots \ldots \ldots \ldots \ldots \ldots \ldots \ldots \ldots \ldots \ldots \ldots \ldots$

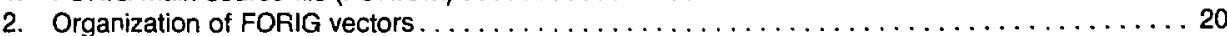

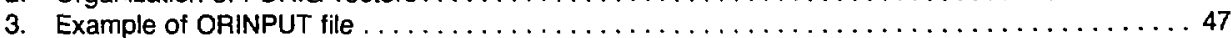

4. Example from TAPE12 (The OROUT Table of Contents) $\ldots \ldots \ldots \ldots \ldots \ldots \ldots \ldots \ldots \ldots 50$

5. Hierarchical organization of FORIG output file, OROUT $\ldots \ldots \ldots \ldots \ldots \ldots \ldots \ldots \ldots \ldots \ldots$

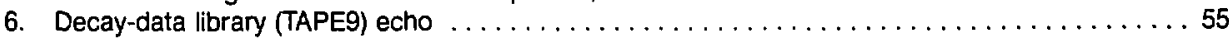

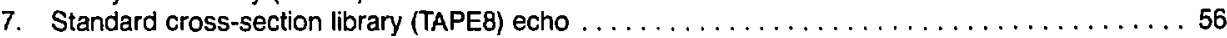

8. Odd-reaction cross-section library (TAPE3) echo $\ldots \ldots \ldots \ldots \ldots \ldots \ldots \ldots \ldots \ldots \ldots \ldots$

9. Page from the reaction-matrix table $\ldots \ldots \ldots \ldots \ldots \ldots \ldots \ldots \ldots \ldots \ldots \ldots \ldots \ldots \ldots \ldots$

10. Page from the listing of "Daughters not in the decay library" $\ldots \ldots \ldots \ldots \ldots \ldots \ldots \ldots \ldots \ldots$

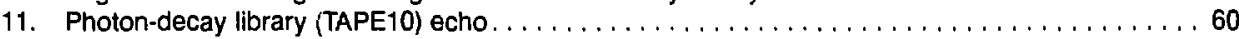

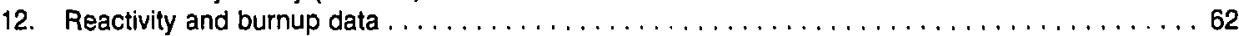

13. Typical FORIG output page $\ldots \ldots \ldots, \ldots \ldots \ldots \ldots \ldots \ldots \ldots \ldots \ldots \ldots \ldots \ldots \ldots \ldots, \ldots \ldots \ldots$

14. Photon-decay emission rates as a function of time and photon energy $\ldots \ldots \ldots \ldots \ldots \ldots \ldots$

15. Principal nuclide contributors to the photon-decay emission rates $\ldots \ldots \ldots \ldots \ldots \ldots \ldots$

\section{List of Tables}

1. Reaction types available from the ORLIB code $\ldots \ldots \ldots \ldots \ldots \ldots \ldots \ldots \ldots \ldots \ldots$

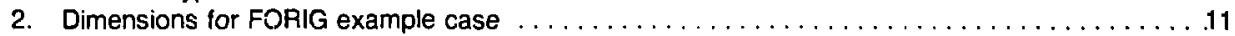

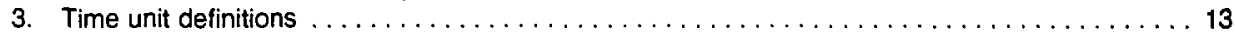

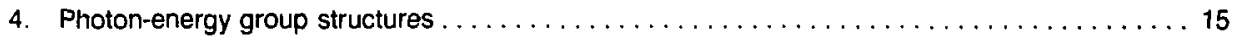

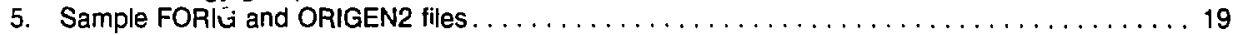

6. FORIG default for individual-element fractional recoveries $\ldots \ldots \ldots \ldots \ldots \ldots \ldots \ldots \ldots \ldots 23$

7. FCRIG default element-group fractional recoveries $\ldots \ldots \ldots \ldots \ldots \ldots \ldots \ldots \ldots \ldots \ldots \ldots$

8. Composition ớ FORIG default-element groups $\ldots \ldots \ldots \ldots \ldots \ldots \ldots \ldots \ldots \ldots \ldots \ldots \ldots$

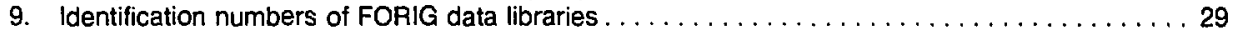

10. Actinide sets with direct fission-product yields $\ldots \ldots \ldots \ldots \ldots \ldots \ldots \ldots \ldots \ldots \ldots \ldots$

11. Types of output tables to be printed $\ldots \ldots \ldots \ldots \ldots \ldots \ldots \ldots \ldots \ldots \ldots \ldots \ldots \ldots \ldots, \ldots \ldots$

12. Description of FORIG ouptut tables $\ldots \ldots \ldots \ldots \ldots \ldots \ldots \ldots \ldots \ldots \ldots \ldots \ldots \ldots \ldots \ldots \ldots \ldots 41$

13. Comparison of code sizes with dimensions selected by the user $\ldots \ldots \ldots \ldots \ldots \ldots \ldots \ldots$ 


\section{Acknowledgments}

The author is grateful for helpful discussions with D. Dorn, J. Hovingh, R. Howerton, G. Lasche, R. C. Manninger, W. Meier, and M. Monsler of LLNL and with D. Berwald of TRW. Considerable programming assistance from W. Warren, R. Dye, and the LLNL computer consulting office is appreciated. Finally, the author is indebted to A. Croff of ORNL for his patience in explaining many of the intricacies of ORIGEN2 and for permitting duplication of some sections of the ORIGEN2 manual. Special thanks to Dolores Bobb for her skillful editing. 


\title{
FORIG: A Computer Code for Calculating Radionuclicie Generation and Depletion in Fusion and Fission Reactors \\ User's Manual
}

\begin{abstract}
In this manual we describe the use of the FORIG computer code to solve isotope-generation and depletion problems in fusion and fission reactors. FORIG runs on a Cray- 1 computer and accepts more extensive activation cross sections than ORIGEN2 from which it was adapted. This report is an updated and a combined version of the previous ORIGEN2 and FORIG manuals.
\end{abstract}

\section{Introduction}

Neutrons arising from fusion reactions are absorbed in structures, coolants, and shields and consequently produce activation products. The subsequent decay of these radionuclides can be a troublesome heat source after shutdown (afterheat), and also may present a radiation hazard to occupational workers during reactor maintenance and to the public if the activated materials are dispersed in an accident. Finally, the long-lived activation products are hazardous waste that must be isolated from the environment for long periods of time.

The FORIG computer code was developed to calculate the time-dependent radionuclide populations in fusion reactors in terms of various figures of merit-isotope mass, activity (curies), inhalation and ingestion biological hazard potentials (bhp's), afterheat (watts), gamma spectrum, surface dose rate, and waste disposal feasibility. The FORIG code is an adaptation of the widely respected fission-reactor code ORIGEN2. ${ }^{1}$

This user's manual is an updated and combined version of the information in the previous FORIG ${ }^{2}$ and ORIGEN2 manuals. ${ }^{1}$ Modifications for allowing fusion-reactor calculations are structured to permit continued use of the code for fission-reactor calculations.

Experienced ORIGEN2 users will wish to read Section 2, where differences in the input files of FORIG and ORIGEN2 are explained and code modifications are described, and then proceed to Section 3. New users of the code should proceed Jirestly to Section 3, where the source, controllee, input and output files are defined. Sections 4 and 5 are detailed descriptions of the input and output formats, respectively.

The ORIGEN2 code, used to generate FORIG, was obtained from Oak Ridge National Laboratory (ORNL) in 1981. Users interested in fission-reactor calculations should contact Allen Croff at ORNL to obtain the ORIGEN2 improvements (or corrections) implemented since 1981. 


\section{A Comjarison of FORIG and ORIGEN2}

To permit fusion-reactor calculations, the major modification was to increase the maximum permitted number of removal paths (activation or Jecay) for each nuclide. The seven paths allowed in the ORIGEN2 code are inadequate. Compared to fission reactors, the high-energy flux in a fusion reactor drives more reactions, such as $(n, n)$ ), $(n, n a)$, (n,d), and $(n, t)$. The FORIG program allows 15 removal paths. Additionally, if the maximum removal paths are exceetted, the ORIGEN2 code proceeds after a warning error, whereas FORIG terminates.

In ORIGEN2, the decay and cross-section libraries are merged (concatenated) into a single file (TAPE9) before the code starts. In FORIG, the two libraries are kept separate. The decay librany is in TAPE9 and the cross-section libraries are in TAPE8. To permit the separation of the decay and crosssection libraries, the LIB command was modified to

LIB NLIB(1)... NLIB(13)

The I IB command entry fields are defined as follows:

NLIB (1) Printing of reaction-rate matrix if $>0$. That is, for each nuclide, we obtain a printout of the production rate from each, 'arent, in addition to the decay rate and the removal rate by activation.

NLIB ( 2 ) Light-nuclide-decay library number.

NLIB (3-4) Actinide and fission-product decay library numbers (zero for pure fusion problems).

NLIB (5-7) The three cross-section library numbers. (Note: If a decay or cross-section library number is negative, replacement cards will also be read later in the "odd-reaction file" for that library.)

NLIB(8) Input unit number for the cross-section library (use 8).

NLIB(9) Input unit number for the decay library file (use 9).

NLIB(1B) Input unit number for the replacement decay and cross-section lines and for reading "oddreaction" cross sections (use 3 ).

NLIB(11) The number of odd reactions to be read. If $\mathrm{NLIB}(11)$ is negative, the data will be read on Unit $\mathrm{NLIB}(16)$. If $\mathrm{NLIB}(11)$ is positive, the data will be read on unit NLIB(8). Use negative NLIB $(11)$ to read the odd reaction on TAPE3.

NLIB(12) Determines the set of actinides that have direct fission-product yields (use 0 for fusion problems).

NLIB (13) Determines the set of variable actinide cross sections to be used (use 0 for fusion problems).

The change is in the addition of the NLIB (9) field.

A new first line was added to the instruction file (ORINPUT). If the line contains a negative integer, FORIG will not print neutron sources from spontaneous fission, from neutron-induced fission, or from $(\alpha, n)$ reactions. Such tables are not applicable to pure fusion problems. If the line is zero or a positive integer, FORIG will print the neutron-source information (like ORIGEN2).

To accommodate larger cross-section librany entries, FORIG was modified to accept 120 character lines in the data files (ORIGEN2 only reads the first 80 characters). FORIG reavis the cross-section libraries in the ORIGEN2 format, if the library number is less than 700. If the librany number is greater than or equal to 700 , the extended FORIG format is used. 
The cross-section formats (used in the TAPE8 input file) are summarized in the following:

- For a library number less than 700, use standard ORIGEN2 library.

NLB TITLE (For the light-nuclide segment)

NLB ZZAAAI $\operatorname{sn} \gamma \operatorname{sn} 2 n \operatorname{sn} \alpha \operatorname{snp} \operatorname{sn} \gamma x \operatorname{sn} 2 n x-1.0$

$$
-1
$$

NLB TITLE (For the actinide segment)

NLB ZZAAAI $\operatorname{sn} \gamma \operatorname{sn} 2 n \operatorname{sn} 3 n \operatorname{snf} \operatorname{sn} \gamma x \operatorname{sn} 2 n x-1.0$$$
-1
$$

NLB TITLE (For the fission-product segment)

NLB ZZAAAI $\operatorname{sn} \gamma \operatorname{sn} 2 n \operatorname{sn} \alpha \operatorname{snp} \operatorname{sn} \gamma \times \operatorname{sn} 2 n \times 1.0$

$Y(1) Y(2) Y(3) Y(4) Y(5) Y(6) Y(7) Y(8)$

$$
\text { . }
$$$$
-1
$$

These entry fields are defined as follows:

NLB Library number for each segment.

zzAAXI Nuclide identification (atomic number, atomic weight, and I = zero for the ground state or one for an isomer).

$\sin \gamma \quad$ Cross section for the $(n, \gamma)$ reaction; $\operatorname{sn} 2 n x$ is the cross section for the $(n, 2 \pi)$ reaction leaving an excited daughter, etc.

$Y$ (1) These represent the percent fission-product yield for fissioning of eight different actinides, as through specified in Table 5.2 of the ORIGEN2 manual (or in Table 10 of this manual). The $Y(1)$ $Y(8)$ through $\times(8)$ line is omitted if the previous line ends in a negative number.

- For a light-nuctide library number greater than 699, use the ORLIB format:"

NLB TITLE (For a pure fusion problem)

Comment line

zzAAAI $\operatorname{sn} 2 n \operatorname{sn} 2 n x \operatorname{Sn} 3 n \operatorname{Snnp} \operatorname{snn} \alpha \operatorname{Snp}$ Snd $\operatorname{snt} \operatorname{sn\alpha } \operatorname{sn} \gamma \operatorname{Sn} \gamma x$

$$
-1
$$

"ORLIB is a cross-section manipulation code ${ }^{3}$ available with FORIG. The code can be used to energy average the ACTL crosssection library, ${ }_{1}^{4}$ using either an input flux or a TARTNP-generated flux $x^{5}$ as a weighting function. One improverment has been made to OALIB since Ref. 3 was published; a flag has been added to the ORLIB input file to allow production of libraries in one of four formats ( 0 or no entry = FORIG light-nuclide format, $1=$ ORIGEN2 light-nuclide format, 2 = actinide format, $3=$ fission-product format without fission product yield-curve entries). This input flag is an l1 format in Column 30 of ine 2 of the ORLIB input. 
This example includes no cross sections for actinides or fission products. If the problem includes either, they are entered in the original ORIGEN2 format following the light nuclide segment.

In both ORLIB and ORIGEN2 formats, the code will error exit if cross sections are entered for nuclides not in the appropriate decay-library segment.

The odd-reaction cross-section file (TAPE3) format was also modified to accommodate (optional) additional information available from the ORLIB cross-section code.

- For a light-nuclide library number less than 700, input the odd reactions in the ORIGEN2 format. The first and second entries on each line are the parent and daughter nuclide identifications. When this format is used, hydrogen and helium isotope production is not calculated for the odd reactions.

ZAAAI ZZAAAI STGMA

- For a light-nucllde Iibrary number greater than 699, input the odd reactions in the ORLIB format.

\author{
NLTB TITIE \\ Comment Line \\ ZZAAAI ZZAAAI SIGNA TYPE \\ ZZAAAI ZZAAAI SIGMA TYPE
}

Here, TYPE is the reaction type number (Table 1). With this format, hydrogen and helium isotope production is calculated for both the odd and the stendard reactions.

In either format, each odd reaction is added to the first library segment (light nuclide, actinide, or fission product) that inciudes the parent in the decay library. Also, if replacement decay or cross-section lines are to be inserted in any of the six library segments, these lines precede the odd-reaction formats shown. (The IIB and LPU commands force the code to read each line in its proper format, as discussed later.)

The decay library format was also altered to add an additional field at the end of each (two-line) nuclide entry. This field is the shallow-burial radioactivity concentration guide (SBRCG), i.e., the nuclide's allowable specific activity in curies per cubic meter if it is to be buried in a low-level disposal site as Class $\mathrm{C}$ waste as

Table 1. Reaction types avallable from the ORLIB code.

\begin{tabular}{|c|c|c|c|}
\hline Type No. & Rasuction & Type No. & Reaction \\
\hline $\begin{array}{l}12 \\
13 \\
14 \\
15 \\
20 \\
21 \\
22 \\
23 \\
24 \\
25 \\
26 \\
27 \\
28\end{array}$ & $\begin{array}{l}(n, 2 n) \\
(n, 3 n) \\
(n, 4 n) \\
(n, f i s s) \\
(n, n p) \\
(n, p n) \\
(n, n d) \\
(n, n d a) \alpha \\
(n, n t) \\
\left(n, n^{3} H \theta\right) \\
(n, n \in) \\
(n, n 2 a) a \\
(n, n t a) \alpha\end{array}$ & $\begin{array}{l}29 \\
30 \\
31 \\
37 \\
38 \\
39 \\
40 \\
41 \\
42 \\
43 \\
44 \\
45 \\
40\end{array}$ & $\begin{array}{l}(n, 2 n p) \alpha \\
(n, \gamma n \alpha) \\
(n, \gamma n \alpha) \\
(n, 2 \alpha) \alpha \\
\left(n,{ }^{3} H e \alpha\right) \alpha \\
(n, t p) \alpha \\
(n, p) \\
(n, d) \\
(n, t) \\
(n, t a) \alpha \\
(n, 3 \theta) \\
(n, \alpha) \\
(n, \gamma)\end{array}$ \\
\hline
\end{tabular}


specific activity in curies per cubic meter if it is to be buried in a low-level disposal site as Class $C$ waste as specified $^{6}$ in 10CFR61. Each S3RCG value assumes only that nuclide will be buried. If multiple nuclides are to be buried,

$$
\sum_{i}^{\text {nuclides }} A_{i}\left(C i / m^{3}\right) / S B R C G_{i} \leq 1,
$$

or the waste must be isolated in a geologic (high-level waste) repository. The shallow burial index $\left(A_{i} / S B R C G_{i}\right)$ is calculated by FORIG when Table 11 or 12 (for absolute cir fractional values, respectively) is specified in the OPTL, OPTA, or OPTE commands.

To calculate the shallow-burial output, the code requires the volume of the activated material (waste). This value is input as a new command,

$$
\text { vol vol, }
$$

where vol is the materiai volume in cubic meters. The vos command must precede the ouT command that outputs Table 11 or 12 (as previously specified by an OPTL, OPTA, or OPTF command).

One final command was added to the code. This command produces a crude calculation, suggested by D. Dorn of LLNL, of the gamma dose rate at the surface of a large (infinite) slab of a given thickness, material, and density and that containe the calculated activity density. The calculation is crude, because it does not consider down-scatter of photons in Compton scattering. Instead, an effective (energydependent) absorption cross saction is used; this cross section is the sum of the (energy dependent) photoelectric and pair-production cross sections plus one-half the Compton cross section. The input format is

$$
\text { RADS rho thick mat' } 1 \text {, }
$$

where rho is the density in $\mathrm{g} / \mathrm{cm}^{3}$, thi ck is the slab thickness in $\mathrm{cm}$, and mat ' $\mathrm{l}$ is $\mathrm{Fe}, \mathrm{Ai}, \mathrm{Mo}, \mathrm{W}$, or $\mathrm{Pb}$. The user must select the element that most closely approximates the actual material. If $r$ ho is entered as a negative number, the output is sent to ihe abbreviated (TAPE11) file, rather than to the full output file (OROUT). The RADS command must be preceded by both vOI and OUT commands. The RADS coinmand was added to allow order of miagnitude estimation, of contact dose rates. More accurate estimates require a formal shielding calculation. Also, during operation, the $d$ se rate from $(n, \gamma)$ reactions (not calculated by FORIG) could be much higher than the dose rate from decay gamma rays. 


\section{Files and General Code Information}

ORIGEN2 is a widely used computer code ${ }^{1}$ for calculating the build-up, decay, and processing of radioactive materials in fission reactors. Here we document changes made in the ORIGEN2 code to allow its use on an LLNL Cray-1 computer. With only slight changes in the input file, any of the standard fission problems can run at LLNL as they do at Oak Ridge and elsewhere.

In addition, the code was modified to read activation cross-section libraries appropriate for fusionreactor design problems. If the flux-weighted cross sections are constant in time, a single FORIG run can calculate activation and decay in a fusion-reactor component. To address fission-fusion hybrid-reactor designs, FORIG will require further modification to account for actinide burn-up and fission-product buildup. This may be done in a manner similar to the fission-reactor treatment in ORIGEN2, or it may be accomplished by cyclically using a neutron-flux code, a cross-section collapsing code, and FORIG.

\subsection{Data Librurios}

FORIG contains three separate and distinct nuclide lists for which nuclear data may be required:

- Activation products (sometimes called "light" nuclides) include low-Z impurities and structural materials.

- Actinides include all of the heavy isotopes $(Z>90)$ and all their decay daughters, including the finat stable nuclides.

- Fission products include all nuclides having a significant fission product yield (either binary or ternary) and somo nuclides resulting from neutron captures of the fission products.

Each of these three segments has three libraries that may be read:

- A decay data librany that gives nuclide half-lives, decay modes, recoverable heat energy, natural abundances, ind toxicities.

- A cross-section and fission-oroduct-yield library that gives the cross sections for several reactions (as effective one-energy-group values in barns) and gives the fission product yields from ${ }^{232} \mathrm{Th},{ }^{233} \mathrm{U}$, ${ }^{235} \mathrm{U},{ }^{238} \mathrm{U},{ }^{239} \mathrm{Pu},{ }^{241} \mathrm{Pu},{ }^{245} \mathrm{Cm}$, and ${ }^{252} \mathrm{Cf}$.

- A decay-photon yield library that gives the phatons per disintegration in 18 energy groups. (Note that photons emitted in $n, \gamma$ reactions are not tabulated by the FORIG or ORIGEN2 computer codes.)

In addition to these normal data-input library facilities in FORIG, two additional options are available to extend, update, or correct these libraries.

The first allows the user to input substitute decay-data lines and substitute cross-section and fissionproduct-yield data lines that override the corresponding data lines present in the main libraries. This option is an alternative to rebuilding the entire data library simply to change one or two items.

The second option allows the user to input any flux-dependent reaction rate between any two nuclides. While the user can duplicate the standard reaction types available in FORIG, the option is principally intended to allow inclusion of nonstandard reaction types.

The ORIGEN2 code cross-section library includes six standard reactions for nonfissionable nuclides: $(n, 2 n),(n, 2 n)$ exc, $(n, p),(n, \alpha),(n, \gamma)$, and $(n, \gamma)$ exc, where "exc" indicates the daughter is in an excited state.

Additional reactions may be added in a separate file, which is called "odd reactions" in the ORIGEN2 manual. For fission reactors, there are few additional reactions. However, fusion-reactor problems require an odd-reaction file many times larger than the standard file because of the higher energy neutrons. Further, ORIGEN2 igiiores the produrtion of helium and hydrogen isotopes from odd reactions.

The neutron-energy spectra differ between regions in a single fusion reactor design and differ between designs. FORIG requires flux-averaged (i.e., energy-weighted) cross sections. Hence, multiple cross-section libraries are required for fusion reactors and even for different regions of any specific design. The ORLIB $\operatorname{codi}^{3}$ was written at LLNL to use the ACTL cross-section library and the TARTNP neutronics $\operatorname{code}^{5}$ to produce a one-energy-group cross-section library for any region of a fusion reactor. 
The ORLIB output includes a cross-section file with 11 standard reactions:

$(n, 2 n),(n, 2 n)$ exe, $(n, 3 n),(n, n p),(n, n \alpha),(n, p),(n, d),(n, t),(n, \alpha)$, $(n, \gamma)$, and $(n, \gamma)$ exc.

ORLIB also produces an odd-reaction file. Table 1 lists the 26 reaction types processed by the code. FORIG will accept these files if the library number is set $\geq 700$. If the library number is less than 700 , the standard ORIGEN2 cross-section format is required. FORIG also calculates helium and hydrogen isotope production from both standard and odd reactions.

FORIG, like ORIGEN2, divides problems into three parts: light nuclides (also called activation products), actinides, and fission products. In some problems, a nuclide may appear in two categories, and the code will treat the two separately. In pure fusion problems, there are no actinides or fission products, and no libraries are input for these categories. In this case, zeros are entered in the appropriate blocks in the I IB an:i PHO commands of the input file. (All FORIG commands are discussed later in this report).

\subsection{FOnio Source and Gontrolles Files}

The amount of memory required to solve a FORIG or OAIGEN2 problem is determined by the number of nuclides, cross sections, etc. that are involved. To prevent excessive use of memory, the source file was divided into two parts: first, a small main program (FORIGM) and, second, a large file containing all the subroutines required by the main program. The subroutines do not change from problem to problem, but the dimensions set up in FORIGM must be predetermined by the user. Figure 1 provides a listing of the main program as well as information required for setting the dimensions of the arrays. Once these are set, the program can be compiled.

\subsubsection{Forion, the Main Program}

FORIGM performs four major functions:

(1) Provides a mechanism for variably dimensioning FORIG to accommodate different problem sizes.

(2) Provides much of the framework necessary for putting some of the arrays to several different uses.

(3) Calls for the subroutines that perform the desired operations.

(4) Provides a mechanism for executing multiple FORIG problems with a single job.

The third function is handled automatically and will not be discussed. The fourth function is discussed in Section 4.2 .1 (STR Command).

In Function 1, FORIG is variably dimensionied to allow the user to tailor the size of the executable module to the problem size or to the available computer space. The sizes of the FORIG executable modules range from about $175 \mathrm{~K}(1 \mathrm{~K}=1024$ bytes $=256$ single precision words) to about $600 \mathrm{~K}$, the size depending mainly on the number of nuclides being considered.

FORIG keeps track of and prints the minimum required size of most of the variably dimensioned arrays (see Section $\mathbf{5 . 3}$ for output details). Table 2 is a summary of the recommended dimensions for several example problems. The magnitudes of the dimensions depend on the number of actinide nuclides having direct fission-product yields, which can range from zero to eight (see the IIB command). Dimensions are given in Table 2 for cases of $0,4,6$, and 8 actinides having direct fission-product yields.

The variable NYTF in FORIGM (see Fig. 1) indicates whether thermal-reactor (NYTP $=0$ ) or fastreactor (NYTF $=1$ ) neutron yields per neutron-induced fission are to be used (see also Section 4.1.1). The variables RMULV, DR, ER, FR, and LAM are related to a multiplier used by the MOV and ADD commands. LAM is the number of possible multipliers (presently four) in a given set of multipliers. These are specified by using Data statements in FORIGM. Variables DR, ER, and FR are equivalenced to the appropriate portion of RMULV. The variable LAK is passed in subroutine parameter lists for variabte dirnensioning purposes. 


\begin{tabular}{|c|c|c|c|}
\hline AAAA & (13) No. output vectors & 1111 & $\begin{array}{l}\text { (2500) Maximum No. nonzero matrix } \\
\text { elements for long-lived nuclides }\end{array}$ \\
\hline $\begin{array}{l}\text { B日BB } \\
\text { CCCC }\end{array}$ & $\begin{array}{l}\text { (900) Maximum No. nuclides } \\
\text { (15) Maximum No. nonzero cross-section } \\
\text { and decay reactions per nuclide } \\
\text { (cannot exceed } 15 \text { without } \\
\text { redimensioning the subroutines) }\end{array}$ & $\begin{array}{l}\text { JJJJJ } \\
\text { KKKK }\end{array}$ & $\begin{array}{l}\text { (10) No. storage vectors } \\
(300) \text { No. nonzero natural abundance }\end{array}$ \\
\hline $\begin{array}{l}\text { DDDD } \\
\text { EEEE } \\
\text { FFFF }\end{array}$ & $\begin{array}{l}\text { (2500) Total No. nonzero matrix elements } \\
\text { (4) No. nonzero fission-product yields } \\
\text { (4) Maximum No. fission products }\end{array}$ & $\begin{array}{l}\text { LLL } \\
\text { MMMM } \\
\text { NNNN }\end{array}$ & $\begin{array}{l}(3300) \text { No. nonzero photon yjelds } \\
(900) \text { Maximum No. light nuclides } \\
\text { (d) Maximum No. variable multipliers } \\
\text { (in RMULV) }\end{array}$ \\
\hline GGGG & (4) Maximum No. actinides + 1 & PPPP & $\begin{array}{l}\text { (3) No. actinides with both direct } \\
\text { fission-product yields and a variable } \\
\text { fiscion cross section (usually } 3 ; \text { cen } \\
\text { be } 4 \text { for plutonlum-enriched } \\
\text { thorlum fuels) }\end{array}$ \\
\hline
\end{tabular}

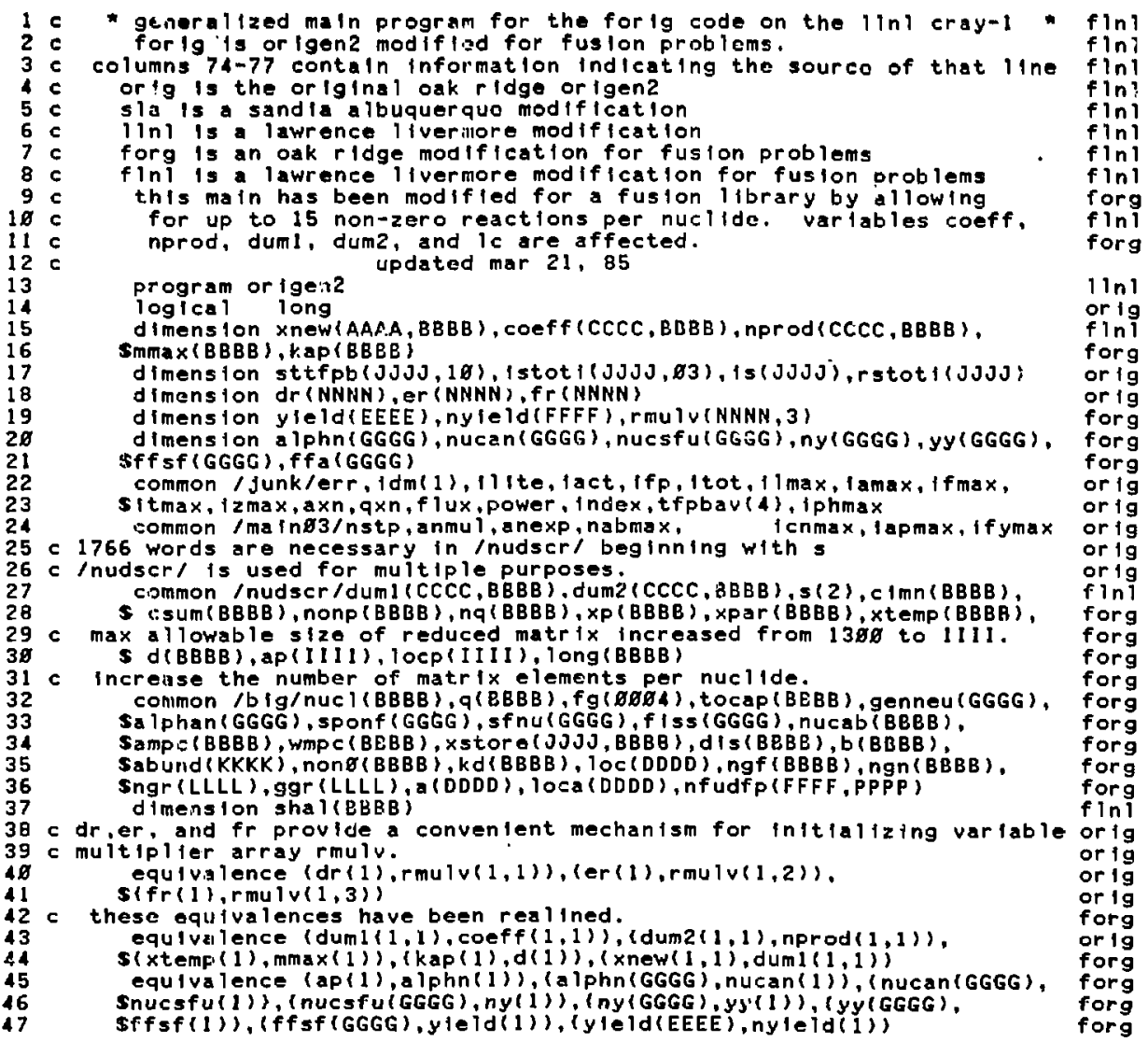

Figure 1. FORIG main source file (FORIGM). The dimensions are set by using the comments above the listing. For a pure fusion problem with less than $\mathbf{9 0 0}$ nuclides, the chosen dimensions are liated parenthetically (continued on next page). 


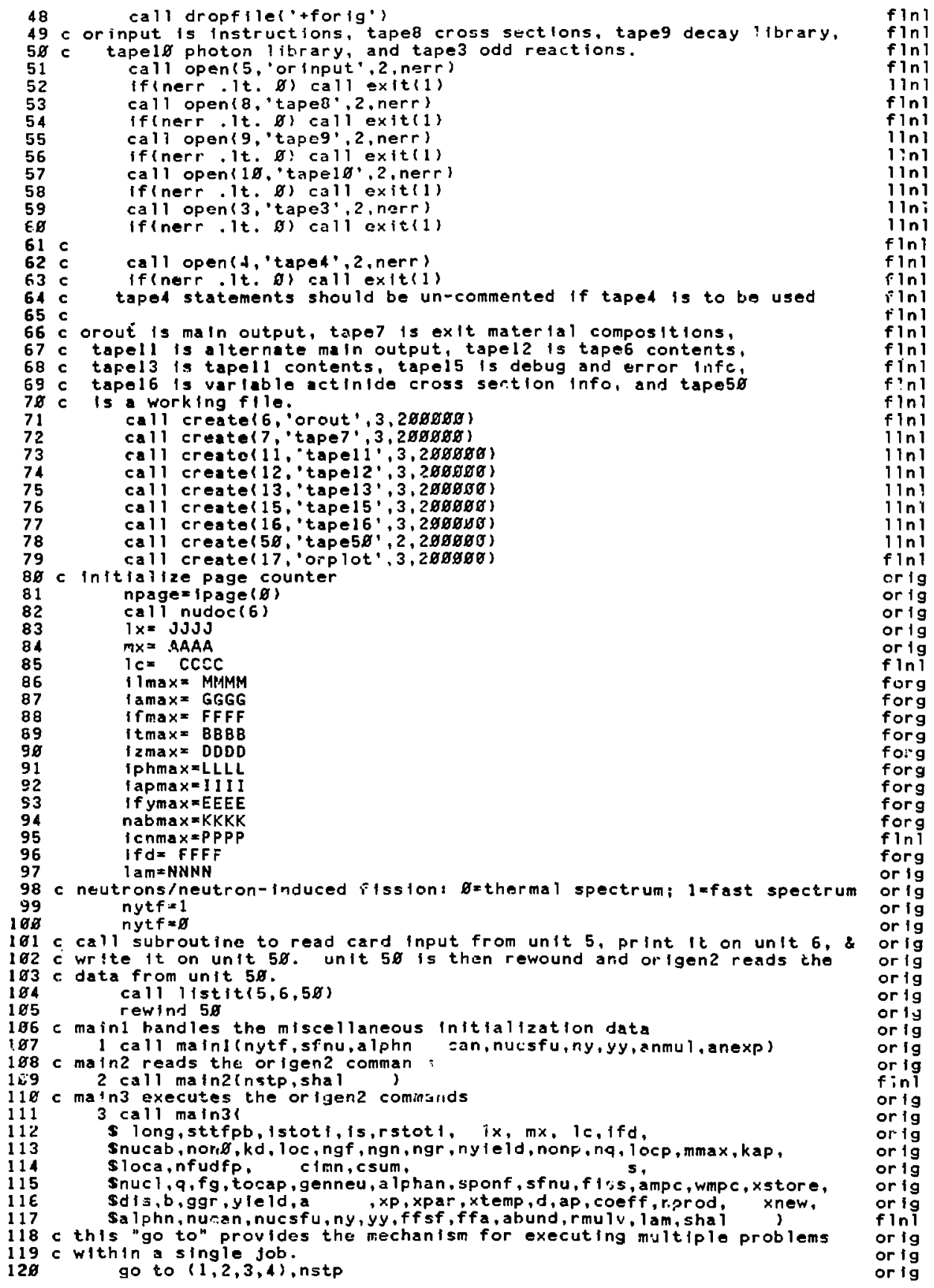

Figure 1. (continued on next page). 


\subsubsection{Complling FOnis Source FHos}

The appropriate files may be obtained from RSIC or NMFECC or, at LLNL, in J. Blink's take directory.

XPORT / t v

.RD . 089975 :ORIGEN2 [FORIG FORIGM FORIGMG FORIGS BFORIGS]

XPORT is a file transport routine at LLNL.

FORIG is the controllee set up for a pure fusion problem with less than 900 nuclides in the decay library. If the probtem of interest does not require actinides or fission products and if the existing decay library is adequate, then only FORIG need be read and no compiling process is needed.

FORIGS is the source file containing all the FORIG subroutines. This file is only required if the subroutines must be changed. Once the changes are made, FORIGS is compiled into a library:

$$
\text { RCFT I =FORIGS } / t v
$$

The compiler RCFT produces the library file BFORIGS. If no changes are to be made in the subroutines, BFORIGS may be read directly from the take directory.

FORIGMG is the main program with generalized dimensions. After it is read and its dimensions adjusted, it may be renamed FORIGM and compiled:

$$
\text { RCFT I=FORIGM, X=FORIG, LIB= (BFORIGS, FORTLIB ) } / \mathrm{t} v
$$

The FORIGM file in the take directory is set up for a pure fusion problem with less than 900 nuclides. The controllee is named FORIG.

\subsection{FOAic Input Files}

FORIG requires the following input files (which are now to be discussed individually):

TAPE9 Decay data library

TAPE8 Cross-section library

TAPE3 Odd-reaction cross-section library

TAPE10 Photon-docay data library

ORINPUT Instruction list

TAPE4 Input composition file (optional) 
Table 2. Dimentions for FORIG exemple cases. (Case 17 is for a fusion problem.)

\begin{tabular}{|c|c|c|c|c|c|c|c|c|c|c|c|c|c|c|c|c|c|}
\hline \multirow[b]{2}{*}{ Paranoler } & \multicolumn{17}{|c|}{ Case } \\
\hline & 1 & 2 & 3 & 4 & 5 & 6 & 7 & 8 & 5 & 10 & 11 & 12 & 13 & 14 & 15 & 16 & 17 \\
\hline Segments conisidered" & $A P, A, F P$ & $A P, A, F P$ & $A P, A, F P$ & $A, F P$ & A,FP & A,FP & AP,A & A & $A P$ & AP,A,FP & A & $\mathbf{A P}$ & $\mathbf{F P}$ & $\begin{array}{l}\text { A,FP } \\
\text { or A,AP }\end{array}$ & AP,A,FP & $A P, A, F P$ & $\mathbf{A P}$ \\
\hline Type of calculation & Any & Anv & Any & Any & Any & Any & Any & Any & Any & Decay & Decay & Decay & Decay & Any & Ariy & Any & Any \\
\hline $\begin{array}{l}\text { Number of actinides } \\
\text { with dirtct fission } \\
\text { product yields }\end{array}$ & 4 & 6 & 8 & 4 & 6 & 8 & o & 0 & 0 & 0 & 0 & 0 & 0 & 4 & 6 & 4 & 0 \\
\hline \multicolumn{18}{|l|}{$\begin{array}{l}\text { Alphabetic array } \\
\text { dimensions }\end{array}$} \\
\hline $\begin{array}{l}\text { AMAA } \\
\text { BBBB }\end{array}$ & $\begin{array}{l}13 \\
1732\end{array}$ & $\begin{array}{l}13 \\
1676\end{array}$ & $\begin{array}{l}13 \\
1676\end{array}$ & $\begin{array}{l}13 \\
1000\end{array}$ & $\begin{array}{l}13 \\
1000\end{array}$ & $\begin{array}{l}13 \\
1000\end{array}$ & $\begin{array}{l}13 \\
820\end{array}$ & $\begin{array}{l}13 \\
132\end{array}$ & $\begin{array}{l}13 \\
700\end{array}$ & $\begin{array}{l}13 \\
1676\end{array}$ & $\begin{array}{l}13 \\
132\end{array}$ & $\begin{array}{l}13 \\
700\end{array}$ & $\begin{array}{l}13 \\
860\end{array}$ & $\begin{array}{l}13 \\
1000\end{array}$ & $\begin{array}{l}13 \\
1676\end{array}$ & $\begin{array}{l}13 \\
1676\end{array}$ & $\begin{array}{l}13 \\
900\end{array}$ \\
\hline $\operatorname{cccc}$ & 7 & 7 & 7 & 7 & 7 & 7 & 7 & $\vec{t}$ & 7 & 7 & 7 & 7 & 7 & 7 & 7 & 7 & 15 \\
\hline DDDD & 6400 & 7900 & 9600 & 5000 & 6600 & 8200 & 1800 & 400 & 1500 & 1700 & 280 & 600 & 1000 & 5000 & 8000 & 9996 & 2500 \\
\hline EEEE ${ }^{d}$ & 3300 & 50Có & 6500 & 3300 & 5000 & 6600 & 4 & 4 & 4 & 4 & 4 & 4 & 4 & 3300 & 5000 & 6600 & 4 \\
\hline FFFFd & 880 & 680 & 880 & 880 & 880 & 880 & 4 & 4 & 4 & 880 & 4 & 4 & 880 & 880 & 880 & 880 & 4 \\
\hline GGGG $^{d}$ & 132 & 132 & 132 & 132 & 132 & 132 & 132 & 132 & 4 & 132 & 132 & 4 & 4 & 132 & 132 & 132 & 4 \\
\hline||||$^{d, d}$ & 3500 & 4200 & 5000 & 2500 & 3100 & 3800 & 1700 & 500 & 1300 & 600 & 500 & 250 & 250 & 2500 & 4500 & 4500 & 2500 \\
\hline JJJJJ & 10 & 10 & 10 & 10 & 10 & 10 & 10 & 10 & 10 & 10 & 10 & 10 & 10 & 10 & 10 & 10 & 10 \\
\hline KKKK' & 502 & 450 & 450 & 160 & 160 & 160 & 300 & 12 & 300 & 450 & 12 & 300 & 160 & 300 & 450 & 450 & 300 \\
\hline LLLLd & 7900 & 7900 & 7906 & 4700 & 4700 & 4700 & 4700 & 1500 & 3300 & 7900 & 1500 & 3300 & 3300 & 4700 & 7900 & 7900 & 3300 \\
\hline $\mathrm{MMMM}^{\mathbf{d}}$ & 732 & 700 & 700 & 4 & 4 & 4 & 700 & 4 & 700 & 700 & 4 & 700 & 4 & 700 & 700 & 700 & 900 \\
\hline NNNN ${ }^{d}$ & 4 & 4 & 4 & 4 & 4 & 4 & 4 & 4 & 4 & 4 & 4 & 4 & 4 & 4 & 4 & 4 & 4 \\
\hline PPPP' & 3 & 3 & 3 & 3 & 3 & 3 & 3 & 3 & 3 & 3 & 3 & 3 & 3 & 3 & 4 & 6 & 3 \\
\hline $\begin{array}{l}\text { Approximate amount } \\
\text { of core required for } \\
\text { execultion (bytes) }\end{array}$ & $546 K$ & $560 K$ & $576 K$ & $396 \mathrm{~K}$ & $412 K$ & $428 \mathrm{~K}$ & $332 K$ & $132 K$ & $298 \mathrm{~K}$ & $494 K$ & $182 \mathrm{~K}$ & $286 K$ & $324 K$ & $396 \mathrm{~K}$ & $560 \mathrm{~K}$ & $576 K$ & \\
\hline
\end{tabular}

AP = activation products; $A$ = actinidev and daughters: FP = fission projucts.

BAny = either irradiation (i.e. IRP or IRF commands) of decay (i.e., DEC command) can be used. Decay = no irradiation, decay only.

cSee Fig. 1 for details on the description and use of these dimensions.

Array dimensions should be evenly divisible by 4 to ensure word boundary alignment.

Larger dimensions may be required for ismall irradiation or decay time step. In the limit of zero time, IIII = DDDD.

'Depends on reactor being considered; slse Fig. 1, item PPPP.

rCan vary, depending on the number of itput/output units and buffer sizes. 


\subsubsection{TAPES: Decay-Data Library}

The first card of each of the three allowable segments (activation product, actinide, and fission product) of the decay-data library is a title card. It contains the number of the decay-library segment and the alphanumeric title of the segment. The lines following the title card are the decay data for the nuclides in a particular library segment. The decay data for each nuclide are specified on two sequential cards. The format of the decay library is given below.

The decay library serves other vitally important functions in the FORIG cods, sddition to supplying decay data. The nuclide identifiers supplied by the decay librarios define the total list of all nuclides that will be considered in subsequent FORIG calculations. Thus, if a nuclide is to be used in a calculation (even if only the cross-section information is required), it must be present in the decay library. The decay library also defines the nuclide membership of each of the three library segments (activation product, fission product, and actinide) considered by the FORIG code. In some cases, a given nuclide can appear in two or even three library segments. Finally, the decay library defines the order in which the nuclides will be printed within each library segment during the normal output.

As a result of these considerations, the decay library must be input before the photon libraries (PHо command) or before the initial compositions (INP command). When the LIB command is invoked, the decay library is automatically read before the cross-section library.

The decay library is input in the following format. Only the final field (SBRCG) differs from that in ORIGEN2.

NLB TITLE (For the light-nuclide segment)

NLB ZZAAAI IU THALF F $\beta \times F \beta+E C F \beta+E C X F \alpha F i t$

NLB FS FIB QREC ABUND ARCG WRCG SBRCG

$-1$

NLIB TITLE (Fur the actinide segment)

NLIB TITLE (For the fission-product segment)

$-1$

$$
-1
$$

The data entry fields are defined as follows:

zzAAAI Nuclide identifier (atomic number, atomic weight, and 0 or 1 for ground or isomeric state).

IU Time unit (see Table 3) for the half life, THALF.

$F \boldsymbol{B}$

$F \beta+E C$

Fraction of all decays by negatron (beta) emission with an excited daughter.

FB $+E C X$ Fraction of all decays by positron emission or electron capture and with an excited daughter.

$\mathbf{F} \boldsymbol{\alpha}$

Fraction of all decays by alpha emission.

Fit Fraction of all decays by internal fission.

Fsf Fraction of all decays by spontaneous fission.

$F \cap \beta \quad$ Fraction of all decays by neutron-plus-beta decay. 
QREC Total recoverable energy (not including neutrinos) released per decay (in MeV).

ABUND Natural isotopic abundance.

ARCG Radioactivity concentration guide (RCG) for continuous inhalation in unrestricted areas as given in Ref. 7 (Table II, column 1), 10CFR20, using the lower of the soluble and insoluble values.

WRCG RCG for continuous ingestion from column 2 of the same table in 10CFR20.

SBRCG Allowable curies of nuclide per cubic meter of waste for shallow burial if only that nuclide is buried (from Ret. 6, 10CFR61).

The fraction of negatron beta decays with a ground-state daughter is calculated from the above fractions (1 minus the sum of the entries).

Since the decay library is used to produce the nuclide list for the calculation, both radioactive and stable nuclides of interest must be included.

Table 3. Time-unit designations.

$$
\begin{aligned}
& 1=\text { seconds } \\
& 2=\text { minutes } \\
& 3=\text { hours } \\
& 4=\text { days } \\
& 5=\text { years } \\
& 5=\text { stable } \\
& 7=10^{3} \text { years }(\mathrm{kY}) \\
& 8=10^{6} \text { years }(\mathrm{MY}) \\
& 9=10^{9} \text { years }(\mathrm{GY})
\end{aligned}
$$

\subsubsection{TAPE8: Cross-Section Library}

- For a library number less than 700, use the standard ORIGEN2 library.

NLB TITLE (For the light-nuclide segment)

NLB zZAAAI $\operatorname{sn} \gamma \operatorname{sn} 2 n \operatorname{sn} \alpha \operatorname{snp} \operatorname{sn} \gamma x \operatorname{sn} 2 n x-1.0$

$-1$

NLB TITLE (For the actinide segment)

NLB $z Z A A A I \operatorname{sn} \gamma \operatorname{sn} 2 n \operatorname{sn} 3 n \operatorname{snf} \operatorname{sn} \gamma x \operatorname{sn} 2 n x-1.0$

$-1$

NLB TITLE (For the fission product segment)

NLB $Z Z Z A A A I \operatorname{Sn} \gamma \operatorname{Sn} 2 n \operatorname{Sn} \alpha \operatorname{Snp} \operatorname{Sn} \gamma \times \operatorname{Sn} 2 n x 1.0$

$Y(1) Y(2) Y(3) Y(4) Y(5) Y(6) Y(7) Y(8)$

$-1$ 
These entry fields are defined as follows:

NLB Library number for each segment.

ZZAAAI Nuclide identification.

$\sin \gamma \quad$ Cross section for the $(n, \gamma)$ reaction.

$\operatorname{sn} 2 n x \quad$ Cross section for the $(n, 2 n)$ reaction leaving an excited daughter, etc.

$Y(1) \quad$ Fission product yic!ds (\%) from up to 8 actinides (see L IB command for more details). through The $Y(1)$ through $Y(8)$ line is omitted if the previous line ends in a negative number. $\mathrm{x}(8)$

- For a light-nuclide library number greater than 699, use the ORLIB format.

NLB TITLE (For a pure fusion problem)

Comment line

zzAMAI $\operatorname{sn} 2 \pi \operatorname{sn} 2 n x \operatorname{sr} 3 n \operatorname{snnp} \operatorname{snn} \alpha \operatorname{snp} \operatorname{snd} \operatorname{snt} \operatorname{sn} \alpha \operatorname{sn} \gamma \sin \gamma$

$-1$

This example includes no cross sections for actinides or fission products. If the problem includes either, they are entered in the original ORIGEN2 format following the light-nuclide segment.

In both formats, the code will error exit if cross sections are entered for nuclides not in the appropriate decay-library segment. The input of TAPES is controlled by the LIB command in ORINPUT.

\subsubsection{TAPE3: Odd-Reaction Cross-Section Library}

- For a light-nuclide library number less than 700, input the odd reactions in the ORIGEN2 format.

ZAAAI ZZAAAI SIGHA

The first and second entries on each line are the parent and daughter nuclide identifications. When this format is used, hydrogen and helium isotope production is not calculated for the odd reactions.

- For a light-nuclide library number greater than 699 , input the odd reactions in the ORLIB format.*

NLIB TITLE

ZZAAAI ZZAAAI SIGMA TYPE

ZZAAAI ZZAAAI SIGMA TYPE

TYPE is the reaction-type number (Table 1). With this format, hydrogen and helium isotope production is calculated for both the odd and the standard reactions.

\footnotetext{
-ORLIB is a cross-section manipulation code ${ }^{3}$ available with FORIG. The code can be used to energy average the ACTL crosssection library, using either an input flux or a TARTNP-generated flux ${ }^{5}$ as a weighting function. One improvement has been made to ORLIB since ReT. 3 was published; a flag has been added to the ORLIB input file to allow production of libraries in one of four formats (0 or no entry = FORIG light-nuclide format, 1 = ORIGEN2 light-nuclide format, 2 = actinide format, $3=$ fission-product format without fission product yield-curve entries). This input flag is an I1 format in Column 30 of line 2 of the ORLIB input.
} 
In either ORIGEN2 or ORLIB formats, each odd reaction is added to the first library segment (light nuclide, actinide, or fission product) that includes the parent in the decay library. Also, if replacement decay or cross-section lines are to be inserted in any of the six library segments, these lines precede the oddreaction formats shown above. (The LIB and LPU commands force the code to read each line in its proper format, as is discussed later). Input for substitute decay or cross-section data is discussed in more detail in Sections 4.2.2 and 4.3.1.

\subsubsection{TAPE10: Photon-Decay Data Library}

- Input this library in the ORIGEN2 format.

NLB TITLE (For the light-nuclide segment)

NLB ZZAAAI NGP(1) RPH( 1 ) …NGP(J) RPF(J)

$\operatorname{NGP}(J+1) \operatorname{RPH}(J+1) \ldots \operatorname{NGP}(18) \operatorname{RPH}(18)-1$

$-1$

These commands are defined as follows:

NGP Group number.

RPH Photon intensity per disintegration.

Only non-zero entries need be made. If actinides and fission products are used in the problem, their segments should be added to the example above. The photon-energy group structure is shown in Table 4. The input of the photon library is controlled by the PHO command in ORINPUT.

Table 4. Photon-energy group structures for activation products, actinides, and fission products.

\begin{tabular}{clll}
\hline & \multicolumn{4}{c}{ Group energy (Mov) } \\
\cline { 2 - 4 } Group & Lower boundary & Upper boundary & Averago \\
\hline 1. & 0.0 & 0.02 & 0.01 \\
2 & 0.02 & 0.03 & 0.025 \\
3 & 0.03 & 0.045 & 0.0375 \\
4 & 0.045 & 0.07 & 0.0575 \\
5 & 0.07 & 0.1 & 0.085 \\
6 & $0: 1$. & 0.15 & 0.125 \\
7 & 0.15 & 0.3 & 0.225 \\
8 & 0.3 & 0.45 & 0.375 \\
9 & 0.45 & 0.7 & 0.575 \\
10 & 0.7 & 1.0 & 0.85 \\
11 & 1.0 & 1.5 & 1.25 \\
12 & 1.5 & 2.0 & 1.75 \\
13 & 2.0 & 2.5 & 2.25 \\
14 & 2.5 & 3.0 & 2.7 .5 \\
15 & 3.0 & 4.0 & 3.5 \\
16 & 4.0 & 6.0 & 5.0 \\
17 & 6.0 & 8.0 & 7.0 \\
18 & 8.0 & 11.0 & 9.5 \\
\hline
\end{tabular}




\subsubsection{ORINPUT: Instruction File}

The input begins with four lines, each usually consisting of " 1 ". These negative entries suppress printing of neutron sources, decline to replace default fractional-recovery efficiencies of individual elements, decline to replace default fractional-recovery efficiencies of element groups, and decline to replace group-membership assignments of elements.

The file input continues with the individual commands, which are listed below by category. Detailed explanations are provided in Section 4.

\subsubsection{Comment and Termination Commands.}

RDA Prints comments in the command list. (Comments may also be added at the end of most command lines.)

TIT Specifies the title to be printed on the output table pages.

BAS Prints a comment line on the output table pages. (For example, the comment can indicate that the calculation is based on one metric ton of steel in the reactor.)

HED Allows a time-column heading to be changed from the actual time to a 10 -character alphanumeric heading.

STP Allows a new case to begin with new commands, new libraries, and/or initialization data.

END Terminates execution.

\subsubsection{Library Commands.}

LIB Inputs the decay and cross-section libraries. (The format of this command has been modified from the original ORIGEN2 format.)

LPU Identifies nuclides requiring replacement lines in decay or cross-section library segments. One LPU command must precede the L IB command for each negative library number in the I IB command.

PHO Inputs the photon data libraries.

LIP Determines whether the decay, gross-section, and photon libraries are printed. The LIP command must precede the LIB command.

\subsubsection{Material Input Commande.}

INP Forces the code to read the input material compositions. The program is set up to read the compositions at the end of the input command file (ORINPUT). However, a previous FORIG run could produce an output file in the proper format for input to this problem. If this output file is to be used directly, it should be named "TAPE4" and be opened in the FORIGM program. The INP command also allows input of continuous feed rates and continuous removal rates. These data follow the initial composition input at the end of ORINPUT.

WAC Allows material to be continuously removed from the reactor with element-dependent efficiency. This waste accumulation can then be decayed.

PRO Allows a material to be processed at a given time into two segments with element-dependent efficiency.

vor Inputs the material volume (to allow calculation of the shallow-burial index and the surface dose rate). 
3.3.5.4. Material Manipulation Commands. FORIG maintains the material composition as a vector at each time step. Because only those vectors required for output or subsequent calculation need be kept, it is sometimes convenient to manipulate the vectors.

MOV Allows a material composition to be moved from one vector to another. The command also allows a constant multiplier to be applied to the composition. The heading moves with the vector.

ADD Allows addition of one material vector to a second material vector. The command also allows the material being added to be multiplied by a constant prior to the addition. The heading for the first vector will be moved to the second vector with this command.

KEQ

Allows two materials to be blended until the resultant material has an infinite neutron multiplication factor that matches either a third material or an input value.

FAC Calculates the sum, product, or ratio of the total fission product plus actinide mass of two vectors or of a vector and an input constant. The resulting constant factor can then be used as a multiplier in subsequent ADD or MOV commands.

\subsubsection{Commands that Take a Time stop}

DEC

Allows a composition vector to decay for a specified time.

IRF Allows irradiation and decay of a composition vector in a constant neutron flux for a specified time.

IRP Allows irradiation and decay of a composition vector at a constant power for a specific time (only applied to fission problems).

BUP

Calculates the average burnup, flux, and specific power for an irradiation period (only applies to fission problems).

\subsubsection{Loop Commands.}

DOL Sets up a "Do loop" through a set of instructions.

CON Ends (continues) a Do loop.

REC Counts the number of times (cycles) a Do loop has been executed (for printing in the output tables).

\subsubsection{Output Commands.}

OUT Specifies composition vectors to be output.

OPTL Specifies printing of light-nuclide output data for each vector in the out command. (Options include fractional or actual composition, activity, thermal-decay power, shallow-burial index, inhalation and ingestion biological-hazard potentials, and chemical-ingestion hazard. Output tables for neutron-absorption rate, neutron induced-fission rate, a-radioactivity, a-induced neutron production, and spontaneous-fission neutron production are automatically produced for the actinide segment. The photon-emission rate table is also automatically produced. The OPTL command also specifies the units of the various tables and whether the output will be by nuclide, element, and/or in a condensed format. The OPTL command must precede the OUT command.

OPTA Output options for actinides (same format as OPTL).

OPTF Output option for fission products (same format as OPTL). 
cur Defines cutoff limits for condensed output tables. The nuclide is omitted if, for all the time steps being output on the page, the output for a partirular nuclide is less than the product of the cutoff fraction and the total output at that time step.

PCH Creates an output file containing the material composition. This file is in a format readable by future FORIG calculations.

RADS Outputs the approximate surface-contact dose rate vs time.

\subsection{Fonic Output Files}

The following output files are generated by FORIG:

OROUT Large île containing most of output (called TAPE6 in the ORIGEN2 manual).

TAPE12 Table of Contents for OROUT,

TAPE11 Abbreviated output file.

TAPE13 Table of Contents for TAPE11.

TAPE7 Output composition file (optlonal) written by the PCH command.

TAPE15 Debug information and error messages.

TAPE16 Actinide cross-section information.

TAPE50 Working file set up and used by FORIG.

ORPLOT Lists total lines for the OROUT tables.

The "total" lines from the OROUT tables are repeated in ORPLOT to facilitate production of graphs. The OUT command, besides sending output to OROUT, can also specify sending the output to a second file (TAPE11 with table of contents TAPE13). The TAPE11 file $i$ : useful if an early, condensed hard-copy file is desired before generation of the full (OROUT) output, which is usually output as microfiche.

Sample FORIG and ORIGEN2 files are licted in Table 5.

\subsection{Ceneral Code information}

\subsubsection{Fonio Input Data in Free Format}

With few exceptions, input data to FORIG can be specified in free format. The restrictions on freeformat input are as follows:

(1) All data must appear in the correct order.

(2) All data must be of the correct type (e.g., integer or real) and may be in I, F, E, or D format.

(3) Each datum must be separated from the next by at least one space.

(4) Zero data values must appear explicitly (i.e., a blank is not equivalent to a zero).

(5) In general, data may be continued onto multiple records if desired.

(6) Certain data must appear as the first datum on anew record. These instances are described later.

(7) The maximum record length for ORINPUT is 80 bytes.

(8) If an and of file is read, control is returned to the calling subroutine.

Thus, in general, the data being read must be in the correct order, must begin on a new card when required, and must be separated by blanks. Other than this, the data may appear at ani' place on an input record. In the special case of numbers in E or D format (e.g., 3.8E 01), the space after the $E$ is acceptable and is not considered as the end of the number.

\subsubsection{Composition "Vectors" that Store and Output Nuclide Data}

Before attempting to read the operational details of FORIG, the user must understand the concept of a FORIG vector. A FORIG vector is a one-dimensional array that specifies the amount of each nuclide being 
Table 5. Sample FORIG and ORIGEN2 files. (The "take directory" of J. Blink at LLNL contains a number of sample FORIG, ORLIB, and URIGEN2 files.)

File description

Directory table of contents

ORLIE files (see Ref. 3)

FORIG source and controllee files

Example FORIG input and data files

Table of contents for ORIJL-supplied file Hist for ORIGEN2

Sample ORIGEN2 main programs for various fission feactors

ORIGEN2 decay library

ORIGEN2 cross-section libraries for various fission reactors

ORIGEN2 photon library for $\mathrm{UO}_{2} \mathrm{~L} \sim$ msstrahlung

ORIGEN2 photon library far $\mathrm{H}_{2} \mathrm{O}$ bremsstrahlung

ORIGEN2 photon library for vacuum (no

bremsstrahlung)

Sample ORIGEN2 cutput files for a sing'e flssionreactor problem (TAPES B, $7,11,12,13,14$, and 16)

Example FORIG input and output files for a fusion problem
Name of file

CONTENTS (in Directory .080975:ORIGEN2)

ORLIB, ORLIES, EORLIEIN, AC820312, and ADEX8203:

FORIGS, BFORIGS, FORIGMG, FJRIGM, and FORIG

EOR. 'JPUT, ETAPE3, ETAPE8, ETAPE9, and ETAPE10

OR01C

ORU3C-ORTBC (ORO3C was modffied to run on FกRIG)

OR21C

OR22C-OR44C

OR45C

OR46C

UR47C

OR4SC-OR54C

2ORINT, 2OROTT

${ }^{3} A C$ files are ACTL libraries created on the given year-month-day; ADEX files are ACTL library indices created on the given year-month; and EORLIBIN is an example ORLIB command file.

considered in a FORIG case. It is printed as a single column of numbers in FORIG output. If the problenr being run includes actinide, activation-jroduct, and fission-product nuclides, a vector might specify the amounts of the Juclides in each of these segments at a given time.

As shown in the diagram (see Fig. 2) of the conceplual vector organization of FORIG, two basic types of vectors are accessible to the user: output vectors and storage vectors.

The twelve output vectors contained in FORIG are written when FORIG output is pr stuced. Each vector is designated by positive integers corresponding to the relative location of the vector, the let.-most vector on the output page being vector 1 and the right-most being vector 12. The information in the output vectors is retained under all conditions except one. This exception occurs (1) when a new set of FORIG commands is read during a single run using the STP command ("Execute previous commands and branch") and (2) when the new set of commands includes a I IB command ("Read neww decay and crosssection data libraries"). Then, the array containing the output vectors is used as scratch space to read the new libraries and the nuclide mass data are lost.

A variable number (LX) of storage vectors in FORIG depend on the variable dimensions employed (see variable JJJJ in Fig. 1). These vectors store intermediate results and cannot be output. The vectors are 


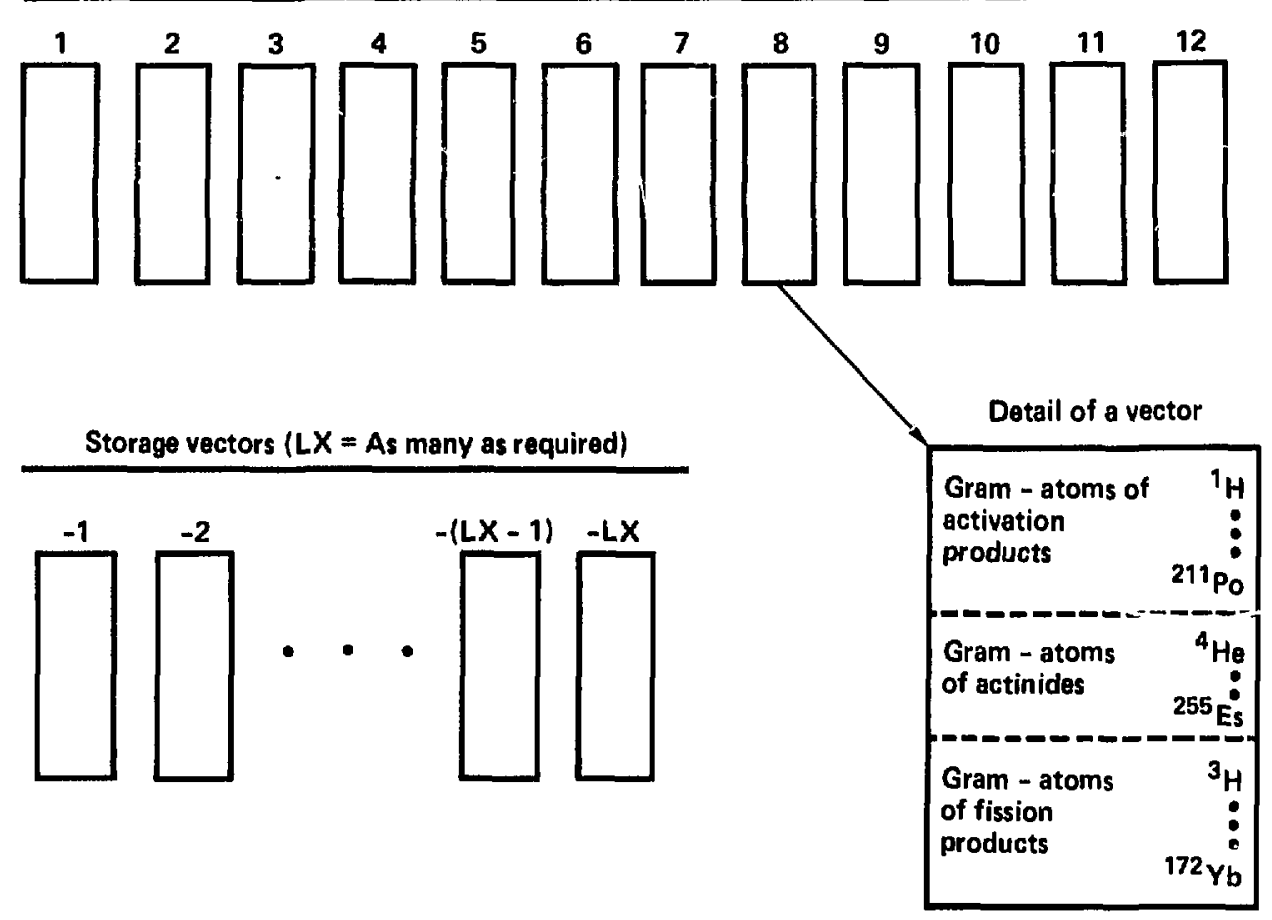

Figure 2. Organization of FORIG vectors.

designated by using negative integers from -1 to $-\mathrm{LX}$. The information in the storage vectors is retained under all circumstances, including those where the output vectors are overwritten.

\subsubsection{Card Input Echo}

Included in FORIG is a subroutine LISTIT whose function is to provide a command echo. The commands are read from ORINPUT, printed on OROUT, and written to TAPE50, which is a temporary file. Commands with a dollar sign (\$) in the first column are printed (in OROUT) but not written (to TAPE50), thus allowing for the inclusion of comments in the input stream without interfering with the operation of the code. TAPE50 is then rewound, and the rest of FORIG reads the commands from TAPE50.

\subsubsection{Nucllde Identifier}

The FORIG nuclide identifier is a six-digit integer that uniquely defires a particular nuclide:

NUCLID $=108 * z+16 * A+I S$

where NUCLID is a six-digit nuclide identifier, $z$ is the atomic number of the nuclide, $\mathrm{A}$ is the atomic mass of the nuclid/, Is is the iso, jeric-state indicator ( $\theta=$ ground state, 1 = excited state, and 2 or greater is not permitted). 
Thus, the nuclide identifier for ${ }^{137} \mathrm{Cs}(\mathrm{z}=55, \mathrm{~A}=137)$ would be 551370 . The trailing zero (or one) is always required. A leading zero, such as for tritium (NUCLID $=010030=10030$ ), is not required.

The six-digit identifier for an element is given by

$$
\text { ELEMID }=10606 * \mathrm{Z}
$$

Where ELEMID is the element identifier anc: 3 is defined as above. Thus, the ELEMID for cesium would be 550000 .

\subsubsection{Machine Compatibility Considerations}

FORIG is designed to be as machine-compatible as possible by using only the FORTFAN computer language, using only standard FORTRAN functions (e.g., SQRT, etc.), usually using $\mathrm{H}$-format specifications for literal data in FORMAT and Data statements, and minimizing the number of partial-word (l.e., one-byte and two-byte word) arrays.

FORIG runs on the CRAY systems at LLNL and at NMFECC. If use of CDC or IBM machines is desired, compatible versions of the ORIGEN2 code are avallable from ORNL. A user could then compare FORIG to the proper ORIGEN2 version and bulld a code in a reasonable time. 


\section{Instruction File for FORIG Computer Code (ORINPUT)}

The command file ORINPUT controls the execution of the FORIG computer code and is divided into three sections:

- Miscellaneous initialization data. (For fusion problems, the default data are usually adequate.)

- The sequence of commands for selecting cross-section libraries, for determining the flux-time history, and for selecting the output options.

- The composition of the input material.

\subsection{Miscellaneous Data in the Source Code (FORlas)}

Miscellaneous data related only by their invariance from case to case are included here. These data are all initialized in the Data subroutine contained in the source code (FORIGS) and include the following:

- Fission neutron yields per neutron-induced fission.

- $(\alpha, n)$ neutron-production rates.

- Neutron yield per spontaneous fission.

- Fracilonal reprocessing recoveries for indlvidual elements.

- Fractional reprocessing recoveries for element groups.

- Assignment of individual elements to fractional reprocessing recovery groups.

- Elemental chemical toxicities

\subsubsection{Suppression of Neutron-Source Printing}

If printing of the spontaneous-fission neutron yield, $(\alpha, n)$ neutron-production rate, and neutroninduced-fission neutron yield is desired, the first line of ORINPUT should be a non-negative integer beginning in column 3. If printing is not desired, the usual case for fusion problems, the first line should be a negative integer beginning in column 3 .

4.1.1.1. Fission Neutron Yield per Neutron-Induced Fission. The Data subroutine supplies spectrum-weighted, single-group, fission neutron yields per neutron-induced fission for a thermal reactor (PWR-U) and for a fast reactor (advanced-oxide LMFBR). These data are used in calculating the infinite neutron multiplication factor for a mixture of nuciides. These data cannot be altered except by changing the values in the Data subroutine and by recompiling the source file (FORIGS).

4.1.1.2. (a,n) Neutron-Production Rate. The Data subroutine supplies measured $(\alpha, n)$ neutronproduction rates (in units of neutrons per gram per second) for nuclides in oxide fuels. These values override values calculated with an empirical equation in FORIG. The $(\alpha, n)$ neutron-production rates for those nuclides not listed explicitly are calculated from an empirical equation. The parameters in the equation and the explicit values can only be altered by changing the values in the Data subroutine and recompiling it in the source code (FORIGS).

4.1.1.3. Fission-Neutron Yield per Spontaneous Fission. The Data subroutine supplies measured values for neutron yields per spontaneous fission, which override values calculated with an empirical equation in FORIG. These neutron yields, denoted as "SF yields", are used to calculate the decay neutron activity of nuclide mixtures. The SF neutron yields for those nuclides not given explicitly are calculated from an empirical equation. These initialization data can only be altered by changing the values in the Data subroutine and recompiling the source code (FORIGS).

\subsubsection{Miscellaneous Input Data}

If neutron-source printing is not desired and if chemical reprocessing will not be required in the problem, the miscellaneous data input section consists of four lines, each with a negative integer in Columns 3 and 4. 
4.1.2.1. Fractional-Reprocessing Recoveries for Individual Eloments. The Data subroutine supplies fractional-reprocessing recoveries (FR's) for each individual element. The FR's are used to separate a specified elemental composition into two separate streams. The individual element FR's initially present in FORIG are given in Table 6. A single FR set specifies an FR for each of 99 elements. There are ten sets of individual FR's in FORIG.

The individual FR sets also serve another purpose under certain circumstances. If one or more wAC (nuclide accumulation) commands are used, then at least one indivicual-element or element-group FR set (see the following section) must contain continuous-removal rates $\left(\mathrm{s}^{-1}\right)$ for the elements. The continuousremoval rates specified in the FR set are those appropriate for a reactor with continuous fuel reprocessing (e.g., a Molten-Salt Breeder Reactor or MSBR). The specified continuous-removal rates are used by the WAC command to generate equivalent continuous-feed rates of waste during waste decay.

In either of the above cases, the initial data can be altered by the following input lines:

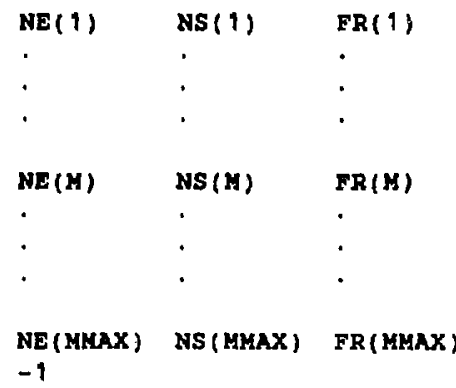

Table 6. FORIG defaults for individual-element fractional recoveries.

\begin{tabular}{|c|c|c|c|c|c|c|c|c|c|c|}
\hline \multirow[b]{2}{*}{ Elemant } & \multicolumn{10}{|c|}{ Fractional recoveries } \\
\hline & Sot 1 & Sot 2 & $\operatorname{set} 3$ & Set 4 & Set 5 & Set 6 & Sat 7 & $\operatorname{Set} 8$ & Sot 9 & Sot 10 \\
\hline$H$ & 0.0 & 0.0 & 0.0005 & 0.0 & 1.0 & 1.0 & 0.0 & 0.0 & 0.9 & 1.0 \\
\hline $\mathrm{He}$ & 0.0 & 0.0 & 0.0005 & 0.0 & 1.0 & 1.0 & 0.0 & 0.0 & 0.0 & 1.0 \\
\hline Li-B & 0.0 & 1.0 & 0.0005 & 0.0 & 1.0 & 1.0 & 1.0 & 0.0 & 0.0 & 1.0 \\
\hline $\mathrm{C}, \mathbf{N}$ & 0.0 & 0.0 & 0.0005 & 0.0 & 1.0 & 1.0 & 0.0 & 0.0 & 0.0 & 1.0 \\
\hline 0 & 0.0 & 1.0 & 0.0005 & 0.0 & 1.0 & 1.0 & 1.0 & 0.0 & 0.0 & 1.0 \\
\hline $\mathbf{F}$ & 0.0 & 0.001 & 0.0005 & 0.0 & 1.0 & 1.0 & 1.0 & 0.0 & 0.0 & 1.0 \\
\hline $\mathrm{Ne}$ & 0.0 & 0.0 & 0.0005 & 0.0 & 1.0 & 1.0 & 0.0 & 0.0 & 0.0 & 1.0 \\
\hline $\mathrm{Na}-\mathrm{S}$ & 0.0 & 1.0 & 0.0005 & 0.0 & 1.0 & 1.0 & 1.0 & 0.0 & 0.0 & 1.0 \\
\hline Cl & 0.0 & 0.001 & 0.0005 & 0.0 & 1.0 & 1.0 & 1.0 & 0.0 & 0.0 & 1.0 \\
\hline Ar & 0.0 & 0.0 & 0.0005 & 0.0 & 1.0 & 1.0 & 0.0 & 0.0 & 0.0 & 1.0 \\
\hline K-Se & 0.0 & 1.0 & 0.0005 & 0.0 & 1.0 & 1.0 & 1.0 & 0.0 & 0.0 & 1.0 \\
\hline Br & 0.0 & 0.001 & 0.0005 & 0.0 & 1.0 & 1.0 & 1.0 & 0.0 & 0.0 & 1.0 \\
\hline Kr & 0.0 & 0.0 & 0.0005 & 0.0 & 1.0 & 1.0 & 0.0 & 0.0 & 0.0 & 1.0 \\
\hline$R b-T \theta$ & 0.0 & 1.0 & 0.0005 & 0.0 & 1.0 & 1.0 & 1.0 & 0.0 & 0.0 & 1.0 \\
\hline 1 & 0.0 & 0.001 & 0.0005 & 0.0 & 1.0 & 1.0 & 1.0 & 0.0 & 0.0 & 1.0 \\
\hline$X_{\theta}$ & 0.0 & 0.0 & 0.0005 & 0.0 & 1.0 & 1.0 & 0.0 & 0.0 & 0.0 & 1.0 \\
\hline Cs-At & 0.0 & 1.0 & 0.0005 & 0.0 & 1.0 & 1.0 & 1.0 & 0.0 & 0.0 & 1.0 \\
\hline Rn & 0.0 & 0.0 & 0.0005 & 0.0 & 1.0 & 1.0 & 0.0 & 0.0 & 0.0 & 1.0 \\
\hline $\mathrm{Fr}-A \mathrm{C}$ & 0.0 & 1.0 & 0.0005 & 0.0 & 1.0 & 1.0 & 1.0 & 0.0 & 0.0 & 1.0 \\
\hline Th & 0.0 & 1.0 & 0.0005 & 0.0 & 1.0 & 1.0 & 1.0 & 0.0 & C.j. & 1.0 \\
\hline $\mathrm{Pa}$ & 0.0 & 1.0 & 0.0005 & 0.0 & 1.0 & 1.0 & 1.0 & 0.0 & 0.0 & 1.0 \\
\hline U & 0.995 & 1.0 & 0.0005 & 0.999 & 1.0 & 0.2 & 0.6 & 1.0 & 0.0 & 1.0 \\
\hline Np & 0.0 & 1.0 & 0.0005 & 0.0 & 1.05 & 0.05 & 0.0 & 0.0 & 0.0 & 1.0 \\
\hline Pu & 0.995 & 1.0 & 0.0005 & 0.9999 & 1.0 & 0.02 & 0.0 & 0.0 & 0.0 & 1.0 \\
\hline Am-Es & 0.0 & 1.0 & 0.0005 & 0.0 & 1.001 & 0.001 & 0.0 & 0.0 & 0.0 & 1.0 \\
\hline
\end{tabular}


These data fields are defined as follows:

NE ( M ) Element atomic number (one or two digits, 1 to 99) for the fractional recovery on the $M$ th line of this input.

NS (M) Set number ( 1 to 10$)$ for the individual fractional recovery on the $M$ th line.

FR(M) Fractional recovery value replacirg the initial value for element NE(M) in set NS (M); or, continuol's removal rate for the WAC command.

MMAX Number of individual-element fractional-recovery values being overridden.

The negative entry terminates reading of the altered data. If no changes are desired, a single negative line instructs the code to continue to the next section.

4.1.2.2. Fractlonal-Reprocessing Recoverles for Element Groups. The Data subroutine supplies FR values for groups of elements. These group FR values can be employed in essentially the same manner as those for Indlyidual elements (discussed in the preceding section). That is, the group values can be used to separate a single specified elemental composition into two streams or to designate continuousremoval rates for the WAC command. The $F R$ values for the groups initially present in FORIG are given in Table 7. FORIG can monitor up to 20 groups of elements. Each of the ten sets of group FR's in FORIG specifies the $E R$ 's for all the element groups.

The FR's for the initial groups of elements can be altered by the following input lines:

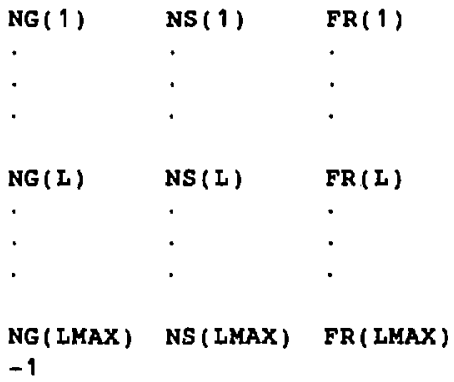

Table 7. FORIG defaults for element-group fractional recoveries.

\begin{tabular}{cllllllllll}
\hline & & \multicolumn{7}{c}{ Fractional recoveries } \\
\cline { 2 - 10 } Group & Sot 1 & Set 2 & Sot 3 & Set 4 & Sot 5 & Sot 6 & Sot 7 & Sot 8 & Sot 9 & Sot 10 \\
\hline 1 & 0.0 & 1.0 & 0.0005 & 0.0 & 1.0 & 1.0 & 1.0 & 0.0 & 0.0 & 0.0 \\
2 & 0.0 & 1.0 & 0.0005 & 0.0 & 1.0 & 1.0 & 0.0 & 0.0 & 0.0 & 0.0 \\
3 & 0.0 & 1.0 & 0.0005 & 0.0 & 1.0 & 1.0 & 0.0 & 0.0 & 0.0 & 0.0 \\
4 & 0.995 & 1.0 & 0.0005 & 0.999 & 1.0 & 0.2 & 0.6 & 1.0 & 0.0 & 0.0 \\
5 & 0.0 & 1.0 & 0.0005 & 0.0 & 0.05 & 0.05 & 0.0 & 0.0 & 0.0 & 0.0 \\
6 & 0.995 & 1.0 & 0.0005 & 0.9999 & 1.0 & 0.02 & 0.0 & 0.0 & 0.0 & 0.0 \\
7 & 0.0 & 1.0 & 0.0005 & 0.0 & 0.001 & 0.001 & 0.0 & 0.0 & 0.0 & 0.0 \\
8 & 0.0 & 1.0 & 0.0005 & 0.0 & 0.001 & 0.001 & 0.0 & 0.0 & 0.0 & 0.0 \\
9 & 0.0 & 1.0 & 0.0005 & 0.0 & 0.001 & 0.001 & 0.0 & 0.0 & 0.0 & 0.0 \\
10 & 0.0 & 1.0 & 0.0005 & 0.0 & 0.001 & 0.001 & 0.0 & 0.0 & 0.0 & 0.0 \\
11 & 0.0 & 1.0 & 0.0005 & 0.0 & 0.001 & 0.001 & 0.0 & 0.0 & 0.0 & 0.0 \\
12 & 0.0 & 0.001 & 0.0005 & 0.0 & 1.0 & 1.0 & 0.0 & 0.0 & 0.0 & 0.0 \\
13 & 0.0 & 0.0 & 0.0005 & 0.0 & 1.0 & 1.0 & 0.0 & 0.0 & 0.0 & 0.0 \\
14 & 0.0 & 0.0 & 0.0005 & 0.0 & 1.0 & 1.0 & 0.0 & 0.0 & 0.9 & 0.0 \\
$15-29$ & 0.0 & 0.0 & 0.0 & 0.0 & 0.0 & 0.0 & 0.0 & 0.0 & 0.0 & 0.0 \\
\end{tabular}


These data fields are defined as follows:

NG (L) Element group number (one or two digits, 1 to 20) for the fractional recovery on line $I$ of this input section.

NS ( $L$ ) Set number (1 to 10) for the fractional recoveries of the element-group on line $L$.

FR( $L$ ) Fractional recovery value replacing the initial value for group NG(L) in set NS (L); or, the continuous removal rate for the waC command.

LMAX Number of group fractional-recovery values being overridden.

The negative entry terminates reading of the altered data. If no changes are desired, a single negative line instructs the code to continue to the next section.

4.1.2.3. Assfenment of Elements to Fractional-Recovery Groups. The Data subroutine also assigns each of the 99 elements to one of the 20-element groups discussed in the preceding section. Any number of elements may be assigned to a given group, but an individual element can be a member of only one group. The initial membership of the FORIG element group is given in Table 8.

The assignment of elements to $\mathrm{F}$ groups can be altered by using the following input lines:

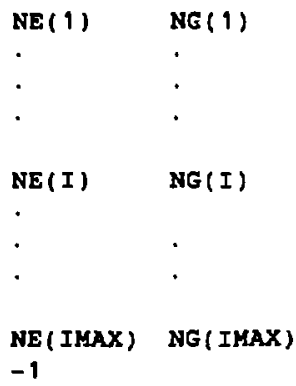

These data fields are defined as follows:

$\mathrm{NE}$ (I) Element atomic number (one or two digits, 1 to 99) on line I of this input section.

NG (I) Element group number (one or two digits, 1 to 20) where element NE ( I) is to be assigned.

IMAX Number of element assignments being overridden.

Table 8. Composition of FORIG default-element groups.

\begin{tabular}{ll||ll}
\hline Group & Elements in group & Group & Elements in group \\
\hline 1 & All elements except & 9 & BK \\
2 & those in groups 2-14 & & $\mathrm{Cr}$ \\
3 & $\mathrm{Th}$ & 10 & $\mathrm{Es}$ \\
4 & $\mathrm{~Pa}$ & 11 & $\mathrm{~F}, \mathrm{Cl}, \mathrm{Br}, \mathrm{I}$ \\
5 & $\mathrm{U}$ & 12 & $\mathrm{He}, \mathrm{C}, \mathrm{N}, \mathrm{Ne}, \mathrm{Ar}, \mathrm{Kr}, \mathrm{Xe}$, \\
& $\mathrm{Np}$ & 13 & $\mathrm{Rr}$ \\
7 & $\mathrm{Pu}$ & 14 & $\mathrm{H}$ \\
8 & $\mathrm{Am}$ & $15-20$ & $\mathrm{None}$ \\
\hline
\end{tabular}


The negative entry terminates reading of the altered data. If no changes are desired, a single negative line instructs the code to continue to the next input section.

4.1.2.4. Elemental Chemical Toxicities. The Data subroutine supplies maximum permissible concentrations (MPCs in water) for each of the chemical elements. The MPC is used to calculate the volume of water required to dilute a given amount of an element to a concentration corresponding to its MFC. The sum of the volumes of water required for the elements in a mixture is assumed to yield the total volume of dilution water required and thus is a measure of the chemical toxicity of the elemental mixture. This measure is sometimes called the chemical biological hazard potential (bhp). The MPC data can only be altered by changing the values in the Data subroutine and recompiling the source code (FORIGS).

\subsection{FORIG Commands}

The FORIG commands (instructions) allow the user to precisely define the order of execution of the FORIG program functions. That is, the commands define a series of operations to be performed sequentially, the sequence being varied according to the option of the user. In this respect, the procedure is analogous to writing a FORTRAN program. The FORIG program flowsheet may use "DO loop" commands, which execute sets of instructions within the loop range a prescribed number of times. Coupled with other options, this allows the user to investigate the fuel-recycle rates (e.g., plutonium or tritium) and nuclear-fuel-cycle waste-production rates as a function of time.

The general format for the FORIG commands is

$$
\text { COM PARM ( } 1 \text { ) PARM( } 2 \text { ) PARM(I), }
$$

where COM represents a keyword that defines the instruction type and PARM ( I ) represents parameters that supply data necessary for execution of operational commands. Note that the command keyword always irtroduces the command. The FORIG commands and their functions are listed in Section 3 and are described in detail in the following.

Belore you attempt to use FORIG, please note that certain restrictions are imposed on the order in which the commands must occur. The primary restriction is that the LIB command, which reads the decay and cross-section libraries, must precede most other commands because it defines the list of nuclides being considered. Other restrictions are noted in the individual command descriptions.

The number of times a FORIG command can occur in a single input stream is limited, the maximum limit depending on the specific command. This limit is specified in the section that describes each individual command. The limits can be changed by varying the dimensions of the appropriate array(s) within the FORIG source file (FORIGS) and then recompiling. The limit on the total number of FORIG commands that may be used is 300 , a number which can also be changed by varying array dimensions within the source file (FORIGS) and then recompiling.

\subsubsection{Comment and Termination Commands}

RDA Read Comments Regarding Case Being input

This command prints alphanumeric comments in the listing of the operational commands being input. The data sequence is

RDA COMMENT

COMMENT $=$ Alphanumeric message.

The only limit on the number of RDA commands is that the maximum total number of commands cannot exceed 300 . These RDA comments are printed in the listing created when FORIG is interpreting the commands. 
This command supplies a title to be printed on most pages of the FORIG output. The data sequence is

$$
\operatorname{TIT} A(9) \ldots A(80)
$$

$A(T)=$ Alphanumeric characters in columns 9 to 80 only.

The code allows up to 20 TIT commands. The TIT command is in effect until it is shanged by a subsequent TIT command.

\section{Case Basis}

This command supplies the case bas $/ \mathrm{s}(\theta . \mathrm{g} .1 \mathrm{~kg}, 1$ ton, all the material, etc.) printed on most pages of the FORIG output. It is purely a comment and has no influence on the code execution. The data sequence is

$$
\text { BAS A(9) ...A(BO) }
$$

$A(I)=$ Alphanumeric characters in columns 9 to 80 only.

Up to ten BAs commands are allowed. The BAs message is printed until it is changed by a subsequent BAS command.

\section{Composition Vector Headings}

This command allows alphanumeric vector headings to be specified. The default is time (e.g. 1 yr after startup or shutdown). Example headings include "shutdown" and "startup." The data sequence is

$$
\begin{aligned}
& \text { HED NHED A(1) ...A(10) } \\
& \text { NHED = Number of vector to be given a heading. } \\
& A(I)=10 \text {-character alphanumeric heading, placed anywhere to the right of NHED. }
\end{aligned}
$$

Up to $\mathbf{5 0}$ HED commands are allowed. The heading remains in effect until it is changed by a subsequent HED command or until the vector is overwritten (e.g., by an IRF or DEC cornmand). The heading is moved with the vector when the sov and ADD commands are used.

If a HED command will label either a vector of input concentrations [vector NINP (1)] or the vectors resulting from a PRO command [vectors NPRO ( 2 ) and NPRO ( 3 )], the HED command must follow the INP or PRO command.

If $A(1)$ is an apostrophe or asterisk (*), the ten characters immediately following $A(1)$ are taken as the vector heading. This permits the inclusion of leading blanks.

\section{Execute Previous Commands and Branch}

This command allows multiple problems to be executed sequentially in the same run. The set of commands preceding the STP command is executed; then more commands are read. There is no limit to the number of STP commands. The data sequence is 
NSTP $=$ Branching control character:

1 = Read new miscellaneous initialization data and a new set of commands and execute them.

2 = Read a new set of commands and execute them.

$3=$ Execute the preceding set of commands again. Additional input data (libraries and initial nuclide concentrations) is required.

4 = Terminate execution (same as END).

END Terminate Execution

This command terminates execution of FORIG. Only one END command is allowed. The data sequence is

END

\subsubsection{Library Commands}

\section{IIB Read Decay and Cross-Section Libraries}

This command reads decay and cross-section libraries, as well as substitute decay and cross-section entries and nonstandard-reaction (odd-reaction) cross sections.

The libraries supplied by ORNL with ORIGEN2 are listed in Table 9 . For fusion problems, the user must supply the cross-section libraries (e.g., by running TARTNP ${ }^{5}$ to obtain the flux and then running ORLIB ${ }^{3}$ to energy-average the ACTL cross-section library, ${ }^{4}$ using the flux as a weighting function). The data sequence is

$$
\text { LIB NLIB(1) . . NLIB(13) }
$$

$\operatorname{NLIB}(1)=$ Control character. The reaction rate matrix is printed if NLIB $(1)$ is greater than zero. (That is, the production rate from each parent, the decay rate, and the removal rate by activation are printed for each nuclide.) Printing the matrix allows determination of the pathways that dominate the activation; without the matrix, only the overall activation results are available.

NLIB ( 2 ) = The light-nuclide decay librany number.

$\operatorname{NLIB}(3)=$ The actinide decay library number (zero for pure fusion problems).

$\operatorname{NLIB}(4)=$ The fission-product decay library number (zero for pure fusion problems).

NLIB (5-7) = The three cross-section library numbers. (Note: If a decay or crosssection library number is negative, replacement cards will also be read later in the odd-reaction file for that library.)

$\operatorname{NLIB}(8)=$ The input unit number for the cross-section library file (use 8 for TAPEB).

NLIB $(9)=$ The input unit number for the decay library file (Use 9 for TAPE9).

NLIB (10) = The input unit number for the replacement decay and cross-section lines and for reading odd reactions (use 3 for TAPE3).

$\operatorname{NLIB}(11)=$ The number of odd reactions to be read. If $N L I B(11)$ is negative, the data will be read on unit $\operatorname{NLIB}(16)$. If $N L I B(11)$ is positive, the data will be read on unit NLIB(8). (Use negative NLIB(11) to read the odd reactions, i.e., uSe TAPE3.) 
Table 9. Identification numbers of FORIG data libraries.

\begin{tabular}{|c|c|c|c|c|c|c|}
\hline & Fin & Type of libeny & $\begin{array}{l}\text { Activetion product } \\
\text { [NLIS(2 or 5)] }\end{array}$ & $\begin{array}{c}\text { Actinide } \\
\text { |xrexa(3 or } 6) \text { ] }\end{array}$ & $\begin{array}{l}\text { Fucion product } \\
\text { [ALIB }(4 \text { or } 7)]\end{array}$ & $\begin{array}{l}\text { Wulabis actinids } \\
\text { SLIE (13) }\end{array}$ \\
\hline & $\begin{array}{l}\text { Decay } \\
\text { Photon }\end{array}$ & $\begin{array}{l}\mathrm{UO}_{2} \text { Bremsstrahtung } \\
\mathrm{H}_{2} \mathrm{O} \text { Bremsstrahkung } \\
\mathrm{NO} \text { Bremsstrahtung }\end{array}$ & $\begin{array}{r}1 \\
101 \\
104 \\
107\end{array}$ & $\begin{array}{r}2 \\
102 \\
105 \\
108\end{array}$ & $\begin{array}{r}3 \\
103 \\
106 \\
109\end{array}$ & $\begin{array}{l}- \\
-\end{array}$ \\
\hline \multicolumn{7}{|c|}{ 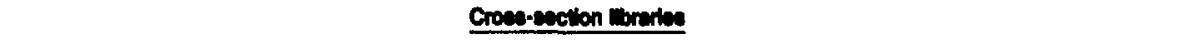 } \\
\hline 22 & PWR: & $\begin{array}{l}\text { 230 U-enriched } \mathrm{UO}_{2} \text {; } \\
33,000 \mathrm{MWd} \text {,'metric ton }\end{array}$ & 204 & 205 & 206 & 1 \\
\hline 23 & PWR: & $\begin{array}{l}{ }^{20} \text { Uenriched } \mathrm{UO}_{2} \text { in a } \\
\text { self penerated } \mathrm{Pu} \text { recycle reactor }\end{array}$ & 207 & 208 & 209 & 2 \\
\hline 24 & PWR: & $\begin{array}{l}\text { Pu-enrlched } \mathrm{UO}_{2} \text { in a } \\
\text { self-penerated Pu recycte reactor }\end{array}$ & 210 & 211 & 212 & 3 \\
\hline 30 & BWR: & $2 x \mathrm{U}$-enriched $\mathrm{UO}_{2}$ & 251 & 252 & 253 & 4 \\
\hline 31 & BWR: & $\begin{array}{l}\text { 2010-enriched fued in a } \\
\text { seff-g̈nerated Pu recycle reactor }\end{array}$ & 254 & 255 & 256 & 5 \\
\hline 32 & BWR: & $\begin{array}{l}\text { Pu-enriched fuel in a } \\
\text { self-generated Pu recycle reactor }\end{array}$ & 257 & 258 & 258 & 6 \\
\hline 25 & PWR: & $\mathrm{ThO}_{2}$-enriched with denatured ${ }^{233} \mathrm{U}$ & 213 & 214 & 215 & 7 \\
\hline 28 & PWR: & Pusenniched $\mathrm{ThO}_{2}$ & 216 & 217 & 218 & B \\
\hline 29 & PWR: & $\begin{array}{l}{ }^{235} \mathrm{U} \text {-enriched } \mathrm{UO}_{2} ; \\
50,000 \mathrm{MWd} / \text { metric ton }\end{array}$ & 219 & 220 & 221 & 9 \\
\hline 27 & PWR: & $\begin{array}{l}\mathrm{ThO}_{2} \text {-nriched with makeup } \\
\text { denatured } 235 \mathrm{U}\end{array}$ & 222 & 223 & 224 & 10 \\
\hline 26 & PWR: & $\begin{array}{l}\mathrm{ThO}_{2} \text { enrlched with recycled, } \\
\text { denatured }{ }^{233} \mathrm{U}\end{array}$ & 225 & 226 & 227 & 11 \\
\hline $\begin{array}{l}34 \\
35 \\
36\end{array}$ & LMFBR: & $\begin{array}{l}\text { Early oxide, LWR-Pu/U/U/U } \\
\text { Core } \\
\text { Axlal blanket } \\
\text { Radlal blanket }\end{array}$ & $\begin{array}{l}301 \\
304 \\
307\end{array}$ & $\begin{array}{l}302 \\
305 \\
308\end{array}$ & $\begin{array}{l}303 \\
316 \\
309\end{array}$ & $\begin{array}{l}18 \\
19 \\
20\end{array}$ \\
\hline $\begin{array}{l}37 \\
38 \\
39\end{array}$ & LMFBA: & $\begin{array}{l}\text { Advanced oxide, LWR-Pu/U/U/U } \\
\text { Core } \\
\text { Axlal blanket } \\
\text { Redial blanket }\end{array}$ & $\begin{array}{l}311 \\
314 \\
317\end{array}$ & $\begin{array}{l}312 \\
315 \\
318\end{array}$ & $\begin{array}{l}313 \\
316 \\
319\end{array}$ & $\begin{array}{l}12 \\
13 \\
14\end{array}$ \\
\hline $\begin{array}{l}40 \\
41 \\
42\end{array}$ & $\begin{array}{l}\text { LMFBR: } \\
\text {. }\end{array}$ & $\begin{array}{l}\text { Advanced oxtde, recycle-Pu/U/U/U } \\
\text { Core } \\
\text { Axill blankel } \\
\text { Radial blanket }\end{array}$ & $\begin{array}{l}321 \\
324 \\
327\end{array}$ & $\begin{array}{l}322 \\
325 \\
328\end{array}$ & $\begin{array}{l}323 \\
326 \\
329\end{array}$ & $\begin{array}{l}15 \\
16 \\
17\end{array}$ \\
\hline $\begin{array}{l}33 \\
43 \\
44\end{array}$ & $\begin{array}{l}\text { Thermat: } \\
\text { GANDU: }\end{array}$ & $\begin{array}{l}0.0253-0 \text { V cross sections } \\
\text { Natural uranium feed } \\
\text { Slightly enriched teed }\end{array}$ & $\begin{array}{l}201 \\
401 \\
404\end{array}$ & $\begin{array}{l}202 \\
402 \\
405\end{array}$ & $\begin{array}{l}203 \\
403 \\
406\end{array}$ & $\frac{0}{-}$ \\
\hline
\end{tabular}

The file number relors to the file number on the RSIC-suppllad ORIGEN2 tape, and in J. Bink's LLNL OCTOPUS take directory, .R:ORIGEN2 (0.9., file 22 is stored as OR22C where the "OR" stands for ORIGEN and the "C" stands for CAAY). 

NLIB (12) = The set of actinides (Table 10) having direct fission-product yields (use zero for fusion problems).
$\operatorname{NLIB}(13)=$ The set of variabie actinide cruss sections (Table 9) to be used (use zero for fusion problems).

Up to five LIB conmands are allowed. The libraries remain in effect until another LIB command is read.

If substitute decay or cross-section lines are to be read, the LPU command(s) must precede the I IB command in which the lines are to be read. The formats for the decay and crosssection libraries were discussed in Section 3. The L I B command must precede the material input (INP) commands.

\section{Data Library Replacement Cards}

This command reads nuclide identifiers for replacement decay and cross-section data lines that will later be read by the I IB command. The data sequence is

$$
\text { LPU NLPU (1) . . NLPU (MAX) - } 1
$$
NLPU (I) = Nuclide identifiers for replacement data lines in the order they occur in the original data library.
MAX = Number (up to 100) of nuclide identifiers to be read for a given LPU command.

Up to nine LPU commands are allowed. The LPU data remain valld until a second $\mathrm{LIB}$ command is read. If less than 100 nuclide identifiers are specified, a "- 1 " must appear after the last identifier. As many lines may be used as are required.

The LPU command(s) must precede the LIB command in which the replacement data cards will be read. The first LPU command is associated with the first negative library number in the NLIB ( 2 )-to-NLIB ( 7 ) set of library numbers in "the LIB command". The second LPU command is associated with the second negative library number, etc.

\section{Read Photon Libraries}

This command reads the photon production rate per disintegration in 18 energy groups. The data sequence is

$$
\text { PHO NPHO(1) . . NPHO (4) }
$$

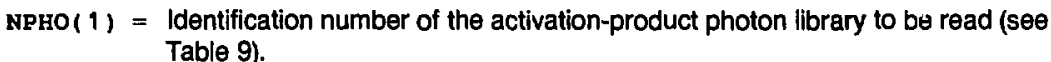

NPHO $(2)=$ Identification number of the actinide-nuclide photon library to be read (see Table 9).

\begin{tabular}{|c|c|c|c|c|c|c|c|c|c|}
\hline \multirow[b]{2}{*}{ NLIB $(12)$} & \multicolumn{9}{|c|}{ Actinides } \\
\hline & ${ }^{232} \mathrm{Th}$ & ${ }^{233} \mathrm{U}$ & ${ }^{234} \mathrm{U}$ & 2350 & $239 \mathrm{U}$ & $235 \mathrm{Pu}$ & 2411Pu & ${ }^{245} \mathrm{Cm}$ & ${ }^{252} \mathrm{Cl}$ \\
\hline 1 & & & & $x$ & $x$ & $x$ & $x$ & & \\
\hline 2 & $\mathrm{x}$ & $x$ & & $x$ & & $x$ & & & \\
\hline 3 & $\mathrm{x}$ & $x$ & & $x$ & $x$ & $\mathrm{x}$ & $x$ & & \\
\hline 4 & $x$ & $\mathrm{x}$ & $x$ & & $\mathrm{x}$ & $\mathrm{x}$ & $x$ & $x$ & $x$ \\
\hline
\end{tabular}

Table 10. Actinide sets with direct fission-product yields. 
NPHO (3) = Identification number of the fission-product nuclide photon library to be read (see Table 9).

NPHO ( 4 ) = Number of input unit on which the photon libraries are to be read (use 10 for TAPE10).

If NPHO (1), NPHO (2), or NPHO ( 3 ) is less than zero, no photon library is read for that segment. Up to five PHO commands are allowed. The libraries remain in effect until a subsequent PHO command is read. The photon library format was described in Section 3.

Library Print Control

This command controls the printing of the input data libraries. Up to five L IP commands are allowed. The LIP command must precede the IIB sornmand. The data sequence is

\section{LIP NLIP(1) NLIP(2) NLIP(3)}

NLIP (1) = Control character for decay library print.

$\operatorname{NLIP(2)}=$ Control character for cross-section library print.

$\operatorname{NLIP}(3)=$ Control character for photon library print.

If an NL.IP entry is zero, the library will not be printed; if an entry is positive, that library will be printed.

\subsubsection{Matorial Input Commands}

Read Input Composition, and Continuous Removal and Feed Rates

The INP command provides read locations and units for input nuclide composition, continuous nuclide-feed rate, or continuous element-removal rate. The asitual format for the data is discussed later in Section 4.3.2.

The initial composition can be input in the final (third section) of the ORINPUT file. Alternatively, it can be input by a separate (TAPE4) file if the main program FORIGM is altered to open TAPE4 and then is recompiled. Either gram or gram-atom mass units can be used. The data sequence is

\section{INP NINP (1) . . NINP (6)}

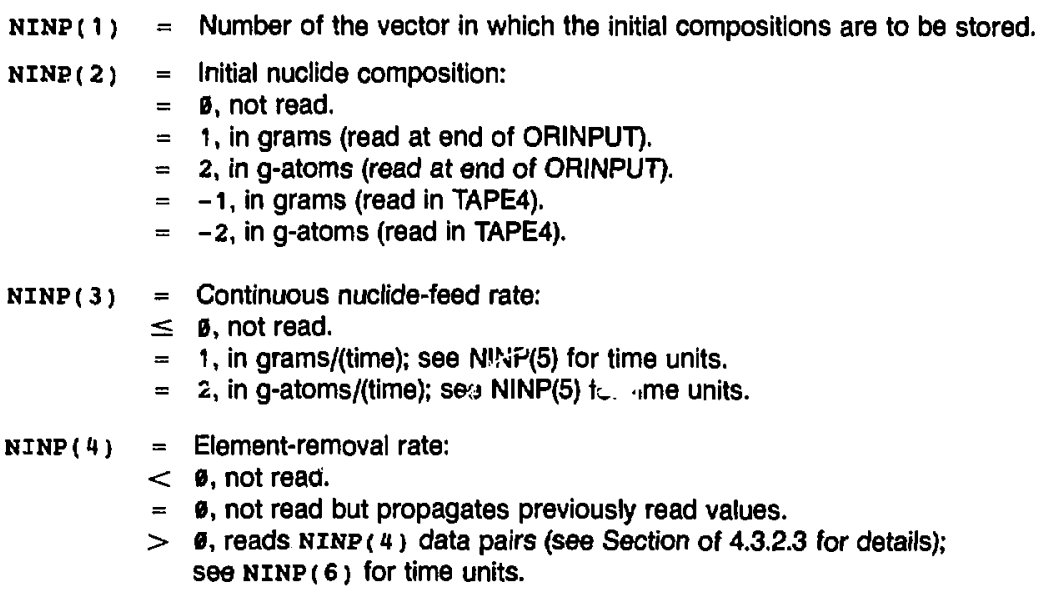


NINP $(5)=$ Time units of continuous nuclide-feed rate data (see Table 3).

NINP (6) = Time units of continuous element-removal rate data (see Table 3).

Up to 15 INP commands are allowed. It is recommended that the initial composition data be entered as either $1.0 \mathrm{~g}$ or $1.0 \mathrm{~g}$-atom. Then, the actual mass can be specified with the Mov command, and the composition entries can be reused in subsequent runs having different masses but unchanged initial compositions. The BAS command provides a repeated reminder (in the output) of the amount of mass in the calculation (of course the comment must agree with the input mass).

พAC

Waste Nuclide Accumulation

This command multiplies a concentration vector by a fractional renovery vector and stores the result, which subsequently can be used as a continuous feed rate to a waste system. The data sequence is

WAC NHAC (1) UWAC (2)

NWAC $(1)=$ Number of the fractional recovery vector to be used to multipiy concentration vector NWAC ( 2 ). Fractional recovery NWAC (1) should contain the removal rate $\left(\mathrm{sec}^{-1}\right)$ of each element from the system (equivalent to the feed rate to the waste system being analyzed). A positive value selects an individual element fractional-recovery set (Section 4.1.2.1); a negative value selects a group fractional-recovery set (Sections 4.1.2.2 and 4.1.2.3).

NWAC ( 2$)=$ Number of concentration vector that is to be multiplied by fractional recovery vecto: NWAC (1).

Up to two WAC commands are allowed. The waC command remains in effect untll a subsequent WAC or LIB command is input. Once reactor equilibrium is attained, the wAC command calculates the continuous accumulation of waste from a reactor with continuous reprocessing (e.g., an MSBA). The steady-state fuel composition in vector NWAC ( 2 ) is multiplied by the appropriate continuous-removal rates stored in fractional recovery vector NWAC (1). Then, the waste can be decayed.

A typical sequence of waste accumulation commands follows:

WAC i 3 Calculate continuous feed rate to the waste system from vector 3 and recovery set 1.

MOV 226 - Initialize vector 2 to all zeros.

DEC 3. 2352 Add three years of waste accumulation and decay and place result in vector 3.

พAC End of waC sequence.

The result in vector 3 is based on continuous feed for three years coupled with continuous decay of the accumulating material.

Reprocess Fuel

This command reprocesses fuel (or other material) into two product compositions. The data sequence is 
$\operatorname{NPRO}(1)=$ Number of vector where composition of the material to be reprncessed is stored.

NPRO(2) = Number of vector where amount of recovered material will be stored. The recovered amount of an isotope of element NE is given by

[Mass of i sotope NE] [f(NPRO(4)]

The fraction $\mathrm{f}$ [ NoRO (4)] is the fractional recovery of element $\mathrm{NE}$ specified by variable NPRO (4) (see below).

NPRO (3) = Nur:ber of vector where amount of unrecovered material will be stored. The amount of an isotope of element NE that is not recovered is given by

[Kass of 1sctope NE] 11.0-E(NPRO(4))]

NPRO (4) = Number of set for fractional recoveries that are to be used in this reprocessing operation. If APRO (") is greater than zero, indlvidual fractional recover* les are to be used. If NPRO ( 4 ) is less than zero, group fractional recoveries are to be used. (See Section 4.1 for a description of fractional recovery data.)

Up to 20 pRo commands are allowed. The reprocessing action is an instantaneous antivity. If continuous separation is desired, it can be approximated by using either the WAC or the INP commands.

VOL

Material volume

This command inputs the material volume to allow calculation of the shallow-burial index and the surface (gamma) dose rate. It must precede the OUT and RADS commands. The data sequence is

VOL RVOL

RVOL $=$ Material volume in $\mathrm{m}^{3}$.

Up to 20 vol commands are allowed. The vol command remains in effect until changed by a new VOL command.

\subsubsection{Material Manipulation Ts Jmmands}

FORIG maintains the material composition as a vector at each specified time step. Since only those vectors required for output or subsequent calculation need be stored, it is sometimes convenient to manipulate the vectors.

Move Nuclida Composition from Vector to Vector

Moves (..e., copies) the nuclide concentration data in one composition vector to ancther vector, nuclide by nuclide. The data sequence is

MOV NHOV (1) NMOV (2) NMOV ( 3 ) RHOV (1)

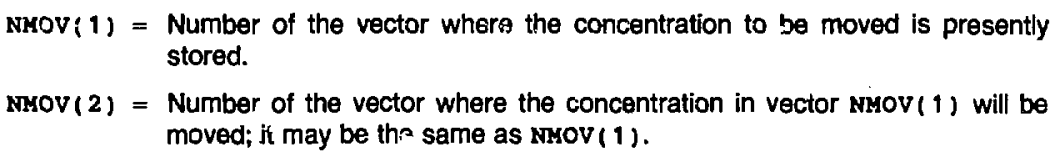


MMOV (3) $=$ Source of additional multiplier:

$>0$, number of the variable multiplier vector that contains the additional factors for mistiplying vector NMOV (1) before moving it to vector NMOV ( 2 ). The variable multipliers are in array RMULV and are inilialized with a Data statement in FORIGM. The particular element of RMULV used is

RMULV [NREC, NHOV (3)]

where NREC is the recycle number (from the REC command). The total multiplier RMULT $T$ is given by

RMULT = RMULV [ NREC, NKOV ( 3) ] *RKOV (1)

NREC must be defined to use the variable multipller option.

$=0$, no addlitional multiplier is used; that is,

$$
\text { RMULT = RMOV(1) }
$$

$<0$, an additional multiplier is used, which was previously calculated by an FAC command and designated as FACTOR [NFAC (1)] at that time. TO use this factor, set NMOV ( 3$)=-\operatorname{NFAC}(1)$; the total multiplier is then given by

$$
\text { RMUL' = FACTOR }[- \text { NMOV }(3)] * \text { RMOV }(1)
$$

RMOV ( 1 ) = Factor by which vector NMOV ( 1 ) is to be multiplied before being stored in vector NMOV ( 2 ), subject to the conditions specified by NMOV ( 3 ) above.

Up to 99 mov commands are allowed. An example kov command is

$$
\text { MOV }-11 \bullet 3.56 E B 2
$$

which moves the composition in vector " 1 " (which could be 1 gram if the INP command filled vector "-1") to vector "1", after multiplying it by 356 (i.e., vector 1 contains 356 grams). In another example, vector NMOV (2) can be zeroed by moving a vector to NMOV (2) with RMOV (1) $=0.0$. The information in vector NHOV ( 1 ) is not destroyed by the rov command. Vector NMOV (2) will have the same heading as vector NHOV (1) after the rov command is executed.

\section{Add Two Composition Vectors}

This command adds the nuclide concentration data in one vector to that in another vector, nuclide by nuclide. The data sequence is

ADD NADD ( 1 ) NADD ( 2 ) NADD ( 3) RADD ( 1 )

$\operatorname{NADD}(")=$ Number of the vector where the concentration to be added is presently stored.

$\operatorname{NADD}(2)=$ Number of the vector where the concentration in vector NADD (1) will be added.

$\operatorname{NADD}(3)=$ Source of additional multiplier:

$>0$, number of the variable multiplier vector that contains the additional factors by which vector NADD ( 1 ) is to be multiplied before being added to vector 
NADD ( 2 ). The variable multipliers are in array RMULV and are initialized with a Data statement in FORIGM. The particular element of RMULV used is

$$
\text { RMULV [NREC, NADD (3)] }
$$

where NREC is the recycle number (from the REC command). The total multiplier, RMULT, is given by

$$
\text { RMULT = RKULV }[\text { NREC, NADD ( 3 ) }] * \text { RADD (1) }
$$

NREC must be defined to use this option.

$=0$, no additional multiplier used; that is,

$$
\text { RKULT }=\operatorname{RADD(1)}
$$

$<0$, this additional multipller to be used was previously calculated by a FAC command and designated as FACTOR [NFAC (1)]. To use this factor, set $\operatorname{NADD}(3)=-\operatorname{NFAC}(1)$; the total multiplier is then given by

$$
\text { RHULT = FACTOR[ - NADD ( 3 ) ]*RADD( १) }
$$

$\operatorname{RADD}(1)=$ Factor by which vector $\operatorname{NADD}(1)$ is to be multiplied before being added to vector NADD ( 2 ), subject to the conditions specifled by NADD ( 3 ) above.

Up to 30 ADD commands are allowed. Vector NADD (1) may be subtracted from vector $\operatorname{NADD}(2)$ by setting $\operatorname{RADD}(1)=-1.0$. (CAUTION: Negative nuclide concentrations can result in fatal errors and ungraceful termination!) The information in vector NADD ( 1 ) is not altered by the ADD Command. After the ADD command has been executed, vector NADD ( 2 ) will have the same headings as vector NADD (1).

\section{Match Infinite Multiplication Factors}

Blend materials in two vectors so that the resulting infinite (neutron) multiplication factor (IMF) matches that of another vector or an input value. The data sequence is

$$
\text { KEQ NKEQ(1) . . NKEQ( } 5 \text { ) RKEQ(1) }
$$

$\operatorname{NKEQ}(1)$ = Vector whose IMF will be matched by vector NKEQ (4).

$\operatorname{NKEQ}(2)=$ Vector whose material will be wholly included in the final blended material in vector NKEQ (4).

$\operatorname{NKEQ}(3)=$ Vector whose material is to be apportioned to obtain the proper IMF for vector NKEQ (4).

$\operatorname{NKEQ}(4)=$ Vector containing all material in vector NKEQ (2) plus part of the material in NKEQ (3) and having the same IMF as either vector NKEQ (1) or RKEQ (1); that is,

$$
\operatorname{NKEQ}(4)=\operatorname{NKEQ}(2)+ \pm * \operatorname{NKEQ}(3)
$$

where $f$ is the factor by which NKEQ (3) must be multiplied to obtain the correct IMF for NKEQ (4).

NKEQ ( 5$)$ = vector containing the portion of NKEQ ( 3 ) not blended into NKEQ ( 4 ); that is,

$\operatorname{NKEQ}(5)=(1-f) * \operatorname{NKEQ}(3)$ 
If $(1-f)$ is less than zero, then NKEQ ( 5$)$ is set to zero.

RKEQ ( 1 ) = Desired IMF data source:

$>0$, the desired final IMF for vector NKEQ (4).

$=0$, the IMF is equal to RMULV ( NREC, 1 ). The RMULV values are specified in a Data statement in FORIGM; the NREC parameter is from the REC command.

$<0$, the IMF of vector NKEQ ( 4 ) is matched to that of vector NKEQ ( 1 ).

Up to $3 \mathrm{KEQ}$ commands are allowed. The equation used to calculate $f$, the parameter for multiplying vector NKEQ ( 3 ) before being combined with material in vector NKEQ $(2)$ and being placed in vector NKEQ ( 4 ), is given by

$$
f=\left[\left(k_{2}-k_{1}\right) * D_{2} \mid /\left(k_{1}-k_{3}\right) * D_{3}\right] \text {. }
$$

$k_{1}=$ IMF to be matched from vector NKEQ( 1 ) or RKEQ ( 1 ).

$k_{2}=$ IMF of material in vector NKER (2).

$k_{3}=$ IMF of material in vector NKEQ (3).

$D_{2}=$ Neutron absorption rate (neutrons/s) of material in vector NKEQ(2).

$D_{3}=$ Neutron absorption rate (neutrons/s) of material in vector $\operatorname{NKSQ}(3)$.

TAPE15 file (Debug Information and Error Messages) contains some of the intermediate information calculated by the KEQ command.

This command calculates a multiplication factor, FACTOR [NFAC (1) ], based on the total actinide plus tission product masses in one or two vectors, for use in kOV or ADD commands. The data sequence is

EAC NFAC (1) . NFAC (4) RFAC(1)

NFAC $(1)=$ Number of factor calculated by this command (must be greater than zero and less than or equal to the maximum number of FAC commands).

$\operatorname{NrAC}(2)=$ Vector number.

$\operatorname{NFAC}(3)=$ Vector number.

$\operatorname{NEAC}(4)=$ Method for calculating FACTOR [NFAC(1)]:

$$
\begin{aligned}
& =1, \text { FACTOR}[\operatorname{NFAC}(1)]-T[\operatorname{NFAC}(2)]+T[\operatorname{NAAC}(3)] \\
& =2, \operatorname{FACTOR}[\operatorname{NFAC}(1)]-T[\operatorname{NFAC}(2)]-T[\operatorname{NFAC}(3)] \\
& =3, \operatorname{FACTOR}[\operatorname{NFAC}(1))=T[\operatorname{NFAC}(2)] * T[\operatorname{NFAC}(3)] \\
& =4, \text { FACTOR }[\operatorname{NFAC}(1)]=T[\operatorname{NFAC}(2)] / T[\operatorname{NFAC}(3)] \\
& =5, \operatorname{FACTOR}[\operatorname{NFAC}(1)]=T[\operatorname{NFAC}(2)] \\
& =6, \text { FACTOR}[\operatorname{NFAC}(1)]=T[\operatorname{NFAC}(3)] \\
& =7, \text { FACTOR }[\operatorname{NFAC}(1)]=1.0 / T[\operatorname{NFAC}(2)] \\
& =8, \text { FACTOR }[\operatorname{NrAC}(1)]=1.6 / T[\operatorname{NFAC}(3)]
\end{aligned}
$$

where the T [NFAC ( I ) ] is the total ( $\mathrm{kg}$ ) fission-product-plus-actinide mass for the indicated vectors.

$\operatorname{RFAC}(1)=$ Constant value (kg) used in place of T [ NFAC ( I )]:

$>0$, substitute RFAC (1) for T [NFAC (2)] when calculating FACTOR [ NEAC (1)].

$=0$, use the $\mathrm{T}[\mathrm{NFAC}$ ( I ) ] as defined.

$<0$, substitute $[-\operatorname{RFAC}(I)]$ for TINFAC (3)] when calculating FACTOR [NFAC (1)]. 
Up to 20 FAC commands are allowed. The result, NFAC ( 1 ), remains in effect until another FAC command with the same value of NFAC $(1)$ is executed. Some intermediate results from this command are printed in the TAPE15 output file (Debug Information and Error Messages).

\subsubsection{Commands that Take a Time Step}

DEC

Decay

This command allows a composition vector to decay for a specified time. The data sequence is

$\operatorname{DEC} \operatorname{DEC}(1) \operatorname{NDEC}(1) \ldots \operatorname{NDEC}(4)$

$\operatorname{DEC}(1)=$ Time at which this oecay interval ends.

$\operatorname{NDEC}(1)=$ Number of the vector where the material composition at the beginning of this decay interval is stored.

$\operatorname{NDEC}(2)=$ Number of the vector where the material composition at the end of this decay interval is stored.

$\operatorname{NDEC}(3)=$ Time units of $\operatorname{DEC}(1)$ (see Table 3).

$\operatorname{NDEC}(4)=$ Specification of time at which this decay interval begins:

$=0$, starting time is the end of the previous IRF, IRP, or DEC interval. All reactivity and burnup information is retained, and the MIRR array is not altered (used for continuing irradiation/decay on the same output page).

$=1$, starting time is set to zero. All reactivity and hurnup information is retained, and MIRR is set to zero (used for beginning a new irradiation on the same output page).

$=2$, starting time is set to zero. All reactivity and burnup information and MIRA are set to zero (used to begin a new irradiation/decay on a new output page).

$=3$, same as $\operatorname{NDEC}(4)=0$, except the first seven lines of the reactivity and burnup information are set to zero (used for continuing irradiation to a new output page).

$=4$, same as $\operatorname{NDEC}(4)=1$, except the first seven lines of the reactivity and burnup information are set to zero (used to $\mathrm{k}$ sgin a new output page for the decay following irradiation while at the same time retaining the average irradiation parameters).

The total number of IRF + IRP + DEC commands must not exceed 150. The "reactivity and burnup information" referred to in NDEC (4) consists of seven lines of data characteristic of an individual vector (e.g., time, infinite multiplication factor, neutron flux) and three lines containing irradiation parameters (e.g., burnup) averaged over the range of the BUp commands. For fusion problems, the "reactivity and burnup information" is largely irrelevant, and $\operatorname{NDEC}(4)$ is 2 when the clock is reset to zero; when the clock is not reset (but just continues), $\operatorname{NDEC}(4)$ should be zero.

Flux Irradiation

This command allows irraciation for a single interval with the neutron flux specified. The data sequence is

IRF RIRF (1) RIRF'(2) NIRF (1) . . NIRF (4) 
RIRF (1) = Time at which this irradiation interval ends.

$\operatorname{RIRF}(2)=$ The neutron flux (neutrons $/ \mathrm{cm}^{2} / \mathrm{s}$ ) during this irradiation interval:

$>0$, the flux is the specified value.

$<0$, the flux is given by:

$$
\text { NEWFLUX = OLDFLUX* [-RIRF }\{2\}]
$$

NEWFLUX $=$ Flux (neutrons $/ \mathrm{cm}^{2} / \mathrm{s}$ ) to be used during this interval.

OLDFLUX $=$ FluX (neutrons $/ \mathrm{cm}^{2} / \mathrm{s}$ ) for the same time period but from the previous irradiation sequence.

For this option to be used, the time steps for the current irradiation and decay sequence must correspond exactly to those in the previous sequence. The scale factors [-RIRF ( 2)] from previous irradiations do propagate.

$\operatorname{NIRF}(1)=$ Number of the vector where the material composition at the beginning of this Irradiation interval is stored.

NIRF (2) = Number of the vector where the material composition at the end of thls irradiation interval will be stored.

NIRE (3) = Time units of RIRF (1) (see Table 3).

$\operatorname{NIRF}(4)=$ Specification of time at which this irradiation interval begins: Values of $0,1,2$, 3, or 4 are permitted. The definitions are identical to those of the DEC command.

The total number of IRF + IRP + DEC commands must not exceed 150. Intermediate parameters related to the flux/specific power calculations are printed in TAPE15 (Debug Information and Error Messages).

Specific Power Irradiation

This command allows activation and decay of a composition vector at a constant power for a specified time interval. It only applies to standard fission-reactor problems. The data sequence is

$\operatorname{IRP} \operatorname{RIRP}(1) \operatorname{RIRP}(2) \operatorname{NIRP}(1) \ldots \operatorname{NIRP}(4)$

$\operatorname{RIRP}(1)=$ Time at which this irradiation inferval ends.

$\operatorname{RIRP}(2)=$ Power level during this irradiation interval.

$>0$, thermal energy $\left(M W_{t}\right)$ per unit of fuel input.

$<0$, specific power, $M W_{t}$ per metric ton of heavy metal.

(NOTE: Both actinides and fission products must be present for the specific power option to work correctly.)

NIRP ( 1 ) = Number of the vector where the material composition at the beginning of this irradiation interval is stored.

NIRP(2) = Number of the vector where the material composition at the end of this irradiation interval is to be stored.

$\operatorname{NIRP}(3)=$ Time units of $\operatorname{RIRP}(1)$ (see Table 3).

$\operatorname{NIRP}(4)=$ Specification of the time at which this irradiation interval begins: Values of 0 , $1,2,3$, or 4 are permitted. The definitions are identical to those of the DEC command. The total number of IRE + IRP + DEC commands must not exceed 150. Intermediate parameters related to the flux/specific power calculations are printed in TAPE15 (Debug Information and Error Messages). 
This command defines the basis and calculates the average burnup, flux, and specific power for an irradiation in a fission reactor. The data sequence is

\author{
BUP \\ IRRADIATION \\ BUP
}

IRRADIATION = the operational commands (generally several IRPs or IRFs) that describe the fuel irradiation to be used as the basis for the burnup calculation.

Up to twenty (10 pairs) of BUP commands are allowed. The resulting values remain valid until superseded by other Bup commands.

A BUP command must appear both before and after the irradlation operational commands on which the burnup calculation is to be based. Other commands may be present between the BUP statements. The Bup sequence is required to properly use the variable cross sections available for fission problems.

\title{
4.2.6. Loop Commands
}

DOL

Do LOOP

This command initiates a "Do loop' which executes the commands within its range a prescribed number of times. The data sequence is

DOL NDOL ( 1 ) NDOL ( 2 )

$\operatorname{NDOL}(1)=$ Number of the CON Command that defines the range of this Do loop. Each DOL must have a unique CON associated with it.

NDOL ( 2) = The total number of times the instructions within the loop are to be executed.

Up to two Dor, commands are allowed.

CON Continuation (End of DO LOOP)

This command defines the range of a DOL command. Up to two coN commands are allowed. There must be one, and only one, con command for each DOL command. The data sequence is

\section{CON NCON}

NCON = Number of this CoN command; must be equal to NDOL (1) for the DOL command that is associated with this CON command.

This command counts the number of times a loop (DOL command) is executed. The data sequence is

REC

Only one REC command is allowed. It must precede the first Do loop to which it applies. This counter is output as the "Recycle \#" in the FORIG output. 


\subsubsection{Output Commands}

OUT

Print Calculated Results

This command calls for the calculated results in some or all of the output vectors to be printed. Up to 20 OUT commands are allowed. The data sequence is

OUT NOUT(1) . . NOUT(4)

NoUT $(1)=$ Number of vectors to be printed (beginning with first vector. The absolute value of NOUT ( 1 ) cannot exceed 12.

$>0$, output in file OROUT.

$<0$, output in file TAPE11.

NOUT ( 2 ) = Frequency of print if instruction is in a Do loop. Printing occurs the first time through loop and every NOUT ( 2 ) th recycle thereafter. A REC command is required if this entry is not 1 .

NOUT $(3)=$ Hrint number of present recycle.

$>0$, yes.

$\leq 0$, no.

NOUT $(4)=$ Type of summary table to be printed. (Vectors are tested in accordance with the cur command.)

$>0$, only vector NOUT ( 4 ) tested to see if a nuclide is included in the summary table.

$=0$. all vectors tested for inclusion in summary table.

$<0$, all vectors tested for inclusion in summary table except vector "-NOUT ( 4 )".

OPTL Specily Activation-Product Output Options

This command specifies the output tables (1 through 24) and the table types (nuclide, element, or summary) to be printed for the activation products. The data sequence is

$$
\text { OPTL NOPTL (1) ... NOPTL (24) }
$$

NOPTL $(I)=$ Control character indicating the output-table types to be printed for the activation products (see Table 11); 1 = table number (see Table 12 for outputtable description).

Table 11. Types of output tables to be printed.

\begin{tabular}{cccc}
\hline $\begin{array}{c}\text { NOPTL (I) } \\
\text { NOPTA (I) } \\
\text { NOPTF (I) }\end{array}$ & \multicolumn{3}{c}{ Table type-printed? (yes or no) } \\
\cline { 2 - 4 } & Nuclide & Element & Summary \\
\hline 1 & Yes & Yes & Yes \\
2 & Yes & Yes & No \\
3 & Yes & No & Yes \\
4 & No & Yes & No \\
5 & Yes & No & No \\
6 & No & Yes & Yes \\
7 & No & No & No \\
8 & No & No & \\
\hline
\end{tabular}


Table 12. Description of FORIG output tables.

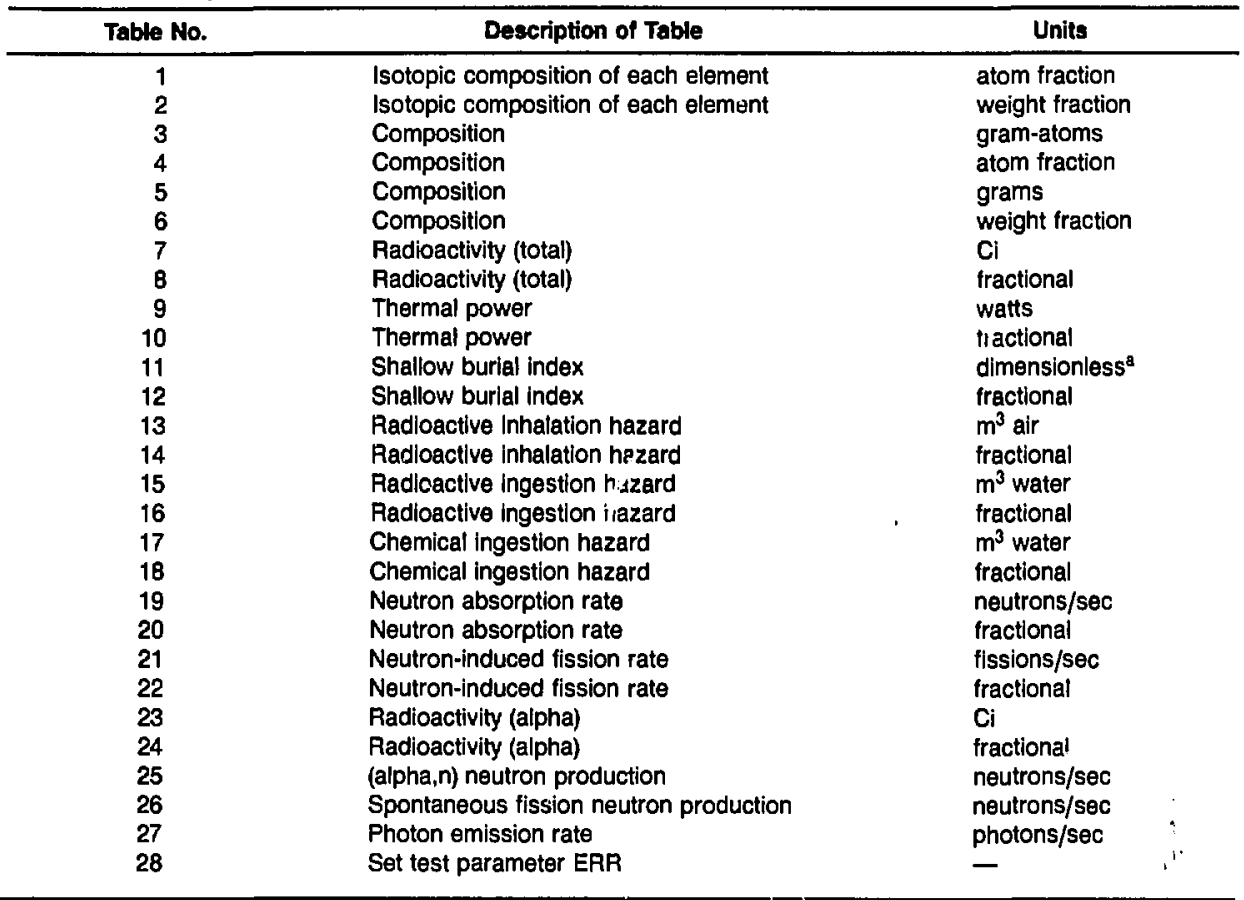

${ }^{3}$ Total values less than 1.0 indicate the material is suitable for disposal by shallow land burial. Total values exceeding 1.0 indicate the need for either dilution or geolugic (high-level) waste disposal.

Up to 20 optu commands are allowed. The command remains in effect until it is superseded by a new OPTL command.

The nuclide tables include results for each nuclide, the element tables include results summed by element, and the summary tables (by nuclide and element) include only the most significant results (as determined by the CUT command). The NOPTI ( $I$ ) must all be on a single line.

If Noptu (1) is less than one, only a summary table (grams) is printed for all nuclides (including actinides and fission products) until new commands (after an STP command) are read. Only the first 24 tables listed in Table 12 are controlled by the opTL command. The OPTL command must precede the first OUT command to which it applies.

\section{OPTA Specify Actinide Output Options}

This command specifies the output tables (1 through 24) and the table types (nuclide, element, or summary) to be printed for the actinide nuclides. The data sequence is 
NOPTA $(I)=$ control character indicating the output-table types to be printed for the actinide nuclides (see Table 11); I = table number (see Table 12).

Up to 20 OPTA commands are allowed. The command remains in effect until it is changed by a new OPTA command. The NOPTA ( I ) must all be on a single line.

If NOPTA ( 1 ) is less than 1 , only a summary (grams) table is printed for all nuclides (including activation and fission products) until new commands (after a STP command) are read. Only the first 24 tables listed in Table 12 are controlled by the OPTA command. The OPTA command mus: precede the first out command to which it applies.

OPTF Specify Fission Product Output Options

This command specifies the output tables (1 through 24) and the table types (nuclide, element, or summary) to be printed for fission product nuclides. The data sequence is

$$
\text { OPTF NOPTF (1) . . NOPTF(24) }
$$

NOPTF $(1)=$ The output-table types to be printed for the fission product nuclides (see Table 11); I = table number (see Table 12).

Up to 20 OPTF commands are allowed. The command remains in effect until it is changed by a new OPTF command. The NOPTF ( I ) must all appear on a single line.

If NOPTF (1) is less than 1, only a summary (grams) table is printed for all nuclides (including activation products and actinides) until new commands (after a STP command) are read. Only the firșt 24 tables in Table 12 are controlled by the OPTr command. The OPTA command must precede the first out command to which it applies.

cuT Cutoff Fractions for Summary Tables

This command overrides default cutoff fractions for summary output tables. The data sequence is

CUT NCUT(1) RCUT(1) . . NCUT(NT) RCUT(NT) -1

$\operatorname{MCUT}(I)=$ Output table number to which cutoff fraction RCUT $(I)$ is to apply (see Table 12 for table numbers and descriptions).

$\operatorname{RCUT}(I)=$ New cutoff fraction for table number NCUT (I).

$\mathrm{NT}=$ Total number of default cutoff values that are being overridden with this CUT command.

Up to three CUT commands are allowed. The CUT command remains in effect until changed by a subsequent cUT command. The CUT command must precede the first ouT command to which it applies.

If an output value for a particular nuclide is less than the cutoff fraction multiplied by the total (all nuclides) value for each vector being tested, then that particular nuclide is not printed.

Table 28 can be used to override the default value for ERR, presently set at 1.0E-25. ERR is used in logical IF statements instead of 0.0.

An-integer (-1) must follow RCUT ( NT) unless all 28 cutoff fractions are specified. If only the defaults are to be used, a "CUT -1 " line is required. The default cutoff fractions for the first 26 tables (see Table 12) are 0.001 ; for the 27 th table, the cutoff is 0.01 .

The "NCUT(I) RCUT(I)" pairs may continue onto subsequent cards; no command keyword is used on the additional cards. 
The application of the cutoff value to photon tables only applies to the "principle contributor" tables; the photon summation tables include no cutoff tests.

PCH "Punch" an Output Vector

This command writes a designated output vector to a FORIG-readable file, TAPE7. The data sequence is

PCH NPCH (1) NPCH ( 2 ) NPCH (3)

NPCH $(1)=$ Control character for light nuclide and structural materiai iactivation product) output.

NPCH ( 2) = Control character for actinide nuclide output.

NPCH $(3)=$ Control character for fission product nuclide output.

With NPCH(I):

$=0$, no output.

$>0$, number of output vector to be output.

$<0$, number of storage vector to be output.

Up to 54 PCH commands are allowed. The punched output is in g-atom units. $T$, iast record (line) written by each PCH command is

\section{BURNUP FLUX SPECIFIC NOWER}

The burnup, flux, and specific power are average values produced by the Bup command and must be present for a file read on TAPE4 (in a subsequent problem). These parameters are not necessary for input material compositions read in ORINPUT (in a subsequent problem).

\section{Surface Gamma-Dose-Rate Output}

This command calculates the surface dose rate from gamma radiation for 12 output vectors. The dose rate only includes decay gamma rays; the dose rate from $(n, \gamma)$ reactions is not calculated. The data sequence is

\section{RADS RRAD (1) RRAD (2) RRAD (3)}

$\operatorname{RRAD}(1)=$ The material density $\left(\mathrm{g} / \mathrm{cm}^{3}\right)$ is the absolute value of $\operatorname{RRAD}(1)$. If $\operatorname{RRAD}(1)$ is negative, the output is to TAPE11, otherwise the output is to OROUT.

$\operatorname{RRAD}(2)=$ Tine material thickness $(\mathrm{cm})$.

$\operatorname{RRAD}(3)=$ The material type (FE, AL, MO, W, or PB).

The RADS command must follow the out command that covers the same time intervals (i.e., output vectors). Also, the RADS command must be preceded by a vol command. Up to 20 RADS commands are allowed. The user must select the material type that most closely approximates the actual material.

The command uses $\operatorname{RRAD}(1),(2)$, and (3) to perform a crude photon-transport calculation from an infinite-slab gamma source. (The source is generated by the out command). Since Compton scattering is approximated as pure absorption by using only one-half the total cross section, the calculation is only by an order-of-magnitude. Yet it does allow an easy estimate of the maintainability of a fusion reactor; a formal calculation would require a shielding code. 


\subsection{Input at the End of ORINPUr}

\subsubsection{Substitute Decay or Cross-Section Library Data}

Substitute decay, cross-section, and fission-product yield data can be read by invoking the $\mathrm{L} P \mathrm{VU}$ command. This procedure is an alternative to having to rebuild an entire data library in order to change a few parameters. It may also be used for parametric studies of output sensitivity to nuclear data changes.

If NLIB (10) from the LIB command is 3 , the substitute data is read at the beginning of TAPE3. If NLIB $(16$ ) is 5 , the data is read at the end of the ORINPUT file (after the last command, END, but before the initial material compositions).

An LPU command must be supplied for each library requiring substitute lines. (The LPU commands must precede the L I B command.) The LPU command lists the nuclides to be replaced in the order in which they appear in the library. Libraries requiring substitute lines are indicated by negative library numbers in the LIB command [NLIB (2) through (7)]. The LPU commands are in the same sequence as the LIB data entries:

(1) Substifute activation-product decay data.

(2) Substltute actinide-decay data.

(3) Substitute fission-product-decay data.

(4) Substitute activation product cross-section data.

(5) Substitute actinide cross-section data.

(6) Substitute fission-product cross-section and yield data.

The format for each substitute line is identical to the format of the appropriate library. A replacement fission-product-yield card can never appear alone; it must always follow a crcss-section card for the same nuclide.

\subsubsection{Specification of Materials and Rates}

In this section, we describe the options available to the user relative to the specification of the initial material compositions, the continuous nuclide-feed rates, and the continuous element-removal (reprocessing) rates. The most-often-used option by far is the specification of the initial composition of some material. The initial composition can be specified on either a nuclide-by-nuclide basis or as amounts of naturally occurring elements. The amount of a naturally occurring element is converted to a nuclide-by-nuclide basis internally, using the natural isotopic abundances input in the decay library. The amounts of individual nuclides or naturally occurring elements may be specified in grams-atoms or grams, depending on the control characters of the INP command.

The continuous-nuclide-feed option allows the user to specify the continuous feed rate of individual nuclide $:$ or naturally occurring telements. Both the mass units (grams or gram-atoms) and the time units are specifiec by using the INP command. This option is useful in stimulating the continuous feed of nuclides to a fluid-fuel reactor (e.g., a MSBR) or to a radioactive waste tank.

The continuous-element-rerioval option allows the user to specify the continuous removal rates (fraction/time unit) of elements during irradiation. The time units are specified by the INP command. This option is most useful when simulating the continuous reprocessing that would be expected to occur during the operation of a fluid-fuel reactor. If this option will be used to calculate continuous element removal in the absence of irradiation, a small (negligible) neutron flux must be specified.

4.3.2.1. Specification of Inltial Material Compostion. This input data specifies initia! amounts of individual nuclides or naturally occurring elements. The data sequence is

NEXT NUCLID (1) RCOMP (1) . . NUCLID (JMAX) RCOMP (JMAX)

NEXT = Segment for w: nich the information is intended and the type of information (i.f., nuclides or elements):

$=1$, individual activation-product nuclides.

$=2$, individual actinide nuclides.

$=3$, individual fission-product nuclides. 
$=4$, naturally occurring activation-product elernents.

$=5$, naturally occurring actınide elements.

$=6$, naturally occurring fission-product elements.

$\operatorname{NUCLID}(\mathrm{J})=$ Six-digit identifier (zaAAAI) for nuclide (or element) $\mathrm{J}$.

RCOMP $(\mathrm{J})=$ Amount of nuclide (or element) NUCLID $(\mathrm{J})$ initially present. The units of RCOMP ( $\mathrm{J}$ ) are specified with the INP command.

JMAX = The maximum number of $\operatorname{NUCLID(J),~RCOMP(J)~pairs~specified~on~each~line.~JMAX~}$ must not exceed four. If JMax is less than four, a zero must be added to the line.

A lin $\theta$ with a single zero entry instructs the code to proceed to the next sectlon of input (if any).

If a given nuclide is specified more than once for a single value of $\operatorname{NEXT}$, all $\operatorname{RCOMP}(\mathrm{J}$ ) values for that nuclide, on lines having this same NEXT value, are added together.

Initial composition lines with different NEXT values may occur in any order as long as the NUCLID(J) and $R \operatorname{COMP}(\mathrm{J}$ ) values on any given line correspond to the NEXT value on that line.

4.3.2.2. Specification of Continuous Nuclide Feed Ratee. This input data specifies constant-feed rates of individual nuclldes or naturally occurring elements. The data sequence is

$$
\begin{aligned}
& \text { NEXT NUCLID(1) RRATE (1) . . NUCLID(JMAX) RRATE (JMAX) } \\
& \text { NEXT = Segment for which the information is intended and the type of information: } \\
& =1 \text {, individual activation-product nuclides. } \\
& =2 \text {, individual actinide nuclides. } \\
& =3 \text {, individual fission-nroduct nuclides. } \\
& =4 \text {, naturally occurring activation-product elements. } \\
& =5 \text {, naturally occurring actinide elements. } \\
& =6 \text {, naturally occurring iission-product elements. } \\
& \text { NUCLID }(J)=\text { The six-digit nuclide identifier (zzAAAI) for nuclide (or element) } \mathrm{J} \text {. } \\
& \operatorname{RRATE}(J)=\text { The feed rate of nuclide (or element) } \operatorname{NUCLID}(J) \text {. The units of RRATE }(J) \text { are specified }
\end{aligned}
$$

If the feed rate of a given nuclide is specified more than once for a single value of NEXT, the total feed rate for NUCLID $(J)$ is computed by adding together all of the nuclide's RRATE $(J)$ values that are on lines having that particular NEXT value.

Continuous-feed-rate lines with different NEXT values may occur in any order as long as the NUCLID $(J)$ and RRATE $(J)$ values and the NEXT value on the same line all correspond.

4.3.2.3. Specification of Continuous Element-Removal Rates. In this data section, the user specifies continuous-element-removal rates during irradiation. The data sequences are as follows:

Group 1 (1-card set)

RREM(1) NPROS (1) . . RREM(M) NPROS (M) . .

RREM ( MMAX) NPROS ( MMAX)

Group 2 [MMAX card sets ( $M=1$ to MMAX)]

$N Z(M, 1) \ldots N Z(M, N) \ldots N Z[M, N P R O S(M)]$ 


\begin{abstract}
$\operatorname{RREM}(H)=$ The removal rate of elements $N Z(M, 1)$ through $N Z[M, N P R O S(A)]$. The units of RREM( $M$ ) are specified with the INP command.

NPROS $(x)=$ The number of elements in card set $x$ of Group 2; that is, the number of elements with a continuous removal rate equal to RREM( $M$ ).

Max $=$ The number of continuous reprocessing rates to be read. Also, the number of card sets in Group 2. ruAX is specified as NINP (4) with the INP command.

$\mathrm{NZ}(K, N)=$ The two-digit atomic number of an element $(\theta . \mathrm{g} ., \mathrm{He}=02)$ with removal rate RREM(K).

Continuous element removal will occur only during irradlation. If continuous removal is desired iil a situation where' no neutron flux is present, use the IRF command with a negligibly small flux.
\end{abstract}




\section{Organization of FORIG Output Files}

FORIG produces a voluminous but well-organized output. In this section we describe each output file in detail and use a sample fusion problem, activation of $a \mathrm{Li}_{17} \mathrm{~Pb}_{83}$ coolant, to demonstrate the output files. Users desiring a sampie fission-reactor problem should consult the user's manual for the ORIGEN2 Compuier Code. ${ }^{1}$

\subsection{Sample Fusion-Problem Input File (OnINPUT)}

For the sample fusion problem, we used the input command file (ORINPUT), shown in Fig. 3 The example also required the data libraries (TAPE9, TAPE8, TAPE3, and TAPE10) and the controllee (FORIG).

The iridividual commands are discussed in detall in Section 4.2. In this section, we show, by example, how the commands can to combined to perform the desired calculation.

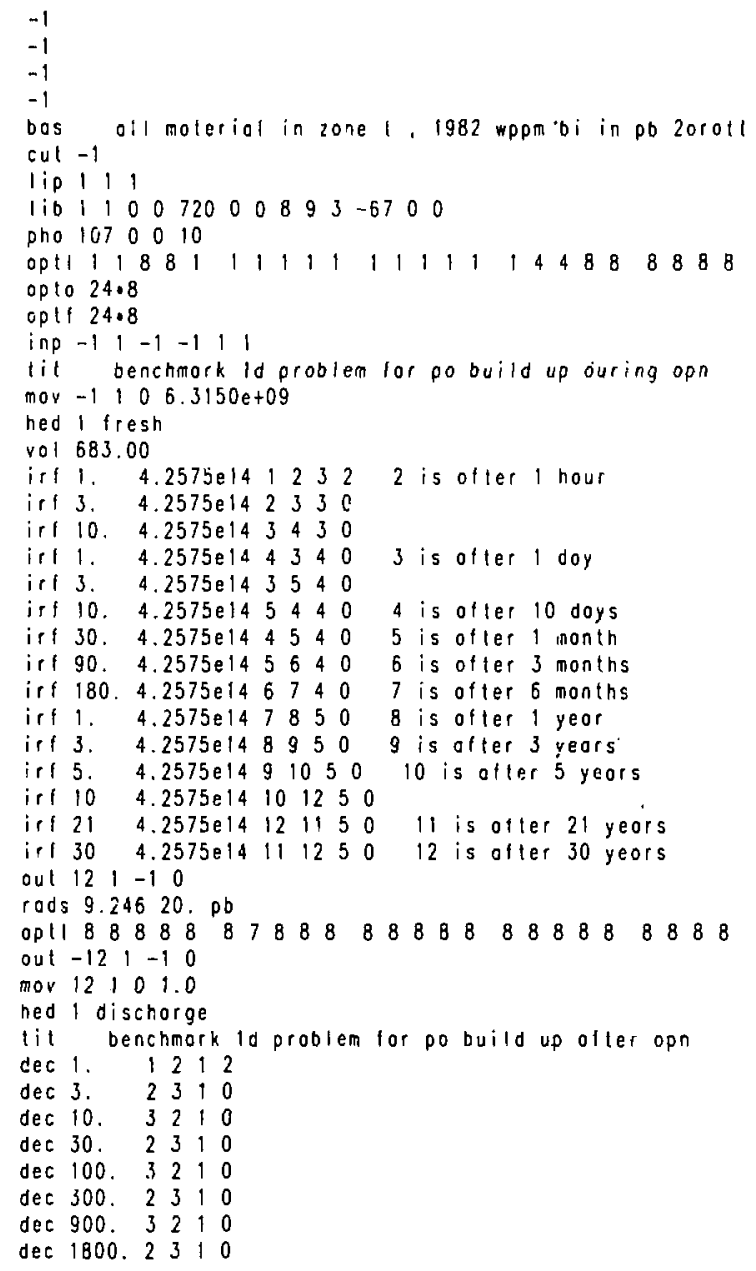

Figure 3. Example of ORINPUT file (continued on next page). 


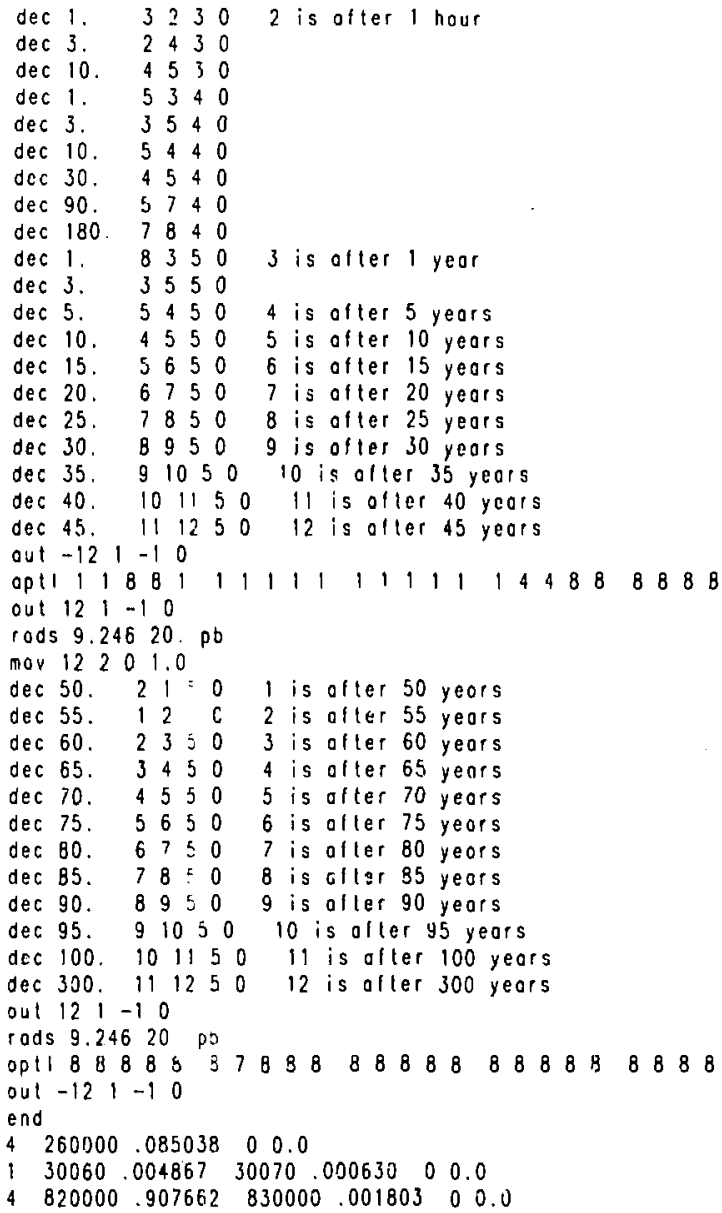

The first four lines of ORINPUT (see Fig. 3) operate to decline printing of the neutron sources and to accept the default chemical reprocessing data tables (which are not required for this particular calculation). The commands after the first four lines are described in the followirig:

IJA.S Reminder of the mass included in the calculation. Because it will be printed on almost every page, the BAS command can also include a user-selected calculation identifier (2OROUT in this case).

CUT Accepts the default cutofi levels for the summary tables. Nuclides with levels below the cutoff in all columns of the table will not be printed.

Forces printing of the decay, cross-section, and photon libraries (22 pages of output in this example). For parametric studies that use the same libraries, the printing can be suppressed by zeroing the arguments. 
LIB Determines the decay and cross-section library numbers. If these library numbers are not present in TAPE9 and TAPEB, respectively, the code will error exit. The LIB command also states the number of odd reactions to be read from TAPE3. The first argument forces the printing of the activation/decay matrix (17 pages of output in this example). This matrix is useful in determining which parents contribute to the production of a particular nuclide.

PHO Determines the photon library number to be read from TAPE10.

OPTL, Determine which tables (grams, curies, etc.) will be printed and in OPTA, which formats (by OPTA, nuclide, by element, or by summary using the OPTF cutoff levels).

OPTF

INP

Instructs the code to read the initial composition (from the end of the ORINPUT file) into vector " -1 " but not to read continuous feed or removal rates. The composition is entered in weight-fraction units; hence, at this point, $1.0 \mathrm{gram}$ of material is being considered.

TIT Determines the title to be printed on most pages of the output.

MOV Multiplies the input composition (vector " 1 ") by $6.3 \times 10^{9}$ and then stores it In vector " 1 ". This use of the INP and MOV commands allows a change in the mass to be calculated without editing the (lengthy) composition listing.

HED Changes the column heading of vector "1" to "fresh" (rather than a numerical time heading).

vor Establishes the material volume in cubic meters.

IRF Allows passage of time with a constant neutron flux. The content of vector " 1 " is irradiated and stored in vector " 2 "; vector " 2 " is irradiated and stored in vector " 3 "; and " 3 " is irradiated and stored in vector " 4 ". Vector " 4 " is irradiated, and the result overwrites vector " 3 ". This procedure allows a reasonable increase in the time step $(<3$ is a good rule of thumb) while saving only the desired output vectors. Once the IRF commands are completed, 12 vectors (the maximum that can be output on one page) are ready to be output.

OUT. Sends the 12 output vectors to file OROUT in the formats determined by the most recent RADS OPTL, OPTA, and OPTF commands. Then, the RADS command sends approximate dose rates to OROUT. Finally, the OPTL command is altered to a minimum amount of output, and the vectors are sent to file TAPE11. File OROUT is designed to be sent to microfiche; it contains 350 pages in this example. File TAPE11 is designed to be printed as it is much shorter.

MOV

This yov command copies the final composition (vector "12") into vector " 1 ". The HED and II commands change the vector " 1 " heading and the title, respectively.

In the above sequence, the first set of DEC commands allows the passage of more time but without a neutron flux. Once 12 output vectors accumulate, they are output to OROUT and TAPE11 using the OuT, OPTL, OUT, and RADS commands. The decay process is continued with the third MOV command, another set of DEC commands, and a final set of output commands. Finally, the END command instructs the code to stop execution. The END command is followed by the composition data requested by the earlier INP command.

\subsection{TAPE12, The Table of Contents for File OAOUT}

The complete TAPE12 for the fusion-problem example is given in Fig. 4. In this section, we discuss the organization of TAPE12 (and hence OROUT). The individual output segments are discussed in the next section,

The output begins with a standard set of information: a few code description pages, a listing of the commands (as read), the chemical reprocessing data, and the chemical toxicities of the elements. Then, the instructions are repeated as they are "compiled" (but not yet executed). Next, the data libraries are listed. 
table of contents on unit $=12$ for output unit $=6$ forig overview and documentotion inpul echo; read on 5 list on 6 copy to 50 individuol element froctionol recoveries group elementol froctionol recoveries elementol ossignnment to froc recoveiy group elemental chemicol toxicities

forig instructions for this cose

nuctide dalo libraries

decoy dala librory--...-- decay librory: octivation producl cross section librory----uses oc 840216 , bench $21 \mathrm{~d}, 1 \mathrm{~cm}$ te ot 5 odd reaclions non-zero motrix elements-. doughters nol in the decoy librory photon librory-activation prod

output lables--title=benchmork id problem for po build up during opn reactivity and burnup dato - oclivotion produclsa....ectivotion products......octivotion pro isotopic compusition of eoch element. isolopic composition of eoch element, weight froction $n$ concentrotions, grams nuctide toble: concentrotions, grams elemenl tobie: concentrotions, groms summory toble: concentrotions, froctionol groms nuclide loble: concentrotions, froctionol groms element toble: concentralions, froctional groms summary table: radiooctivity, curies nuclide table: radiooctivity, curies element toble: rodiooctivity, curies summory toble: rodioactivity, froctionol curies nuclide table: rodiooctivity, froctionol curies element table: rodiooctivity. troctional curies summory toble: thermol power, wolls nuclide loble: thermol power, wolts element toble: thermol power, wotts summory loble: thermol power, froctional wotts nuclide toble: thermol power, froctionol wolts element toble: thermol power. lroclional wotts summory loble: shollow burial index, per cent nuclide loble: shallow burial index. per cent element table: shallow buriol index. per cent summory toble: shollow buriol index, froctional per cent nuclide table shallow buriol index, Froctional per cent element lable shallow buriol index. froctional per cent summory loble rodioaclive inholation hozord, mas oir of rog nuclide $t$ rodioactive inholation hozord, mos oir of rag element

Figure 4. Example of TAPE12 (OROUT Table of Contonts) (continued on next page). 
toble of contents on unit $=12$ for output unit $=6$ radiooclive inholation hozord, mas air at reg summary $t$ radioaclive inholation hazard, froctional mas air ol $\mathrm{cog} n$ radioaclive inholation hozard, froctional mos air of roge rodioaclive inholotion hozard, froctional me.3 oir al rcgs rodioactive ingestion hozard, mas woter ot reg nucti radioactive ingestion hozard, mas woter at rcg eleme radioaclive ingestion hozard, mo.3 woler ot reg summa radiooclive ingestion hazard, froctional mas woter at reg radioaclive ingestion hazard. froctional me.s woter at rog radiooctive ingestion hazord, froctional me.s water at rog chemicol ingestion hazord. mo.3 woter element loble: chemical ingestion hozord, mos woler summary loble: chemical ingestion hazord, froctional me.3 woter element 1 chemicol ingestion hazord, froctional meis woter summary $t$ octivotion product photan table octivotion product dose rate loble

oulput lobles--lille=benchmork la problem for po build up ofter opn reactivity and burnup doto

- octivation products..... octivation productse...ectivation pro isotopic composition of each element, otom froction n isotopic composition of eoch element. weight froction n concentrolions, grams nuclide table: concentrotions, groms element table: concentrations, groms summary table:

concentrations, froctional grams nuclide loble: concentrations, fractional grams element lable: concentrations, froctional groms summary table rodiooctivity. curies nuclide table:

rodiooctivity, curies element toble: rodiooctivity, curies summory toble: rodiooctivity, fractional curies nuclide toble: rodiooctivity, fractional curies element lable: rodiooctivity, fractionol curies summory loble: thermal power, watts nuclide toble: thermal power, walts element table: thermal power, walts summory toble: thermol power. fractional watls nuclide table: thermal power, fractionol wotts element toble: thermal power, froctional walts summary toble: shallow burial index, par cent nuclide table: shallow burial index, per cent element toble: shallow buriol index, per cent summery toble: shaliow burial index, froctional per cent nuslide toble shallow burial index. froctional per cent element table shollow burial index. froclional per cent summary table rodiaoctive inhalation hazard, mo.3 oir of rcg nuclide $t$ codiooctive inhalation hazord, mo.s oir ot icg element rodiooctive inhalation hazord, mas oir ot reg summary

Figure 4. (continused on next page). 
loble of cantents on unit $=12$ for outpul unit $=6$ radioactive inhalation hazard, tractionol $m \cdot 3$ air al reg $n$ rodiooctive inholalion hozord, fractional ma.3 air al rcge rodiooctive inholotion hozard, tractional mes air al rcgs rodiooctive ingestion hozard, mes waler ot rcg nucli rodiooctive ingestion hazard, m.3 woler ot rca eleme rodiooctive ingestion hozard, m*3 woler ot rcg summo rodiooctive ingestion hozard, fractional m..3 woler al reg rodiooctive ingestion hozord, fractional mas woter al reg rodioaclive ingestion hozard, froctionol mes woler al rcg chemicol ingestion hozord, mo.3 woter element toble: chemicol ingestion hozord, mo3 woler summory toble: chemicol ingestion hozord, froctionol me.3 woler element 1 chemical ingestion hozord, froctionol mas woter summory octivotion product photon tuble octivotion producl dose rote loble

oulput tobles--lille=benchmork lo problem for po build up olter opn reoctivity ond burnup doto

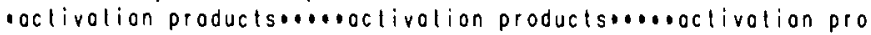
isolopic composition of eoch element, otom froction n isolopic composition of eoch element, weight froction $n$ concentrotions, grams nuclide toble: concentrotions, groms element toble: conrentrotions, grams summory toble: concertrotions, fractionol grams nuctide labta: concentrotions, froctionol groms element lable: concentrotions, froctional groms summory loble: rodiooctivity, curies rodioactivity, curies rodiooctivity, curies nuclide toble: summary loble: rodiooctivity, froctionol curies nuclide toble: rodiooctivily, froctionol curies element toble: radiooctivily. fractional curiej summary toble: thermal power, watts nuclide loble: thermol power. wotts element loble: thermal power, wotts summory loble:

thermol power, froctionol wotts nuclide toble: thermol power, froctional wolts element toble: thermal power, froctionol wotts summory table: shollow butiol index, per cent nuclide table: shollow burial index, per cent element toble: shollow burial index, per cent summory toble: shollow burial index, fractianol per cent nuclide toble shollow buriol index, tractional per cent element table shollow buriol index. froctional per cenl summary toble rodiooctive inholotion hozord, mes oir ot reg nuclide rodiooctive inholotion hazord, mes oir ot rcg element I rodiooctive inholation hazord, ma.3 oir at reg summory 1 rodiooctive inholation hozord, froctionol mus oir ot regn

Figure 4. (continued on next page). 


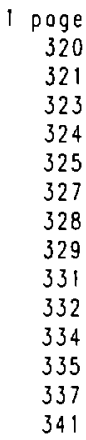

loble of contenls on unil $=12$ for output unit $=6$ rodiooctive inholotion hozord, froclional me3 oir ot rcge radioactive inholation hozord, froctionol mas oir ol regs rodiooctive ingestion hazard, $m+3$ woter at rag nucli rodiooctive ingestion hozord, m*3 woter ot rcg eleme radioactive ingestion hazord, m.3 woter ot rcg summo rodiooctive ingestion hozord. froctional mas woter of reg rodiooclive ingestion hazord, froctionol m.3 woter of rcg rodiooctive ingestion hazord, froctionol m+o3 woter ot rcg chemicol ingestion hozord, m.3 woler element lable: chemical ingestion hazard, mes woler summory table: chemicol ingestion hazord, fractionol m*03 water element $t$ chemicol ingestion hazard, fractionol m*a water summory $t$ octivolian product photon table activotian product dose rate lable

Finally, the main body of the output begins. This information is organized in a hierarchical fashion. For each out command, there is a title, reactivity and burnup data, the activation product tables, the actinide tables, and finally the fission product tables (if requested). These are followed by the neutron production tables for actinides and the photon production tables for activation products, actinides, and fission products.

Within a segment (e.g., activation products), the requested tables (1 through 24) are prinicd in the sequence stiown in Table 12. For each table type, the data are printed by nuclide, by element, summarized by nuclide, and summarized by element (if requested).

The hierarchical organization is illustrated in Fig. 5.

\subsection{The OROUT Output File}

The organization of the OROUT file was discussed in the previous section. In the following we show the detailed format of some of the individual output-data tables.

The first page from the decay library echo is given in Fig. 6 . This output table is much more readable than the original (TAPE9) data file. Similarly, Fig. 7 is the first page from the standard cross-section file (TAPE8) echo, and Fig. 8 is the first page of the odd cross-section file (TAPE3) echo. The units for all cross sections are in barns.

Figure 9 is one page from the activation-decay matrix. The entries are for the nuclide sequence number (from TAPE9), the nuclide identification (ZZAAAI), its disintegration constant (per second), its total cross section in barns, and the number of different possible daughters from the nuclide (including those from activation and decay, and including protons, deuterons, tritons, and alphas generated by activation and decay). Then, all the possible parents for the nuclide are listed along with the reaction cross section (if the nuclide is produced by activation) or the parent-decay constant multiplied by the branching ratio (if the nuclide is produced by decay).

When a decay or activation reaction produces a nuclide that is not in the decay library (TAPE9), that mass is effectively removed from the calculation since no further decay or activation will be calculated because of lack of data. Figure 10 is a page from the listing of these "limbo" reaction products. This output data should be reviewed, because it indicates potential improvement points for the decay and crosssection libraries. To aid in this review, we screen the data for two conditions. First, for a "naturally occurring" parent, the input composition should be checked, because if that parent element is input, significant quantities of the limbo daughter could be produced. Second, if the parent "is not produced," the daughter cannot be produced unless the parent is input in the initial composition.

Figure 11 is a page from the photon library (TAPE10) echo. Each nuclide entry occupies two lines to show the photon production per disintegration in the 18 photon-energy groups. This data file contains only decay-gamma information. Gamma production from $(n, \gamma)$ reactions is not calculated by FORIG. However, we can obtain that information from neutron-photon transport codes such as TARTNP. ${ }^{5}$ 
Cornmand code documentation input echo

Miscellaneous input

Fission neutron yield per neutron-induced fission

(alpha,n) neutron production rate

Fission neutron yield per spontaneous fission

Individual-element fractional reprocessing recoveries

Element-group fractional reprocessing recoveries

Assignment of elements to fractional recovery groups

Elemental chemical toxicities

Listing of ORIGEN2 commands

Data libraries

Decay

Activation product segment

Actinide segment

Fission product segment

Cross section [same segments as for Decay data library]

Photon [same segments as for Decay data library]

First Output Group (from a single out command)

Reactivity and burnup data

Activation product segment

Table type $1^{\mathrm{a}}$

Nuclide aggregation ${ }^{b}$

Element aggregation

Summary isotope aggregation

Summary element aggregation

Actinide segment [same table types and aggregations as for activation products]

Fission product segment [same table types and aggregations as for activation products]

Neutron production rates for the actinide segment

(alpha,n)

Spontaneous fission

Photon production rates

Activation product segment

Summation tables

Principal contributor tables

Actinide segment [same aggregations as for activation products]

iission product segment [same aggregations as for activation products]

Final Output Group

a Table types are defined in Table 12. The table types printed are controlled by the entries in the OPTL, OPTA, and OPTF commands.

bThe aggregations printed are controlled by the magnitude of the entries in the OPTL, OPTA, and OPTF commands.

Figure 5. Hierarchical organization of FORIG output file, OROUT. 
output unit $=6$

decoy library: octivalion products updated jan 885

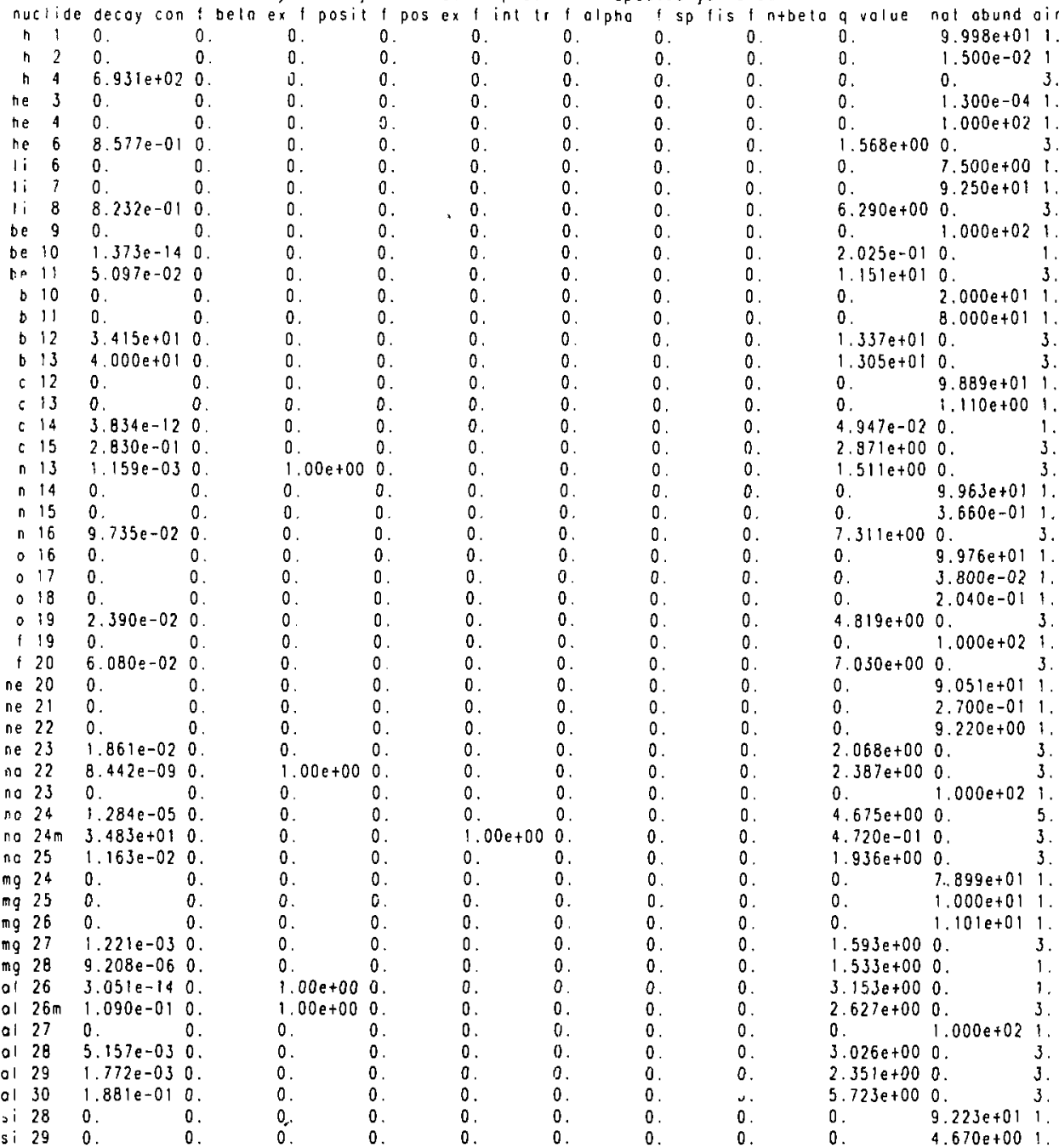

Figure 6. Decay-data library (TAPE9) echo. 


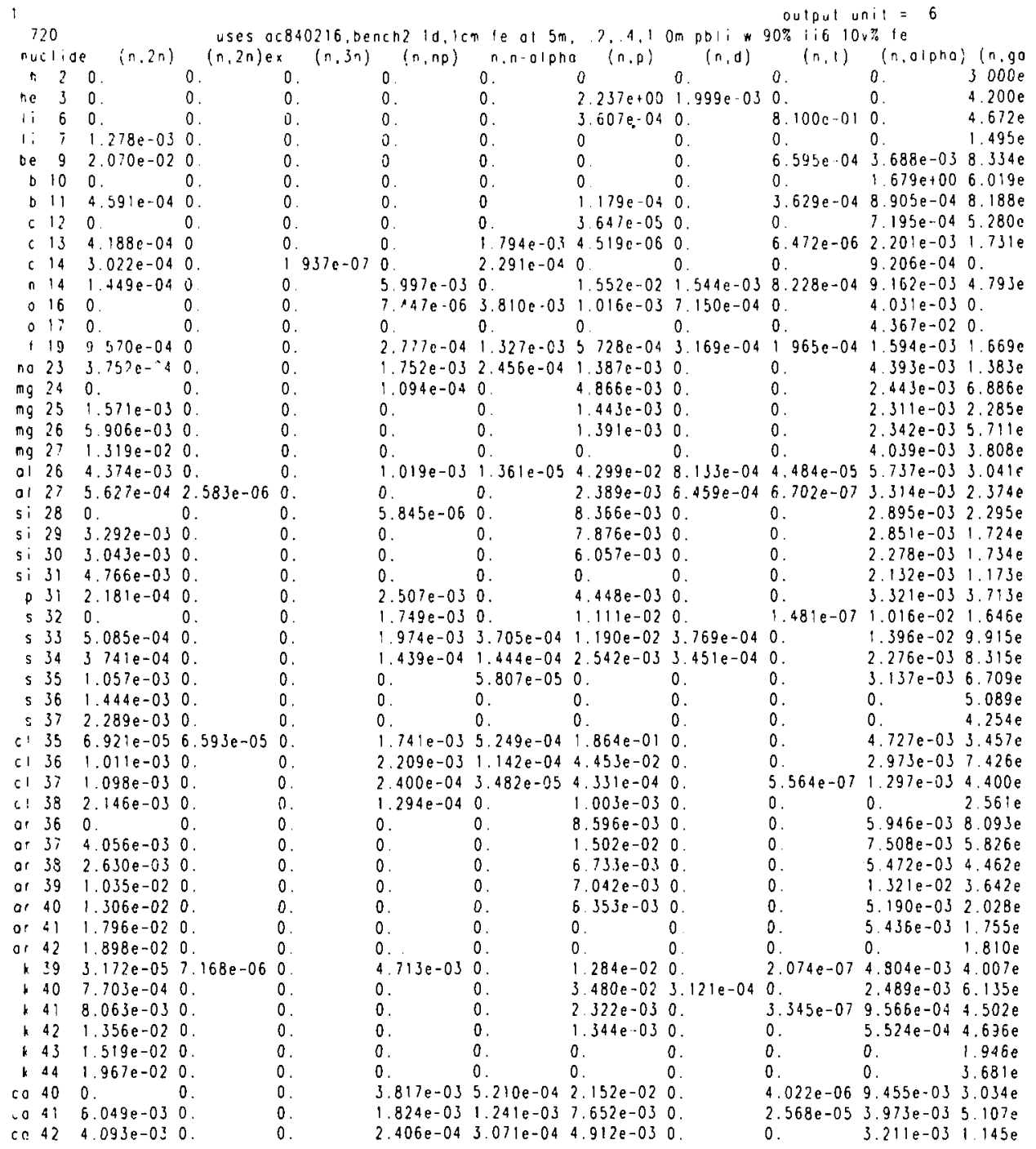

Figure 7. Standard cross-section library (TAPE8) echo. 
odd reactian cross sections reoction lypes (Irtyp): (o=olpho, $h=3$ he, $(a j=$ residual is on olpho)

$\begin{array}{llllll}12 n, 2 n & 13 n, 3 n & 14,1,4 n & 15 n, 1 i s & 20 n, n p \\ 21 n, p n & 22 n, n d & 23 n, n d a(0) & 24 n, n 1 & 25 n, n h \\ 26 n, n o & 27 n, n 20(0) & 28 n, n 10(0) & 29 n, 2 n p(0) & 30 n, g n a \\ 31 n, 2 n p o(0) & 37 n, 2 a(0) & 38 n, h o(0) & 39 n, t p(0) & 40 n, p \\ 41 n, d & 42 n, l & 43 n, 10(0) & 44 n, h & 45 n, a\end{array}$

$46 \cap, 9$

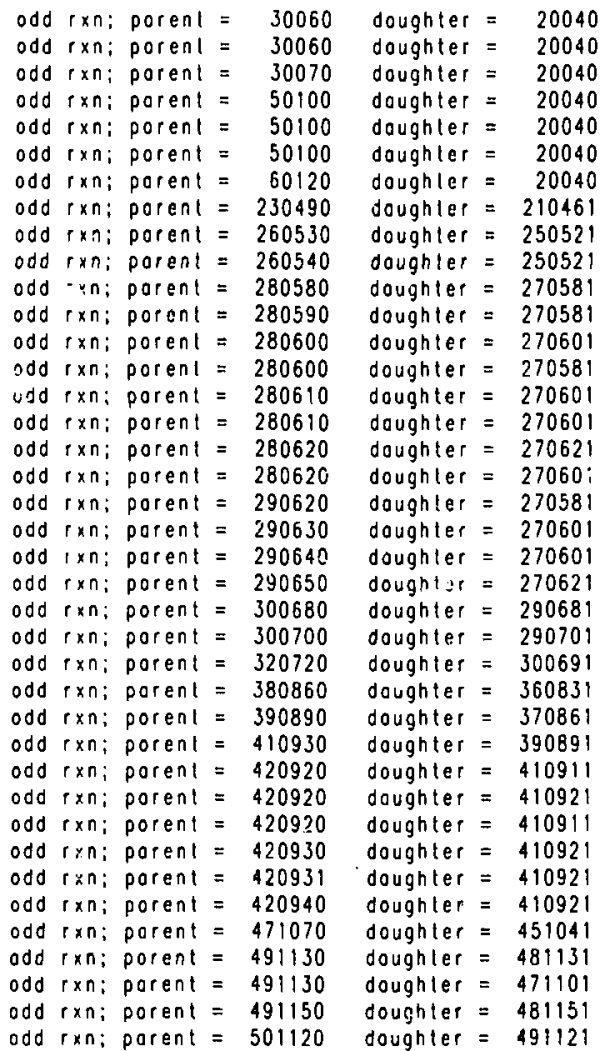

cross section $=1.93900-02$ barns cross section $=1.8800 e-03$ borns cross section= cross section= cross section = cross section= cross section= cross section= cross section= cross seclion= cross section= cross section = cross section= cross section= cross section= cross section= cross seclion= cross section= cross section= cross section= cross section= cross section= cross section= cross secticn= cross section= cross section= cross sectinn $=$ cross section= cross section= cross section= cross seclion= cross section= cross section= cross section= cross section= cross section= cross section= cross section= cross section=
$9.8060 e-03$ borns $2.8620 e-03$ borns

5. 2310e-04 borns

$4.60 \% 0$ e-03 borns 9.9260e-03 borns $1.2710 e-03$ borns 1.0550 e-02 borns 2.5340 e-07 boins 8. $4030 \mathrm{e}-03$ borns $2.9390 \mathrm{e}-03$ borns 1.8950e-03 borns 6. 1610e-07 borns 1.7000 e-04 borns 7.1080 e-05 borns $5.0410 \mathrm{e}-04$ borns $1.7880 \mathrm{e}-08$ borns $4.8350 \mathrm{e}-04$ borns 6. 3540 e-04 borns $3.8390 e-45$ borns 1.7900e-04 borns 20370 e-04 borns 1.2290 e-04 borns 3. $8100 \mathrm{e}-04$ borrs 2. 3650e-05 borns 8.5530 e-05 borns 6. $4720 \mathrm{e}-05$ borns $8.8310 e-05$ borns 2.1170e-03 borns $5.1100 \mathrm{e}-04$ barns 1.7770 e-03 borns 2.7770 e-03 borns 1. $4850 \mathrm{e}-08$ borns 2.7220e-04 borns $2.2520 e-04$ borns $1.8780 e-05$ borns $2.0680 \mathrm{e}-04$ borns $1.2890 \mathrm{e}-03$ borns
Iype $=22$

Iype $=29$

1 ype $=24$

type $=23$

type $=29$

type $=43$

lype $=27$

type $=45$

type $=20$

lype $=42$

lype $=40$

type $=20$

lype $=40$

type $=42$

type $=20$

type $=41$

type $=40$

type $=42$

lype $=26$

lype $=45$

$1 Y P C=26$

type $=45$

lype $=40$

type $=40$

lype $=45$

type $=45$

type $=45$

type $=26$

type $=20$

type $=40$

type $=41$

type $=41$

type $=41$

lype $=42$

lype $=45$

lype $=40$

type $=45$

type $=40$

lype $=40$

Figure B. Odd-reaction cross-section library (TAPE3) tcho. 
1 non-zero matrix elements; i= of doughter:

$i$ nucl(i) dis(i) locop(i) max rale porent $95210441 \quad 3.288 e-06 \quad 1.179 e-01 \quad 8 \quad 2.423 e-03210450$ $96210450 \quad 0 . \quad 3.639 \mathrm{e}-02 \quad 8 \quad 4.923 \mathrm{e}-08200450$ i. $263 e-0221046$ !

$97210460 \quad 9.574 e-08 \quad 2.371 e-02$

$982104613.713 e-02 \quad 2.408 \mathrm{e}-02$ $99210470 \quad 2.394 \mathrm{e}-06 \quad 3.661 \mathrm{e}-02$

$100210480 \quad 4.395 e-052.833 e-02$ $1012104902.009 \mathrm{e}-040$.

102210500 6.762e-030.

ij3 220460 0. $1,452 \mathrm{e}-02$

1042204700 2.195e-02

1052204800.

$2.280 e-02$

$106220490 \quad 0$.

$2.286 \mathrm{e}-02$

$107220500 \quad 0$.

$1.453 \mathrm{e}-02$

$108220510 \quad 2.006 e-03 \quad 2.538 c-02$ $109230470 \quad 3.544 e-04 \quad 3.533 e-02$ $110230480 \quad 5.020 \mathrm{e}-07 \quad 3.738 \mathrm{e}-01$ $111230490 \quad 2.431 \mathrm{e}-08 \quad 3.484 \mathrm{e}-02$

$112230500 \quad 5.491 \mathrm{e}-25 \quad 2.627 \mathrm{e}-01$

1132305100 .

$2.667 \mathrm{e}-02$

$114230520 \quad 3.081 \mathrm{e}-03 \quad 7.164 \mathrm{e}-02$

$1152305307.175 e-030$.

$116230540 \quad 1.260 \mathrm{e}-020$.

$117240490 \quad 2.755 \mathrm{e}-04 \quad 1.397 \mathrm{e}-01$

$118240500 \quad 0$

$3.136 e-02$

$1192405102.895 e-075.510 e-02$

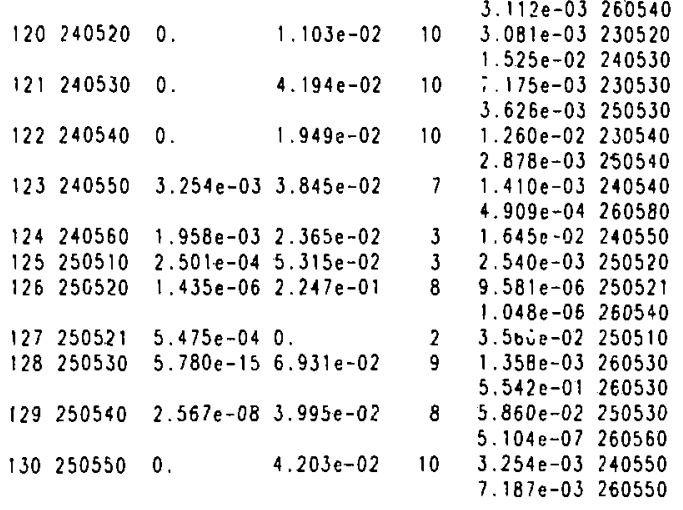

1. $313 e-03200490$

4. $444 \mathrm{e}-04220500$

$9.574 e-08210460$

$4.063 e-03230480$

$8 \quad 4.395 e .06210480$

$1.822 \mathrm{e}-01230480$

$4,9600-03 \quad 230490$

$6.7 .62 e-03210500$

8. $520 \mathrm{e}-03230500$

1. $105 \mathrm{e}-03220500$

4. $219 e-03230480$

$3.533 \mathrm{e}-02230470$

2. $755 e-04240490$

$3.669 \mathrm{e}-03240500$

1. $766 e-02230490$

$3.103 e-08240520$

$8 \quad 2.006 \mathrm{e} .03220510$

$8.893 e-03240510$

$8 \quad 9.212 \mathrm{e}-03230510$

8. $678 \mathrm{e}-04250550$

4. 387e-02 230520

$3.404 e-04240540$

.3 $2.019 e-04240500$

$10 \quad 1.647 e-25 \quad 230500$

$2.501 e-04250510$ output unit $=6$

rote porent

2. $814 \mathrm{e} \cdot 02 \quad 210440$

i. $011 e-04220460$

1. $658 \mathrm{e}-02210450$

$1.939 \mathrm{e}-03230490$

1. $271 \mathrm{e}-03230490$

$7.066 \mathrm{e}-03210460$

1. $188 e-05220480$

$1.946 e-03220480$

$6.751 e-03210480$

$7.900 \mathrm{e}-03220470$

$3.544 \mathrm{e}-04230470$

$1.156 \mathrm{e}-03240500$

$5.020 e-07230480$

2. $191 e-03230490$

$2.431 e-08230490$

8. $776 e-04230500$

3. $844 \mathrm{e}-25230500$

4. $657 \mathrm{e}-04230510$

$1.213 e-03230510$

6 $821 e-03230490$

1. $764 \mathrm{e}-01230480$

4. $916 \mathrm{e}-03250520$

$1.483 e-02230510$

2. $296 e-03250530$

i.895e-07240510

$1722 \mathrm{e}-04240520$

2. $417 \mathrm{e}-03240520$

1. $215 e-03240530$

3. $558 \theta-04250570$

$5.569 e-02240490$

1. $816 \mathrm{e}-02240500$

$1.435 e-06250520$

1. $889 \mathrm{e}-01250520$

5. $780 e-15250530$

$7.499 e-04250540$

$2.567 e-08250540$

$5.994 e-04250550$

2. 297e-02 240560

$7.815 e-04250560$

$1.755 e-02250510$

1. $358 e-03250530$

$4.566 e-0326053 i$

$5.077 e-03260540$

1. $809 e-02250550$

$1.985 e-05270580$

8. $448 \mathrm{~B}-09260550$

2. $060 \mathrm{e}-03260560$ role porent

$2.814 \mathrm{e}-02 \quad 210441$

$6.871 \mathrm{e}-03230480$

1. $391 e-02210470$

$7.066 a-03210461$

1. $501 e-03230500$

1. $319 e-05220490$

g. $522 \mathrm{e}-04220490$

$3.786 e-03240490$

4. $964 a-03220460$

$6.427 \mathrm{e}=03220470$

1. $261 e-03240510$

1. $382 \mathrm{e}-02220460$

$3.641 e-04240520$

5. $460 e-03220490$

7. $226 \mathrm{e}-04240530$

$1.501 e-04230520$

$7.737 e-03240490$

1. $719 e-02230500$

$8.170 e-03240500$

$2.346 e-01230500$

$2.593 e-06240530$

$7.263 e-05240530$

$2.602 e-06 \quad 240540$

E $413 \mathrm{e}-03240510$

5. $936 \mathrm{e}-03240520$

5. $379 \mathrm{e}-04250521$

1. $700 \mathrm{e}-03250530$

$2.14 i \mathrm{e}-03240520$

1. $226 \mathrm{e}-05250550$

$2.468 \mathrm{e}-02 \quad 240530$

1. $518 \mathrm{e}-03250570$

$1.084 \mathrm{e}-03250550$

$2.365 e-05250570$

$1.728 \mathrm{e}-03250530$

$1.055 e-02260530$

$2.534 \mathrm{e}$

$2.529 \mathrm{e}-02250520$

1. $558 \mathrm{e}-02 \quad 260540$

$.896 \mathrm{e}-0527058$

1. $686 \mathrm{e}-02.250540$

3.027 e-07 260570 1.825e

1. $889 \mathrm{e}$

$\operatorname{rot}$

$1.259 \mathrm{e}$

$7.671 \mathrm{e}$

$1.895 \mathrm{e}$

$9.276 \mathrm{e}$

$8.553 \mathrm{e}$

1. $953 \mathrm{e}$

5. $978 \mathrm{e}$

$1.565 \mathrm{e}$

1. 280

$2.181 \mathrm{e}$

$3.028 \mathrm{e}$

$6.789 \mathrm{e}$

7. $200 \mathrm{e}$

1. $500 \mathrm{e}$

$2.485 \mathrm{e}$

1. $209 \mathrm{e}$

$1.029 \mathrm{e}$

$8.016 \mathrm{e}$

$1.002 \mathrm{e}$

$3.060 \mathrm{e}$

3. $703 e$

$3.470 \mathrm{e}$

1. $743 \mathrm{e}$

1. $870 \mathrm{e}$

2. $172 \mathrm{e}$

$9.127 \mathrm{e}$

2.78 is

2. 7200

1. 51 te

Figure 9. Page from the reaction-matrix table. 


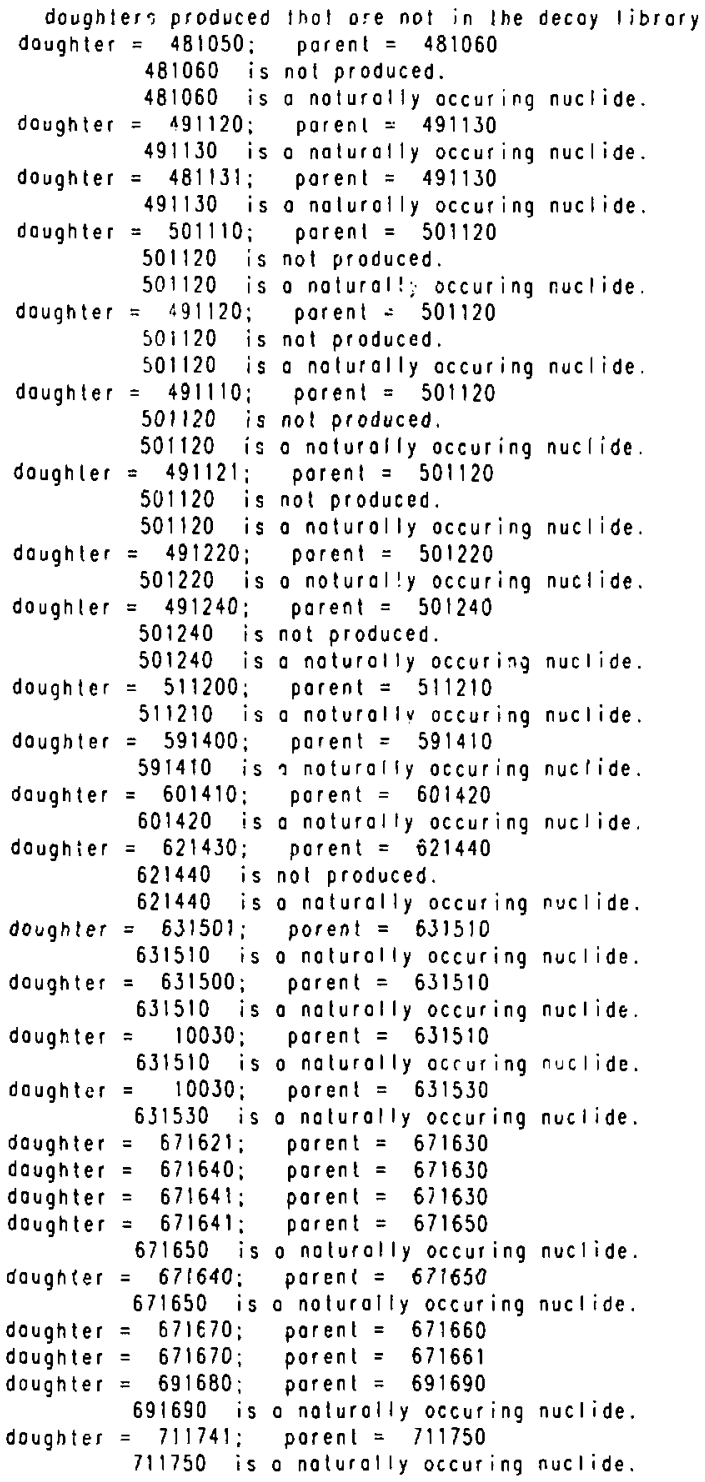

Figure 10. Page from the listing of "Daughters not in the decay fibrary." 


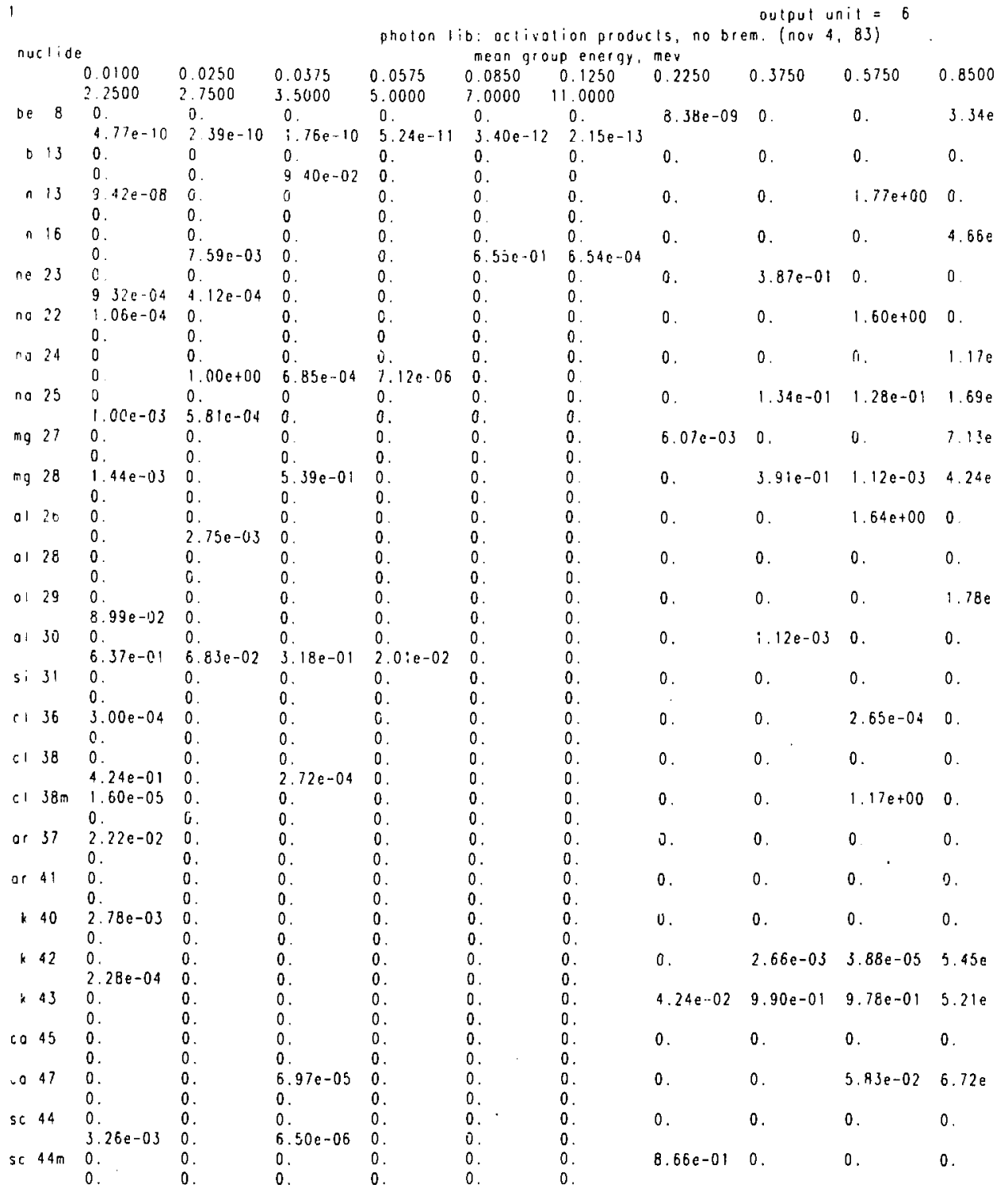

Figure 11. Photon-decay library (TAPE10) echo. 
Figure 12 is the first reactivity and burnup-dala table from the example (i.e., the data taken during the neutron flux). The table begins with the title (from the TIT command). Then, the power, burnup, and flux are listed. For fusion problents, these values are not computed, but iristead a value of 1.0 is always printec. For fission problems, these values are computed by the Bup commands. Next, the BAs comments are printed. The first two rows of the time-dependent output are for the time in seconds (useful for plotting) and for the neutron flux $\left(n / \mathrm{cm}^{2} \cdot s\right)$. The entries "or "size of mMAx(i)" indicate the number of nuclides with " $i$ " daughter nuclides (including decay and activation reactions as well as the $p, d, t$, and $\alpha$ particles produced by those reactions). In the example, one nuclide had 14 possible daughters. In ORIGEN2, a maximum of only seven daughters was permitted. (The higher energy spectrum in fusion reactors can drive more reaction types than the spectrum in fission reactors.) The final segment of the reactivity and burnup data indicates the size of the arrays. These sizes should not exceed the dimensions of the code (see Fig. 1). If the dimensions are exceeded (say by an overly large decay library), the arrays will overflow and overwrite other arrays. A comparison is shown in Table 13 between the numbers printed in the output and the dimensions given in Fig. 1.

Figure 13 illustrates a typical output table, that is, a summary table by element for radioactivity in curies. The "sumtot" line is the total of the table entries, and the "total" line is the overall total. The difference indicates activity "lost" by using the cutoff values. [Similarly, inspaction of the "totals" line of the "grams" table as a function of time indicates the mass lost to the production of limbo daughters (i.e., daughters not in the decay library).] The "cumulative table totals" are a running total by segment. For the activation-product output, the other two segments are not yet accumulated, and the totals "ap \& fp," "act \& $f p, "$ and "ap \& act \& fp" should be ignored.

Figure 14 shows the (decay) photon-emission rates as functions of both time and photon energy. The upper table is in terms of photons per second for each photon-energy group. Its line of totals is immediately followed by the total photon-energy release rate $(\mathrm{MeV} / \mathrm{s})$. The lower table is the photon-energy release rate $(\mathrm{MeV} / \mathrm{s})$ divided by the reactor power $(\mathrm{MW})$. For fusion problems, the reactor power is not computed by FORIG, and $1 \mathrm{MW}$ is assumed in the table. Hence, il! the lower table, the total line is the gamma-energy release rate (MeV/MW.s). The final line ("gam pow") is more easily understood; it is the actual decay gamma power in watts. In the example, the 30 year-shutdown decay-gamma power is $2.4 \mathrm{MW}$, or less than $0.1 \%$ of the reactor fusion power.

Figure 15 shows one page of the principal contributors to the various photon-energy groups. The units are in photons per second, and the sums for each group (not printed) are the entries in the top half of Fig. 14.

The approximate gamma dose rate $(\mathrm{mR} / \mathrm{hr})$ is printed in a similar format. First, the dose rates for al! 18 photon-energy groups are printed in one table. Then, each energy group is reprinted to show the individual contributions from the most significant nuclides. Finally, the total dose rate is broken down to show the contributions of the most significant contributors. Also, in this final table, the "sum" of the significant contributors is shown as well as the "total" from all nuclides. The difference between these two totals can be reduced by changing the cuT command.

\subsection{TAPE13: Table of Contente and TAPE11: Abbreviated Output}

The organization of these files is identical to that of TAPE12 and of OROUT, except that output begins with the first requested "Reactivity and Burnup" table.

\subsection{TAPE15: Debug Information}

This file serves three principe: functions. For the first function, which is useful in some debugging situations, a single line of informatisn is printed just before each command is executed. The number of each command type is also printed. However, ior counting the number of commands of a particular type, all IRP, IRF, and DEC commands are counted as IRF commands. There will always be a total of zero IRP and DEC instructions.

The second function of the output on TAPE15 is to provide selected internal information calculated by FORIG. This type $f$ information is prinied for the IRP, IRF, KEQ, and FAC commands. The significance of the printed infornation is discussed below. 


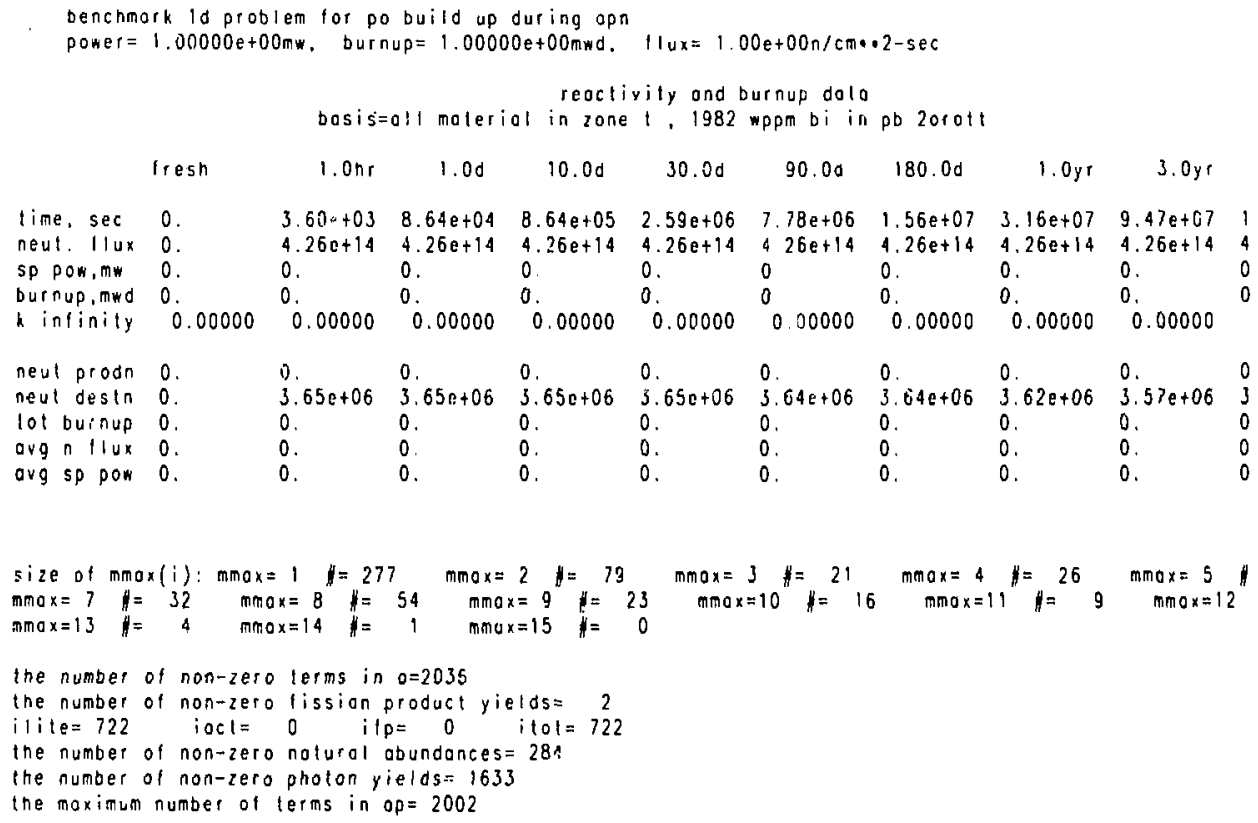

Figure 12. Reactivity and bumup data.

Table 13. Comparison of code sizes with dimensions selected by the user.

\section{Code size (from the table of reactivity and bumup data)}

The number of non-zero terms in "a" (2035)

The number of nonzero fission product yields (2)

ilite (722)

iact (0)

ifp (0)

ito: (722)

The number of nonzero natural abundances (284)

The number of noncero photon yields (1633)

The maximum number of terms in "ap" (2002)

\section{Dir :nsion (from Fig. 1)}

Total numb- of non-zero matrix elements: DDDD 12500)

Number of rionzero fission product yields = EEEE (4)

Maximum number of light nuclides $=$ MMMM (900)

Maximum number of actinides $=$ GGGG $-1(4-1=3)$

Maximum number of fission products $=$ FFFF (4)

Maximum number of non-nuclides $=$ BBBB $(900)$

Number of nonzero natural abundances $=$ KKKK $(300)$

Number of nonzero photon yields = LLLL (3300)

Maximum number of nonzero matrix elements for long-lived nuclides $=1111$ (2500) 


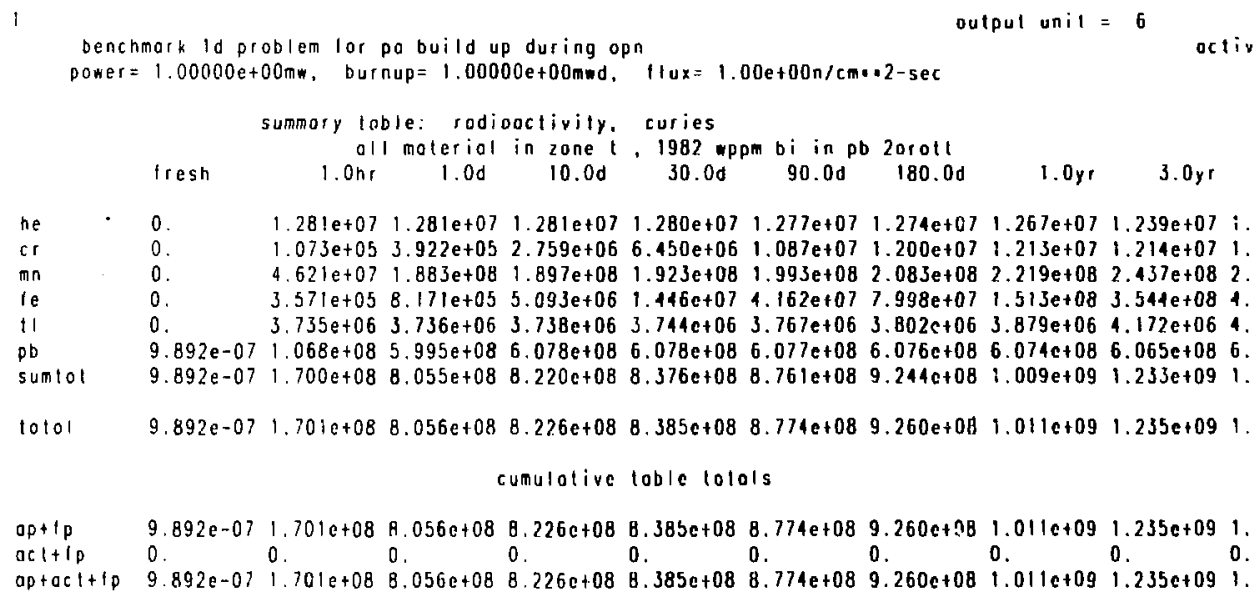

Figure 13. Typical FORIG output page.

Basically the same information is printed for both the IRP and IRF commands. Most of the parameters printed are intermediate values used in SUBROUTINE FLUXO to calculate the flux when the power is given, or vice versa. (Th6se values will not be described in detail, but the nomenclature in the TAPE15 output is the same as that in FLUXO. Thus the interested user can readily perform the filux/power calculation with a hand calculator if required.)

The following parameters pruted in TAPE15 are of more general interest:

TSEC Absolute time at the end of the current irradiation step (s).

DELT Duration of the current irradiation step (s).

EPF 1, Recoverable energy per fission associated with the zero-, first-, and second-time derivatives EPF2, used in the flux/power calculation (MeV/fission).

EPF 3

EPFAVG Average recoverable energy per fission for this time step (MeV/fission).

FLUX Calculated or specified flux for the irradiation step (neutrons $/ \mathrm{s} / \mathrm{cm}^{2}$ ).

POWER Calculated or specified power for the irradiation step (MW per basis unit).

In some situations, this type of information can be useful either as input to auxiliary hand calculations or in finding errors.

The internal information printed for the $\mathrm{KEQ}$ command is related to the calculated neutron production and destruction rates, to the infinite multiplication factors, and to the fraction of the allocated material that is included in the final mixiure. The parameters are defined as follows:

NPROA, Relative neutron production rates of vectors NKEQ ( 1 ), NKEQ (2), and NKEQ( 3 ), NPROB, respectively.

NPROC

NDESA, Relative neutron destruction rates of vectors NKEQ(1), NKEQ(2), and NKEQ (3), NDESB, respectively.

NDESC 
photon spectrum lor octivolion products

benchmork ld problem for po build up during opn power $=1.00 \mathrm{mw}$, burnup $=1$. mwd. flux=1.00e+00 n/cmer-sec

iB group pholon teieose rales, pholons/second basis=oll molerial in zone 1,1982 mpm bi in pb 20 coll

eneor

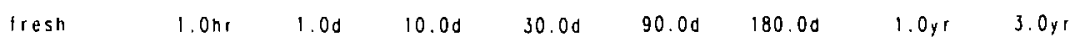

1. $500 e-02 \quad 0$

$2.500 \mathrm{e}-0$ ? 0

3. $250 \mathrm{e}-020$

5. $750 e-020$

8 500e-02 0

1. $250 e-01$

2. $2500-01$

s $7500-01$

5. $750 e-01$

8. $500 e-01$

1. $250 e+00$

1. $750 \mathrm{e}+00$

2. $250 e+00$

2. $750 \mathrm{e}+00$

3. $500 e+00$

5. $000 \mathrm{e}+00$

7. $000 \mathrm{e}+00$

1. 100e+01

lotal mevisec

$1.284 e+16 \quad 1.469 e+16 \quad 3.070 e+16 \quad 5.931 e+16 \quad 1.139 e+17 \quad 1.645 e+172.347 e+173.452 e+173$ $7.245 \mathrm{e}+093.086 \mathrm{e}+10 \quad 3.260 \mathrm{e}+10 \quad 3.567 \mathrm{e}+10 \quad 4.088 \mathrm{e}+10 \quad 4.364 \mathrm{e}+104.498 \mathrm{e}+104.727 \mathrm{e}+104$ $9.594 \mathrm{e}-08 \quad 1.280 \mathrm{e}-03 \quad 9.502 \mathrm{e}-01 \quad 1.570 \mathrm{e}+012.187 \mathrm{e}+02 \quad 8.845 \mathrm{e}+02 \quad 3.673 \mathrm{e}+033.333 \mathrm{e}+049$ $6.717 \mathrm{e}+03 \quad 2.289 \mathrm{e}+06 \quad 1.306 \mathrm{e}+0 \mathrm{~B} \quad 1.000 \mathrm{e}+09 \quad 6.773 \mathrm{e}+09 \quad 1.948 \mathrm{e}+104.934 \mathrm{e}+10 \quad 1.732 \mathrm{e}+113$ $1.309 e+12 \quad 3.106 e+13 \quad 2.905 e+14 \quad 7.5 e 6 e+14 \quad 1.551 e+15 \quad 1.958 e+15 \quad 2.096 e+15 \quad 2.116 e+15 \quad 2$ $9.690 \mathrm{e}+159.690 \mathrm{e}+159.691 \mathrm{e}+159.693 \mathrm{e}+159.700 \mathrm{e}+159.710 \mathrm{e}+159.730 \mathrm{e}+159.810 \mathrm{e}+159$. $3066 e-044.828 e+173.716 e+18 \quad 3.8770+18 \quad 3.881 e+183.887 e+183.890 e+183.890 e+183.884 e+183$. 0. $\quad 2.953 e+161.825 e+171.973 e+172.089 e+172.230 e+172.273 e+172.295 e+172.357 e+172$. 0 . $\quad 9.508 e+153.764 e+163903 e+163.903 e+163.903 e+163.904 e+163.906 e+163.911 e+163$. $1.222 \mathrm{e}-04 \quad 1.603 \mathrm{e}+18 \quad 6.778 \mathrm{e}+18 \quad 6.832 \mathrm{e}+18 \quad 6.925 \mathrm{e}+18 \quad 7.181 \mathrm{e}+18 \quad 7.505 e+188.001 \mathrm{e}+188.791 \mathrm{e}+188$. 6. $952 \mathrm{e}-05 \quad 5.414 \mathrm{e}+15 \quad 1.232 \mathrm{e}+16 \quad 1.243 \mathrm{e}+16 \quad 1.249 \mathrm{e}+16 \quad 1.253 \mathrm{e}+16 \quad 1.259 e+16 \quad 1.274 \mathrm{e}+16 \quad 1.349 \mathrm{e}+16 \quad 1$. $3.483 \mathrm{e}-05 \quad 4.572 \mathrm{e}+17 \quad 1.932 \mathrm{e}+18 \quad 1.935 \mathrm{e}+18 \quad 1.935 \mathrm{e}+18 \quad 1.935 \mathrm{e}+18 \quad 1.935 \mathrm{e}+18 \quad 1.935 \mathrm{e}+18 \quad 1.937 \mathrm{e}+18 \quad 1$.

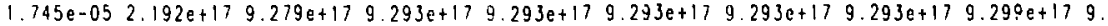
B. $745 e-063.083 e+16+300 e+17, .302 e+17 \quad 1.302 e+17 \quad 1.302 e+17 \quad 1.302 e+17 \quad 1.303 e+17 \quad 1.303 e+17 \quad 1$ $6.440 \mathrm{e}-06 \quad 2.650 \mathrm{e}+15 \quad 1.115 \mathrm{e}+16 \quad 1.117 \mathrm{e}+16 \quad 1.117 \mathrm{e}+16 \quad 1.117 \mathrm{e}+16 \quad 1.117 \mathrm{e}+16 \quad 1.117 \mathrm{e}+16 \quad 1.118 \mathrm{e}+16 \quad 1$ $1.917 e-061.306 e+12 \quad 1.306 e+12 \quad 1.306 e+12 \quad 1.306 e+12 \quad 1.306 e+12 \quad 1.307 e+12 \quad 1.308 e+121.313 e+12 \quad 1$ $1.244 e-075.019 e-022.614 e+01 \quad 1.780 e+038.512 e+032.653 e+044.530 e+046.554 e+04 \quad B .101 e+048$ $7.867 e-093.173 e-03 \quad 1.653 e+001.125 e+025.382 e+02 \quad 1.678 e+032.865 e+034.144 e+035.123 e+035$.

$5.679 e-04 \quad 2.862 e+18 \quad 1.375 e+19 \quad 1.400 e+19 \quad 1.414 e+19 \quad 1.447 e+19 \quad 1.486 e+19 \quad 1.543 e+19 \quad 1.633 e+19 \quad 1$. $4.171 \mathrm{e}-04 \quad 2.883 \mathrm{e}+18 \quad 1.257 \mathrm{e}+19 \quad 1.267 \mathrm{e}+19 \quad 1.275 \mathrm{e}+19 \quad 1.298 \mathrm{e}+19 \quad 1.326 \mathrm{e}+19 \quad 1.368 \mathrm{e}+19 \quad 1.436 \mathrm{e}+19 \quad 1$.

ene on

18 group specilic energy releose rotes, mev/wolt-sec

bosis=oll material in zone 1. 1982 mppm bi in pt 20 rot

fresh $\quad \begin{array}{llllllllll} & 1.0 \mathrm{hr} & 1.00 & 10.00 & 30.00 & 90.00 & 180.0 \mathrm{~d} & 1.0 \mathrm{yr} & 3.0 \mathrm{yr}\end{array}$

1. $500 e-020$.

2. $500 \mathrm{e}-020$.

3. $750 \mathrm{e}-020$.

5.750e-02 0 .

8. $500 \mathrm{e}-02$.

$1.250 e-010$.

$2.250 e-01$

3. $750 \mathrm{e}-01$

5.750e-01

$8.500 e-01$

1. $250 \mathrm{e}+00$

$1.750 \mathrm{e}+00$

$2.250 \mathrm{e}+00$

$2.750 e+00$

3. $500 e+00$

J. $000 e+00$

$7.000 e+100$

$1.100 e+01$

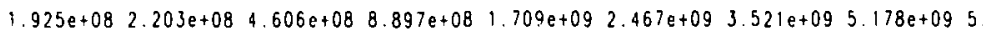
$1.811 e+02 \quad 7.715 e+02 \quad 8.149 e+02 \quad 8.917 e+02 \quad 1.022 e+03 \quad 1.091 e+03 \quad 1.124 e+03 \quad 1.132 e+03 \quad 1$ $3.598 e-15 \quad 4.800 e-11 \quad 3.563 e-08 \quad 5.888 e-07 \quad 8.202 e-06 \quad 3.317 e-05 \quad 1.377 e-04 \quad 1.250 e-03 \quad 3$ $3.862 e-04 \quad 1.316 e-01 \quad 7.509 e+005.752 e+01 \quad 3.895 e+02 \quad 1.120 e+03 \quad 2.837 e+03 \quad 9.960 e+03 \quad 1$ $1.113 e+05 \quad 2.640 e+06 \quad 2.469 e+07 \quad 6.431 e+07 \quad 1.318 e+08 \quad 1.665 e+08 \quad 1.781 e+08 \quad 1.799 e+081$ $1.211 e+091.211 e+091.211 e+09 \quad 1.212 e+091.212 e+09 \quad 1.214 e+09 \quad 1.216 e+09 \quad 1.226 e+09 \quad 1$. $6.899 \mathrm{e}-111.086 \mathrm{e}+118.360 \mathrm{e}+118.723 \mathrm{e}+118.732 \mathrm{e}+118.747 \mathrm{e}+118.753 \mathrm{e}+118.752 \mathrm{e}+118.7 .38 \mathrm{e}+118$. $0 . \quad 1.107 e+10 \quad 6.844 e+10 \quad 7.400 e+10 \quad 7.833 e+10 \quad 8.363 e+108.524 e+10 \quad 8.605 e+108.840 e+10 \quad 9$. 0. $\quad 5.4 E^{7} \mathrm{e}+092.105 \mathrm{e}+102.244 \mathrm{e}+10 \quad 2.244 \mathrm{e}+10 \quad 2.244 \mathrm{e}+102.245 \mathrm{e}+102.246 \mathrm{e}+102.249 \mathrm{e}+102$. $1.039 e-10 \quad 1.362 e+12 \quad 5.762 e+12 \quad 5.807 e+12 \quad 5.887 e+12 \quad 6.104 e+12 \quad 6.380 e+12 \quad 6.801 e+12 \quad 7.472 e+127$. $8.690 \mathrm{e}-11 \quad 6.768 \mathrm{e}+09 \quad 1.539 \mathrm{e}+10 \quad 1.554 \mathrm{e}+10 \quad 1.561 \mathrm{e}+10 \quad 1.566 \mathrm{e}+10 \quad 1.574 \mathrm{e}+10 \quad 1.593 \mathrm{e}+10 \quad 1.686 \mathrm{e}+10 \quad 1$. $6.096 e-118.001 e+113.381 e+12 \quad 3.387 e+12 \quad 3.387 e+12 \quad 3.387 e+12 \quad 3.387 e+123.387 e+123.389 e+123$. $3.927 e-114.931 e+112.088 e+12 \quad 2.091 e+12 \quad 2.091 e+1222.091 e+122.091 e+122.091 e+122.092 e+122$. $2.405 e-118.477 \mathrm{e}+103.576 \mathrm{e}+113.582 \mathrm{e}+113.582 \mathrm{e}+113.582 \mathrm{e}+113.582 \mathrm{e}+113.582 \mathrm{e}+113.584 \mathrm{e}+113$ $2.254 \mathrm{e}-119.274 \mathrm{e}+093.904 \mathrm{e}+103.910 \mathrm{e}+10 \quad 3.910 \mathrm{e}+103.910 \mathrm{e}+103.910 \mathrm{e}+103.910 \mathrm{e}+103.913 \mathrm{e}+103$ $9.586 e-126.528 e+06 \quad 6.529 e+06 \quad 6.529 e+06 \quad 6.530 e+06 \quad 6.532 e+06 \quad 6.535 e+06 \quad 6.541 e+06 \quad 6.564 e+06 \quad 6$ 8.708e-13 3.513e-07 1.830e-04 $1.246 e-02 \quad 5.958 e-02 \quad 1.857 e-01 \quad 3.171 e-014.588 e-01 \quad 5.671 e-015$ $8.653 e-14 \quad 3.491 e-08 \quad 1.818 e-05 \quad 1.238 e-03 \quad 5.921 e-03 \quad 1.846 e-02 \quad 3.151 e-02 \quad 4.559 e-02 \quad 5.635 e-02 \quad 5$

$10101 \quad 1.179 e-102.983 e+12 \quad 1.257 e+13 \quad 1.267 e+13 \quad 1.275 e+13 \quad 1.298 e+13 \quad 1.326 e+13 \quad 1.368 e+13 \quad 1.436 e+13 \quad 1$ gom pow $\begin{array}{lllllllll}6.687 e-17 & 4.621 e+05 & 2.015 e+06 & 2.031 e+06 & 2.044 e+06 & 2.080 e+06 & 2.125 e+06 & 2.193 e+06 \quad 2.302 e+06 \quad 2\end{array}$

Figure 14. Photon-decay emission rates as a function of time and photon energy. 


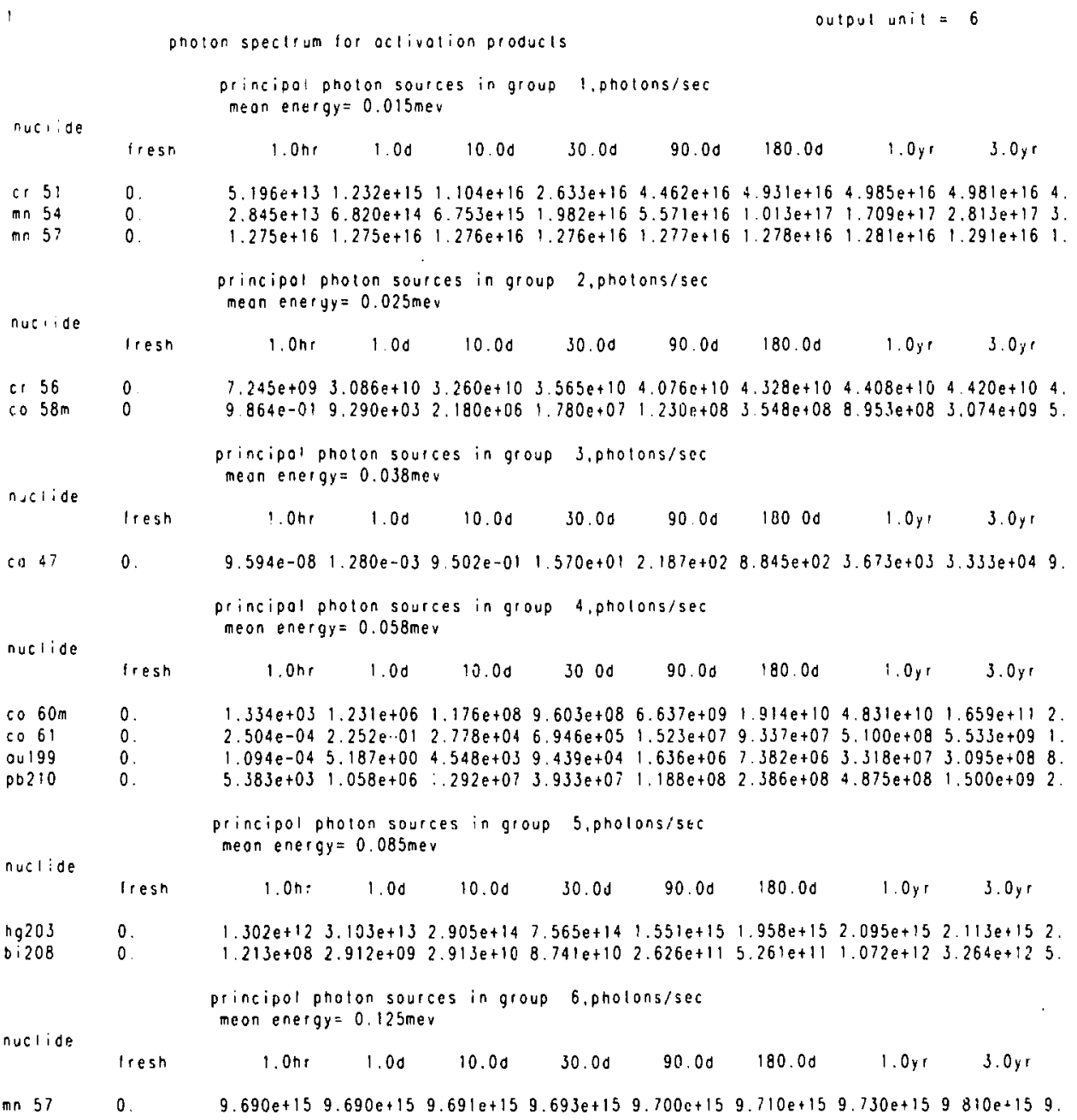

Figuie 15. Principal nuclide contributors to the photon-decay emission rates.

IMFA, Infinite multiplication factors (= NPRON/NDESn) of vectors NKEQ( 1 ), NKEQ ( 2 ), and IMFB, NKEQ (3), respectively.

IMFC

FRC (IMFB-IMFA)/(IHFA-IHFC).

FRD FRC *NDESB/NDESC.

The neutron production and destruction rates are relative, because they have not been multiplied by the neutron flux. 
The internal information printed for the FAC command is relatively simple compared with that for the irradiation and KEQ commands. The FAC output information in TAPE 5 consists of the value of NFAC (1) in the FAC instruction and the value of FACTOR [NFAC (1)].

The third function of TAPE15 is to provide a mechanism for printing internal FORIG error messages. Three general types of error messages are contained in FORIG.

- The first type of error message is related to size of specified problem. If the specification requires arrays that exceed the size of the arrays actually present, an error message will be output to indicate the dimension exceeded. (Although this was also the intention of the ORIGEN2 author, some runs produced crashes, indicating that not all possible errors are monitored. Hence, the user should compare the dimensions with the actual array sizes as indicated in the output table of reactivity and burnup data.)

- The second type of message is similar except it is the individual command count that is checked. That is, if the times a particular command is actually used exceeds the allowable number given in Section 4.2, an error message will be printed Neither of these two error types will stop program execution.

- The third type of error is printed when the command key word, defining the type of command, fails to match one of the 30 key words contained internally in ORIGEN2. In this case, a message will be printed and program execution will be terminated.

\subsection{TAPE16: Variable Actinide Cross Sections}

The output on TAPE16 relates to the changing of the variable actinide cross sections included in FORIG. These cross sections are altered by linear interpolation based on the anticipated burnup during the next irradiation step. Thus, the first output on TAPE16 contains parameters related to the anticipated burnup during the next irradiation step and also contains the weighting factors used in the cross-section interpolation. A small table is output that contains the following information for each nuclide with a variable cross section.
NUCLID
Six-digit nuclide identifier.
XSEC TYPE
Type of cross section; $1=(n$, gamma $), 2=(n, g a m m a)$ to an excited state of the daughter, $4=$ (n,fission).
TOCAP (I)
$I$ is the location of the cross section in array J'Ocap that contains the total neutron absorption cross section (not meaningful for fission cross sections).
$A(N)$
$\boldsymbol{N}$ is the location of the reaction rate corresponding to the cross section being varied in the matrix of reaction rates (i.e., A).
FR YIELD INDIC ARR Number of the array containing the locations of the fission-product yields that must be adjusted when fission cross sections are varied.
FISS (J)
$\mathrm{J}$ is the location of the fission cross section in array FISS, which contains all fission cross sections.
OLD XSEC
Value of the cross section during the previous irradiation step.
NEW XSEC
Value of the cross section during the upcoming irradiation step.

Each of these pieces of information, in one way or another, indicates whether the routines that vary the actinide cross sections are functioning properly. Under normal circumstances, this output is not useful and can be suppressed.

\subsection{TAPE7: Compositions}

This output is generated by the PCH commands. The format of the output written on TAPE7 is. the same as the format for FORIG input material compositions. The PCH command also outputs the average 
burnup, flux, and associated power for each material. These values are required for compositions to be read by a subsequent FORIG problem on Unit 4 (TAPE4) but are ignored for compositions to be read from ORINPUT. If TAPE4 is used to input the compositions, the FORIGM (main) program must be altered to open TAPE4 and then must be recompiled.

\section{References}

1. A. G. Croff, A User's Manual for the ORIGEN2 Computer Code, Oak Ridge National Laboratory, Oak Ridge, TN, ORNL/TM-7175 (1980); also published as a report of the National Radiation Shielding Information Center (RSIC), Oak Ridge, TN, CCC-371.

2. J. A. Blink, FORIG: A Modification of the ORIGEN2 isotope-Generation and Depletion Code for Fusion Problems, Lawrence Livermore National Laboratory, Livermore, CA, UCRL-53263 (1982).

3. J. A. Blink, R. E. Dye, and J. R. Kimlinger, ORLIB: A Computer Code that Produces One-Energy Group, Time- and Spatially-Averaged Neutron Cross Sections, Lawrence Livermore National Laboratory, Livermore, CA, UCRL-53262 (1981).

4. M. A. Gardner and R. J. Howerton, ACTL: Evaluated Neutron Activation Cross Section LibraryEvaluation Techniques and Reaction Index, Lawrence Livermore National Laboratory, Livermore, CA, UCRL-50400, Vol. 18 (1978). In 1981, Howerton expanded the ACTL library to allow treatment of fusion-reactor structural materials. See also R. J. Howerton, A Study Report for Data Files and Monte Carlo Transport Codes Maintained by the Physical Data Group of LLNL, Lawrence Livermore National Laboratory, Livermore, CA, UCID-19907 (Oct. 18, 1983).

5. E. F. Plechaty and J. R. Kimlinger, TARTNP: A Coupled Neutron-Photon Monte Carlo Transport Code, Lawrence Livermore National Laboratory, Livermore, CA, UCRL-50400, Vol. 14 (1976).

6. Title 10, Code of Federal Regulations, Part 61 ("Licensing Requirement for Land Disposal of Radioactive Waste Disposal'), Federal Register (Dec. 27, 1982).

7. Title 10, Code of Federal Regulations, Part 20 ("Standards for Protection Against Radiation"), Federal Register (1978). 